Cochrane Database of Systematic Reviews

\title{
Overground physical therapy gait training for chronic stroke patients with mobility deficits (Review)
}

States RA, Pappas E, Salem Y

States RA, Pappas E, Salem Y.

Overground physical therapy gait training for chronic stroke patients with mobility deficits.

Cochrane Database of Systematic Reviews 2009, Issue 3. Art. No.: CD006075.

DOI: 10.1002/14651858.CD006075.pub2.

www.cochranelibrary.com 
TABLE OF CONTENTS

HEADER 1

ABSTRACT

PLAIN LANGUAGE SUMMARY

BACKGROUND

OBJECTIVES

METHODS

RESULTS

DISCUSSION

AUTHORS' CONCLUSIONS

ACKNOWLEDGEMENTS

REFERENCES

CHARACTERISTICS OF STUDIES

DATA AND ANALYSES

Analysis 1.1. Comparison 1 Gait training versus control at end of treatment, Outcome 1 Gait function (\%).

Analysis 1.2. Comparison $1 \mathrm{Gait}$ training versus control at end of treatment, Outcome 2 Barthel Index (unitless).

Analysis 1.3. Comparison 1 Gait training versus control at end of treatment, Outcome 3 Gait speed $(\mathrm{m} / \mathrm{s})$.

Analysis 1.4. Comparison 1 Gait training versus control at end of treatment, Outcome 4 Timed-up-and-go test (s).

Analysis 1.5. Comparison 1 Gait training versus control at end of treatment, Outcome 5 Six-minute-walk test $(\mathrm{m})$.

Analysis 1.6. Comparison 1 Gait training versus control at end of treatment, Outcome 6 Death or dependency (unitless).

Analysis 1.7. Comparison 1 Gait training versus control at end of treatment, Outcome 7 Other adverse effects (unitless). ........

Analysis 2.1. Comparison 2 Gait training versus control at three-month follow up, Outcome 1 Gait function (\%). ....................

Analysis 2.2. Comparison 2 Gait training versus control at three-month follow up, Outcome 2 Barthel Index (unitless). ...........

Analysis 2.3. Comparison 2 Gait training versus control at three-month follow up, Outcome 3 Gait speed (m/s). ....................

Analysis 2.4. Comparison 2 Gait training versus control at three-month follow up, Outcome 4 Timed-up-and-go test (m). ........

Analysis 2.5. Comparison 2 Gait training versus control at three-month follow up, Outcome 5 Six-minute-walk test (m). .........

Analysis 2.6. Comparison 2 Gait training versus control at three-month follow up, Outcome 6 Death or dependency (unitless).

Analysis 2.7. Comparison $2 \mathrm{Gait}$ training versus control at three-month follow up, Outcome 7 Other adverse effects (unitless).

Analysis 3.1. Comparison 3 Subgroup analysis: extent of intervention, Outcome 1 Gait speed $(\mathrm{m} / \mathrm{s})$.

Analysis 3.2. Comparison 3 Subgroup analysis: extent of intervention, Outcome 2 Six-minute-walk test (m).

ADDITIONAL TABLES

APPENDICES

HISTORY

CONTRIBUTIONS OF AUTHORS

DECLARATIONS OF INTEREST

SOURCES OF SUPPORT

INDEX TERMS 
[Intervention Review]

\section{Overground physical therapy gait training for chronic stroke patients with mobility deficits}

Rebecca A States ${ }^{1}$, Evangelos Pappas ${ }^{1}$, Yasser Salem ${ }^{1}$

1Division of Physical Therapy, Long Island University, Brooklyn, NY, USA

Contact address: Rebecca A States, Division of Physical Therapy, Long Island University, 1 University Plaza, HS 213, Brooklyn, NY, 11201, USA.Rebecca.States@liu.edu.

Editorial group: Cochrane Stroke Group.

Publication status and date: New, published in Issue 1, 2010.

Citation: States RA, Pappas E, Salem Y. Overground physical therapy gait training for chronic stroke patients with mobility deficits. Cochrane Database of Systematic Reviews 2009, Issue 3. Art. No.: CD006075. DOI: 10.1002/14651858.CD006075.pub2.

Copyright @ 2010 The Cochrane Collaboration. Published by John Wiley \& Sons, Ltd.

\section{A B S T R A C T}

\section{Background}

Overground gait training forms a major part of physical therapy services for chronic stroke patients in almost every setting. Overground gait training refers to physical therapists' observation and cueing of the patient's walking pattern along with related exercises, but does not include high-technology aids such as functional electrical stimulation or body weight support.

\section{Objectives}

To assess the effects of overground physical therapy gait training on walking ability for chronic stroke patients with mobility deficits.

\section{Search methods}

We searched the Cochrane Stroke Group Trials Register (last searched March 2008), the Cochrane Central Register of Controlled Trials (CENTRAL) (The Cochrane Library Issue 2, 2008), MEDLINE (1966 to May 2008), EMBASE (1980 to May 2008), CINAHL (1982 to May 2008), AMED (1985 to March 2008), Science Citation Index Expanded (1981 to May 2008), ISI Proceedings (Web of Science, 1982 to May 2006), Physiotherapy Evidence Database (http://www.pedro.org.au/) (May 2008), REHABDATA (http://www.naric.com/research/rehab/) (1956 to May 2008), http://www.clinicaltrials.gov (May 2008), http://www.controlled-trials.com/ (May 2008), and http://www.strokecenter.org/ (May 2008). We also searched reference lists of relevant articles, and contacted authors and trial investigators.

\section{Selection criteria}

Randomised controlled trials comparing overground physical therapy gait training with a placebo intervention or no treatment for chronic stroke patients with mobility deficits.

\section{Data collection and analysis}

Pairs of authors independently selected trials. Three authors independently extracted data and assessed quality. We contacted study authors for additional information.

\section{Main results}

We included nine studies involving 499 participants. We found no evidence for a benefit on the primary variable, post-test gait function, based on three studies with 269 participants. Uni-dimensional performance variables did show significant effects post-test. Gait speed increased by 0.07 metres per second ( $95 \%$ confidence interval $(\mathrm{Cl}) 0.05$ to 0.10 ) based on seven studies with 396 participants, timed upand-go (TUG) test improved by 1.81 seconds $(95 \% \mathrm{Cl}-2.29$ to -1.33$)$, and six-minute-walk test (6MWT) increased by 26.06 metres (95\% $\mathrm{Cl}$ 7.14 to 44.97 ) based on four studies with 181 participants. We found no significant differences in deaths/disabilities or in adverse effects, based on published reports or personal communication from all of the included studies. 


\section{Authors' conclusions}

We found insufficient evidence to determine if overground physical therapy gait training benefits gait function in patients with chronic stroke, though limited evidence suggests small benefits for uni-dimensional variables such as gait speed or 6MWT. These findings must be replicated by large, high quality studies using varied outcome measures.

\section{PLAIN LANGUAGE SUMMARY}

\section{Overground physical therapy gait training for chronic stroke patients with mobility deficits}

Stroke is a leading cause of serious, long-term disability in the United States, with 700,000 new or recurrent attacks each year. Twothirds of survivors have difficulty walking immediately after suffering a stroke, and six months later over $30 \%$ still cannot walk without assistance. Overground gait training forms a major part of physical therapy services for chronic stroke patients and is aimed at improving gait function. Overground gait training involves the physical therapist observing and cueing the patient's walking pattern, along with related exercises(it does not include use of high-technology aids). We reviewed nine studies, with 499 participants, that investigated the effectiveness of overground gait training for improving overall measures of gait function. No evidence was found for a benefit on gait function at the end of the trial, based on the three available studies (269 participants). Other single measures of performance did show significant effects post-test. Gait speed increased by 0.07 metres per second, based on seven studies with 396 participants. The timed 'upand-go' test improved by 1.81 seconds, and the six-minute-walk test increased by 26.06 metres, based on four studies with 181 participants. Even fewer data were available at three-month follow up. No significant differences in deaths/disabilities or in adverse effects were found between groups. Therefore, we found insufficient evidence to determine if overground physical therapy gait training improves gait function in patients with chronic stroke. The more targeted interventions for overground gait training used in recent studies suggest small and short-term benefits for performance measures like gait speed, the timed up-and-go test, and distance walked in six minutes. Along with the small number of large, high quality, randomised controlled trials, limitations of this review include the wide range of disabilities in the stroke patients involved, the slow rate of recovery for chronic stroke patients, incomplete descriptions of the experimental interventions in studies of community physical therapy that included overground gait training, the blunt nature of the primary variable - gait function, the limited duration of follow up (generally less than four months), and the diverse outcomes measured in the trials. Additional well-designed randomised controlled trials of sufficient size and quality are needed to clarify the effects of overground physical therapy gait training. 


\section{B A C K G R O U N D}

Stroke is a leading cause of serious, long-term disability in the United States, with about 700,000 new or recurrent attacks each year (AHA 2005). Almost two-thirds of the immediate survivors have initial mobility deficits (Jorgensen 1995; Shaughnessy 2005), and six months after a stroke over $30 \%$ of survivors still cannot walk independently (Jorgensen 1995; Mayo 2002; Patel 2000). However, the relatively high rate of walking independence may mask substantial mobility deficits. One year after a stroke, half of community-dwelling stroke survivors (and thus survivors with relatively good recovery) could not complete a six-minute-walk test (6MWT) and those that did were only able to walk $40 \%$ of their predicted normal distance (Mayo 1999). Intensive rehabilitation services, including physical therapy, can aid significant recovery within the first three to six months (Duncan 2002; Duncan 2005; OST 2003). However, few studies have addressed whether additional services for chronic patients (more than six months since stroke) will lead to further recovery in mobility, and if so which aspects of the services are most important.

Within physical therapy services for stroke, gait training forms the major component of interventions, at least for acute patients (less than six months since stroke) (Jette 2005). Gait training refers to a wide range of physical therapy interventions, all aimed at improving the functional activity of ambulation. Overground gait training, perhaps the predominant form, includes a physical therapist's observation and manipulation of the patient's gait over a regular floor surface, and is often accompanied by practice walking overground, and exercises specifically designed to improve gait. Overground gait training is performed in virtually every setting from home care to small outpatient to large rehabilitation units and reflects a basic element of physical therapist training. Recently, efforts aimed at improving rehabilitation of gait have shifted toward increased amounts of gait practice through use of mechanical devices or fitness oriented exercise protocols. A systematic review that considered treadmill training with or without body weight support for stroke patients did not find significant and consistent benefits compared with other gait training methods (Moseley 2003). A systematic review that considered fitness programmes for stroke patients (Saunders 2004) found no evidence that cardiorespiratory training, or a combination of cardiorespiratory and strength training, leads to an increase in comfortable walking speed. In contrast, that review did find limited evidence that cardiorespiratory training improves functional ambulation category and maximum walking speed though those gains were achieved through the use of high-technology devices like treadmills with or without body weight support. Interestingly, no systematic review has specifically addressed whether the less technologically demanding intervention of overground gait training is effective at improving mobility in stroke patients. While there is an overwhelming clinical consensus that overground gait training is needed during the acute stage of recovery for those patients who can not walk independently (Bates 2005), there has been little discussion of whether overground gait training would be beneficial for chronic patients with continuing mobility deficits.

\section{O B JECTIVES}

The purpose of this review is to evaluate whether overground physical therapy gait training is effective at improving walking ability for chronic stroke patients with mobility deficits. We measured effectiveness based on:

1. multi-dimensional measures of gait function;

2. performance measures such as overground gait speed, the timed up-and-go test (TUG) and the 6MWT;

3. adverse events, and death or disability.

\section{METHODS}

\section{Criteria for considering studies for this review}

\section{Types of studies}

Randomised controlled trials (RCTs) comparing overground physical therapy gait training with no intervention or a control intervention (other rehabilitative techniques that do not include gait training).

\section{Types of participants}

Adults (over 18 years) who have had a stroke at least six months prior to inclusion in the study and who have mobility deficits; that is, they use an assistive device, exhibit an abnormal gait pattern or have slowed gait speed. Participants must have the cognitive ability to follow directions and participate in physical therapy treatments. There were no restrictions on the participants' living environment or the setting in which care was received.

\section{Types of interventions}

Overground gait training was the intervention of interest. For the purposes of this review, we defined overground gait training as treatment that consisted of at least one of the following:

1. real-time cueing of the patient's gait through the use of manual, verbal, positional, or rhythmic cueing techniques;

2. practice of the walking pattern overground; and/or

3. pre-gait activities such as step-up and step-down exercises, dynamic balance training, weight-bearing exercises to strengthen the lower extremities, and other exercises that require standing and weight shifting.

Interventions that did not include consistent face-to-face interactions between the therapist and patient (such as home exercise programmes) or whose primary goal was not to improve gait (such as progressive resistance training using exercises for isolated muscle groups) do not fit within this definition. In addition, gait training interventions that focus on the use of treadmills, complex technical equipment such as body weight supported treadmill training, functional electrical stimulation, biofeedback based on electromyography (EMG) or joint-position measurement, or virtual reality systems, do not fit within this definition. The rationale for this restrictive definition is to focus on the types of gait training that are available in a typical community-based physical therapy facility or during home-care visits by a physical therapist.

We only included studies if the main intervention was overground gait training as defined above. We excluded studies that only used treadmill training, only used technologically demanding forms of gait training like body weight supported treadmill training, only used progressive resistance training without gait-oriented exercises, or only included home-care programmes. We included interventions that combined overground gait training with other 
rehabilitation techniques if the main intervention focused on either full-gait activities (items 1 and 2 from the above definition) or on pre-gait activities (item 3 ).

\section{Types of outcome measures}

The primary outcome measure is gait function. Gait function was assessed by any of various multi-dimensional, ordinal scales that evaluate gait function and that are validated for use with stroke patients. Suitable scales included the following:

- Rivermead Motor Assessment (RMA) (Finch 2002; Lincoln 1979) or the Rivermead Mobility Index (RMI) (Collen 1991; Hsieh 2000);

- Motor Assessment Scale (MAS) (Carr 1985; Teasell 2005);

- Stroke Rehabilitation Assessment of Movement (STREAM) (Daley 1997);

- Barthel Index (Mahoney 1965; Teasell 2005).

In three studies (Green 2002; Lin 2004; Wade 1992) multiple outcome measures fit our definition of 'walking ability.' In Green's study, the RMI and the Barthel Index were reported; Lin reported both the STREAM and the Barthel Index; Wade reported both the RMA and the Barthel Index.

When considering which of the scales to designate as the primary measure of walking ability, we relied on the purpose and type of instrument. Since the goal of overground gait training is to improve the patient's ability to walk in a functional context, we preferred a multi-dimensional scale that directly measured walking performance within a functional context. Both the RMI and the STREAM are clinical observation instruments designed to measure motor performance for persons with stroke. The RMI uses a hierarchical scoring system to measure motor performance for three subscales: Total Body Movements; Leg and Trunk Movements; and Arm Movements. The STREAM is designed to evaluate basic motor ability and also has three subscales: Voluntary Motor Upper Extremity; Voluntary Motor Lower Extremity; and Basic Mobility. The Barthel Index has 10 items and is designed to measure functional independence in self-care and mobility rather than functional performance per se. It is administered in various formats including observational, written, and oral self-reports. All four scales are validated for use with stroke patients and have shown adequate internal validity and test-retest reliability (Finch 2002; Teasell 2005). Since the RMI and STREAM are focused more precisely on judging the quality of motor performance, as opposed to the Barthel's focus on ability to function independently, we preferred the RMI or the STREAM over the Barthel Index. In each of the studies that evaluated at least one of these measures, the study provided data on either the RMI or the STREAM but not both, and also provided data on the Barthel Index. Hence, we designated the RMI or STREAM as the primary outcome measure depending on which was available, and then considered the Barthel Index as an unanticipated secondary measure that provided information on the participant's ability (or inability) to function independently.

Several other secondary outcome measures assessed independent walking performance with objective, quantitative variables.

- Gait speed measured over a short distance (10 metres or less) (Finch 2002; Murray 1967).

- TUG (Matthias 1986; Podsiadlo 1991; Teasell 2005).

- 6MWT (Butland 1982; Finch 2002).
We analysed three additional secondary outcome measures when available in the identified studies: quality of life, adverse events, and death or disability. Quality of life was measured by validated multi-dimensional, ordinal, scales such as the Medical Outcomes Study Short Form Health Survey Questionnaire, the Frenchay Activities Index, the Nottingham Health Profile, the Quality of Life Index, and the Stroke Adapted Sickness Impact Profile (Finch 2002). The prevalence of adverse events during the treatment period was used as a measure of the safety of the intervention. Adverse events were categorised into injurious falls, other injury, major cardiovascular events, and any other adverse outcomes. Death and disability was defined based on the Stroke Unit Trialists' Collaboration definitions for death or dependency, and death or institutional care (Duncan 2002). The criterion for dependency is a score less than 18 on the Barthel Index or greater than two on the Modified Rankin Scale, while institutional care refers to care in a residential home, nursing home or hospital at the end of the scheduled follow up.

For inclusion in the analysis, outcome measures must have been recorded prior to the intervention and immediately following the intervention. We examined follow-up data for the follow-up point closest to three months after the intervention.

\section{Search methods for identification of studies}

See the 'Specialized register' section in the Cochrane Stroke Group module in The Cochrane Library.

We searched the Cochrane Stroke Group's Trials Register, which was last searched by the Review Group Co-ordinator in March 2008. In addition we searched the Cochrane Central Register of Controlled Trials (CENTRAL) (The Cochrane Library Issue 2, 2008), MEDLINE (1966 to May 2008), EMBASE (1980 to May 2008), CINAHL (1982 to May 2008), AMED (1985 to March 2008), Science Citation Index Expanded (1981 to May 2008), ISI Proceedings (Web of Science, 1982 to May 2006), the Physiotherapy Evidence Database (http://www.pedro.org.au/) (May 2008), REHABDATA (http://www.naric.com/research/rehab/) (1956 to May 2008), http://www.clinicaltrials.gov/ (May 2008), http://www.controlledtrials.com/ (May 2008), and http://www.strokecenter.org/ (May 2008) (see Appendix 1).

In an effort to identify further published, unpublished and ongoing trials, we:

- examined the reference lists from retrieved articles;

- liaised with investigators of identified trials and authors of relevant Cochrane physiotherapy reviews; and

- used Science Citation Index Cited Reference Search to track relevant papers.

We carried out the above searches in April 2006 and updated them in Spring 2008. When we combined the results and removed duplicates, we identified 3793 citations.

\section{Data collection and analysis}

\section{Selection of trials}

The studies retrieved by the electronic search were distributed to three review authors (RAS, EP, and YS). Based on titles and, where available, abstracts, each review author deleted the obviously irrelevant studies (that is, obviously false hits such as 'running 
during a tennis stroke'). We obtained abstracts for all remaining references. Two review authors (RAS and EP or RAS and YS) independently screened the remaining abstracts, classifying each study as 'definitely irrelevant' or 'possibly relevant'. Where there was disagreement between review authors, a third review author assessed the abstract, and discussion among the three review authors led to consensus. We obtained full references for all studies classified as 'possibly relevant'. The three review authors applied the selection criteria to these studies. We resolved disagreements by discussion to reach consensus.

\section{Data extraction}

For each study selected, the three review authors extracted and documented data relating to study participants (such as patients' age, time since stroke, side of hemiplegia, initial walking ability), details of the intervention, methodological quality, and numeric results, and recorded this information on a data coding form.The three review authors resolved disagreements by discussion. For those articles that did not contain sufficient information, we contacted the study authors.

\section{Quality assessment}

The three review authors independently assessed the methodological quality of the studies, with disagreements resolved by discussion. We evaluated quality according to the methods described in the Cochrane Handbook for Systematic Reviews of Interventions (Higgins 2008), by reporting the score for each of the 11 items contained in the PEDro Scale for Rating Quality of Randomized Controlled Trials (Maher 2003), and by determining whether validity has been established for each relevant outcome measure from the study. We considered the last category from the Cochrane Handbook (detection bias) in two parts: blinding of evaluators and reporting bias.

The PEDro scale is based on the Delphi List (Verhagen 1998) and includes the following items: specification of eligibility criteria; random allocation to groups; concealed allocation; groups similar at baseline; blinding of participants, therapists and assessors; primary outcome measure obtained from at least $85 \%$ of participants; presence of an intention-to-treat analysis; reporting of results of between-group statistical comparisons; and report of point measures and measures of variability.

If an article did not contain information on the methodological criteria, we contacted the study authors for additional information.

\section{Data synthesis}

We conducted meta-analyses for the comparisons listed in the 'Types of studies' section at the end of the treatment period, and again for data from the latest time point within the three months following the end of the intervention. Thus, we conducted meta-analyses for the following two comparisons on all available variables:

- Comparison 01: Overground gait training versus a control intervention at the end of the treatment period; and

- Comparison 02: Overground gait training versus a control intervention at the three-month follow-up time point.

The review authors checked all the extracted data for agreement, with conflicts resolved through mutual discussion. Where necessary, we contacted study authors to request more information or data.

We used the Cochrane Review Manager software, RevMan 5.0, for all analyses (RevMan 2008).

For the primary outcome measure of walking ability, data were derived from validated, multi-item, ordinal rating scales. The scales were treated as continuous data. Since various trials used different measurement scales (a scale of 1 to 15 for the RMI versus a scale of 1 to 100 for the STREAM), we calculated the meta-analysis for gait function based on the standardised mean difference (SMD) and 95\% confidence intervals $(\mathrm{Cl})$. For the other outcome measure based on multi-item ordinal data (Barthel Index), all of the trials used a single scale and thus, we analysed them using the mean difference (MD) method. For the continuous variables (gait speed, TUG, 6MWT) every study used the same unit of measure, hence, we did the metaanalyses by calculating the MD and $95 \% \mathrm{Cl}$. For the continuous variables, some trials provided only post-test scores, while others provided change scores indicating post-test/pretest, or follow-up/ pretest. We used change scores when they were available, along with a measure of their variability (Pang 2005; Salbach 2004; Wall 1987; Yang 2006) in accordance with the Cochrane Handbook for Systematic Reviews of Interventions, Section 9.4.5.2 (Higgins 2008). For dichotomous variables like death or dependency, we calculated relative risk (RR) and $95 \% \mathrm{Cl}$. If the results were significant, we calculated the number needed to treat and $95 \% \mathrm{Cl}$.

We quantified homogeneity between trial results using the 12 statistic. If the trials were homogeneous, we used a fixed-effect model to combine the results across trials and checked the robustness of the results using a random-effects model. If there was substantial heterogeneity $(12>50 \%)$, we calculated the overall effects using a random-effects model and we performed a series of sensitivity analyses to investigate the reason for the heterogeneity. The sensitivity analyses included true versus unclear randomisation, concealed versus unconcealed allocation, acceptable versus unacceptable number of withdrawals, blinded versus unblinded outcome assessment, and the use of a validated or unvalidated outcome measure. If the data were highly heterogeneous we did not calculate overall effects.

We planned to test for publication bias using funnel plots, but did not do so because so few studies (fewer than nine) were available for any given analysis.

We planned three subgroup analyses. The first was designed to assess the effects of initial walking ability using the cut point established for walking dependency defined in a previous Cochrane Review (Moseley 2003). The second subgroup analysis investigated the nature of the intervention, comparing trials that used realtime cueing versus those that used a combination of real-time cueing and pre-gait activities versus those that used only pre-gait activities. The third subgroup analysis considered the extent of training defined as net hours of training. We planned the third subgroup analysis in case a substantial discrepancy in the extent of training was seen between trials. In that case, the cut point was the mid point of the range of values for extent of training observed in the identified studies. We performed each subgroup analysis only if a sufficient number of studies was available and the original finding showed a statistically significant effect (Sandercock 2006). In those cases, the Deeks method for investigating differences between subgroups was used (Deeks 2008). 


\section{RESULTS}

\section{Description of studies}

We identified a total of 3793 studies by July 2008. We considered 92 for further review based on their abstracts and titles. Of those, we excluded 82 studies as shown in the 'Characteristics of excluded studies' table, and one study is ongoing. The most common reason for exclusion was that the participants were not chronic stroke patients or the control group included gait training and therefore could not serve as a true control. We reviewed the nine remaining studies in detail (see the 'Characteristics of included studies' table). Taken together, the included studies recruited 499 participants, and their data were assessed in the following comparisons:

- Comparison 1: Overground gait training versus control at the end of treatment;

- Comparison 2: Overground gait training versus control at threemonth follow up.

All of the included studies were randomised controlled trials (RCTs), although two used randomised cross-over designs (Lin 2004; Wade 1992). Follow-up data were reported in five studies (Dean 2000; Green 2002; Lin 2004; Wade 1992; Wall 1987). For the two studies using cross-over designs (Lin 2004; Wade 1992), only the first phase of the data was analysed here, rendering the comparison a randomised comparison between an intervention group and a no treatment control group. For these two studies, follow-up data could not be analysed as the control group received the experimental intervention during the usual follow-up period.

In addition, for two studies (Salbach 2004; Wall 1987) parts of the data reported by the study authors did not meet our criteria, hence we only extracted parts of the data. In the Salbach trial (Salbach 2004), only 61 of 91 participants had a stroke at least six months before the beginning of the study. The author provided data on those 61 participants for us through personal communication (Salbach 2004). In the Wall study (Wall 1987), participants were randomised to one of four groups (on-site physical therapy; home exercise programme; half on-site and half home exercise; no treatment). Two of the treatment groups met our definition for overground gait training (on-site physical therapy; and half onsite and half home exercise) and one group met our definition for a control group that refrained from walking exercises (no treatment group). We excluded data from the group that received home exercise only as it did not meet our definition for either the experimental or control interventions. Because the number of participants in the two treatment groups was small (five participants for each), they were combined following the methods outlined in the Cochrane Handbook for Systematic Reviews of Interventions, Section 7.7.3.8 (Higgins 2008).

The number of participants for studies in Comparison 1 'Overground gait training versus control at the end of treatment' varied from 10 (Wall 1987) to 170 (Green 2002). For comparison 2 'Overground gait training versus control at three-month follow up', the number of participants varied from 12 (Dean 2000) to 63 (Pang 2005). Note that these figures only count those participants who were assigned to groups that are analysed here. In Salbach (Salbach 2004) and Wade (Wade 1992), additional participants were enrolled and completed the original studies but are not considered here.
We have detailed the characteristics of participants in the included studies in Table 1, and summarise the information here.

The average age of participants in any one group ranged from 57 years for the experimental group in Yang 2006 to 74 years in the control group for Green 2002. In all studies both sexes were represented. The percentages varied from 30\% female in Lin 2004 to $50 \%$ female in Wade 1992.

The average time since stroke onset ranged from 6.1 months in the control group in Salbach 2004 to 64 months in the control group in Yang 2006. For one study (Salbach 2004), there was no preset limit on the required time since stroke. Thus, we communicated with the authors to obtain data for only those participants who began the study within six months since stroke onset. For one study, the required time since stroke was six months (Dean 2000). For six studies, the required time since stroke was one year (Green 2002; Lin 2004; Pang 2005; Wade 1992; Yang 2006; Yang 2007). For one study the required time since stroke was 18 months (Wall 1987). In two of the nine studies, an outer limit of five, seven or 10 years was set for time since stroke (Wade 1992; Wall 1987). In four studies, participants were only included if they had suffered only one stroke (Dean 2000; Pang 2005; Yang 2006; Yang 2007). The other studies allowed any number of strokes before the study began.

Mobility at beginning of study was assessed using various criteria. The most common was that the participant had to be able to walk independently for 10 metres with or without an assistive device (Dean 2000; Pang 2005; Salbach 2004; Yang 2006; Yang 2007). For those studies, the participant also had to have hemiparesis (Dean 2000; Pang 2005; Yang 2006; Yang 2007), or a walking deficit resulting from the most recent stroke (Salbach 2004). One study defined the criteria as an acceptable range of scores on the Barthel Index (Lin 2004), and two studies included a multi-part definition listing various mobility deficits (Wade 1992; Wall 1987).

Six of the studies excluded participants due to some aspect of cognitive functioning (Green 2002; Lin 2004; Salbach 2004; Wall 1987; Yang 2006; Yang 2007). Of those, three referred to the inability to follow directions (Lin 2004; Yang 2006; Yang 2007), one to cognitive disturbances (Wall 1987), one to a minimum score on a test of mental competency (Salbach 2004) and one to dementia (Green 2002). Three studies did not specifically address cognitive function (Dean 2000; Pang 2005; Wade 1992), though both Dean and Pang may have excluded people with cognitive deficits since they allowed exclusion for 'medical conditions that precluded participation'. The exclusion criteria for defining other comorbidities were also variable. Restrictions ranged from none (Lin 2004), to a list of specific conditions (Pang 2005), to 'medically stable' (Yang 2006; Yang 2007), to leaving the decision about medical readiness to the participant's physician (Salbach 2004).

All of the studies used a sample of convenience. For two studies participants were recruited from a research database (Dean 2000; Wade 1992); for four studies participants came from hospitals or rehabilitation centres (Pang 2005; Salbach 2004; Wall 1987; Yang 2006); and for the remaining three studies participants were recruited from the community, including from some hospitals or rehabilitation centres (Green 2002; Lin 2004; Yang 2007).

Four studies reported using an intention-to-treat analysis (Green 2002; Pang 2005; Salbach 2004; Wade 1992). Of those four studies, only Salbach (Salbach 2004) imputed results for those participants 
who could not be evaluated while the other three used 'available case analysis.' The remaining studies did not report whether or not they used an intention-to-treat approach. Due to the low rate of participant withdrawals in four of the remaining five studies, however this omission is not likely to impose substantial bias.

The overground gait training intervention varied considerably across studies as shown in Table 2.

Three of the studies described their intervention as standard physical therapy care designed to improve a broad range of functional deficits including mobility and balance (Green 2002; Lin 2004; Wade 1992). We determined that the physical therapy care included a substantial amount of overground gait training based on the descriptions of the intervention, or because the results documented the types of physical therapy services provided, and/ or based on personal communication with the study authors (Wade 1992). In those three studies, the therapy provided was tailored to the individual patient and the particular therapeutic services provided to each participant varied. For the other six studies, the intervention consisted of a standardised set of exercises uniquely designed by the investigators to improve gait and that were described within the report or in another published source. None of the studies provided an additional aspect to the intervention other than the physical therapy services described.

Five of the studies used one-to-one training approaches. For two studies that used group training the ratio of participants to instructors varied from 2:1 to 4:1 (Dean 2000; Pang 2005) and for the other two no information was given on the size of the group (Yang 2006; Yang 2007). The net treatment time provided by the intervention varied from a low of 0 treatment sessions for some participants in Green (Green 2002) to 57 sessions of 60 minutes each in Pang (Pang 2005). This translates into a net duration of treatment that ranged from 0 to 57 hours over a course of anywhere from 0 to six months. In the two studies where the number of sessions was determined individually for each participant, the range was 0 to 22 sessions in Green (Green 2002) and one to 11 sessions in Wade (Wade 1992). The setting for the intervention varied. Two studies provided the intervention only at the participant's home (Lin 2004; Wade 1992). One study provided the intervention both at home and at a community setting (Green 2002). Four studies provided the intervention only at a community setting (Dean 2000; Pang 2005; Salbach 2004; Wall 1987), and two did not report where the intervention was given (Yang 2006; Yang 2007).

The nature of the control intervention differed among the included trials. Four studies provided no treatment for the control group (Green 2002; Wall 1987; Yang 2006; Yang 2007). Two others (Lin 2004; Wade 1992) used a randomised cross-over design so that the control group received the same treatment as given to experimental group during the second phase of the experiment. To reduce bias, however, the second phase of those studies was not considered here. The remaining studies provided some type of sham exercise programme for the control group. In Dean (Dean 2000), Pang (Pang 2005), and Salbach (Salbach 2004), the sham condition involved seated exercises for the upper extremities.

With regards to reporting of the primary outcome measure, only three of the included studies reported data on a multi-item, ordinal scale of gait function. Two studies used the RMI (Green 2002; Wade 1992), one study used the STREAM (Lin 2004), and all three reported the aggregate scores. Those three studies also each reported the
Barthel Index, which we analysed as an unanticipated secondary measure. The other included studies did not report any multidimensional scale of walking ability in a functional context, and hence could not be assessed on our primary outcome measure.

With regards to our other secondary measures, all of the included studies reported some direct measure of walking performance. Seven of the included studies measured 'comfortable' or 'preferred' gait speed - five based on a 10-metre walk test (Dean 2000; Green 2002; Wade 1992; Yang 2006; Yang 2007), the others based on walking across a shorter distance (Salbach 2004; Wall 1987). In three studies, participants walked without an assistive device (Dean 2000; Yang 2006; Yang 2007). Assistive devices were allowed in three studies (Pang 2005; Salbach 2004; Wade 1992), whereas that detail was not reported in the other studies (Green 2002; Lin 2004; Wall 1987). In addition to gait speed, three studies assessed the TUG test (Dean 2000; Salbach 2004; Yang 2006), and four studies assessed the 6MWT (Dean 2000; Pang 2005; Salbach 2004; Yang 2006).

We expected to report on three additional secondary outcome measures: quality of life, adverse events, and death or disability. None of our included studies reported data on quality of life, however. Information on adverse events, and death or disability is provided by all nine studies.

All studies measured the outcome variables immediately before (within one week of) the intervention. In addition, for one study (Wade 1992) baseline variables were also measured a second time prior to the intervention to establish reliability of measurements. The assessment closest to the beginning of the intervention was used for reporting the baseline data. All studies measured the outcome variables immediately following the intervention. In one study (Wall 1987), the outcome variables were also measured monthly throughout the six-month intervention period. Only data from the end of the intervention are used here. Three studies provided data for one or more follow-up periods (Dean 2000 - two months later; Green 2002 - three and six months; Wall 1987 - one, two, and three months later). For consistency across studies, we analysed the follow-up data collected closest to three months after the intervention (Dean 2000 - two months later; Green 2002 - three months; Wall 1987 - three months later).

\section{Risk of bias in included studies}

We carried out a pilot study of quality assessment on five articles; three that had been categorised as possibly relevant and two classified as irrelevant. The three review authors agreed on nine of the 11 PEDro criteria for all five studies, and for three of the four Cochrane criteria for all five studies. We resolved the remaining instances of disagreement by discussion leading to consensus. We considered this level of agreement acceptable to proceed with the full quality review.

All three authors assessed the methodological quality of the nine included studies using both the Cochrane items and the PEDro scale. The authors demonstrated $100 \%$ agreement on the Cochrane items and $99 \%$ agreement (98 out of a total of 99 test items) on the PEDro scale. The one item of disagreement was regarding blinding of participants in Salbach 2004, and it was resolved after discussion. We counted $10 \%$ of the PEDro test items and $9 \%$ of the Cochrane items as 'unknown' due to missing information. 
We contacted seven trialists by email, requesting additional information on randomisation, nature of the experimental intervention, details of outcome measurement, results for subsets of participants, and adverse events. We received responses from five of the seven study authors (Dean 2000; Pang 2005; Salbach 2004; Wade 1992; Wall 1987) who provided details of methodology. In addition, email responses from Dean, Pang and Wade provided additional information on adverse events (Dean 2000; Pang 2005; Wade 1992). After receiving this information the following changes were made: concealed allocation was confirmed for Pang and Wade (Pang 2005; Wade 1992). In both cases, assignment was conducted by a co-worker not involved in other aspects of the study. In addition, Wade verified that the random allocation was done using a random numbers table (Wade 1992). Personal communication from Salbach provided the subset of data needed for the participants from that study who met our inclusion criteria (Salbach 2004). We used published data only for two studies (Green 2002; Lin 2004). The ratings for the Cochrane items are listed in Table 3, and for the PEDro items in Table 4. The allocation concealment classification is detailed in the 'Characteristics of included studies' table. All studies were of good quality with quality scores based on Cochrane criteria ranging from 1.5 to 3 , and PEDro scores ranging from 6 to 9 .

Six studies (Dean 2000; Green 2002; Pang 2005; Salbach 2004; Yang 2006; Yang 2007) used a parallel group design with true randomisation to groups, while one study (Wall 1987) reported randomisation but no procedures were given. Two trials (Lin 2004; Wade 1992) used a cross-over design with random allocation to the order of treatments. One study (Lin 2004) did not describe the method of randomisation, while one study (Wade 1992) used restricted randomisation (permuted blocks of 10 ) with random number tables.

Seven studies (Dean 2000; Green 2002; Pang 2005; Salbach 2004; Wade 1992; Yang 2006; Yang 2007) used concealed allocation of participants to groups, while two studies (Lin 2004; Wall 1987) did not describe allocation concealment.

One reason for the relatively low Cochrane quality scores relates to a problem found in most physical therapy studies; it is nearly impossible to keep the therapists providing the treatment and the participants blind as to whether they are receiving a behavioural intervention or not. As a result, only one of the nine studies (Lin 2004) was able to achieve blinding of therapists providing treatment. In contrast, the assessors were blinded to group allocation in six of the included studies (Lin 2004; Pang 2005; Salbach 2004; Wade 1992; Yang 2006; Yang 2007), blinding of assessors was incomplete in one study (Dean 2000), and blinding of assessors occurred at baseline and immediately after treatment but not in subsequent follow ups in one study (Green 2002). Blinding of assessors was not reported in one study (Wall 1987).

The withdrawal rate by the end of treatment was $15 \%$ or less in eight studies and was considered acceptably low based on the PEDro scale for rating quality of randomised controlled trials (Maher 2003); in contrast, it was $25 \%$ in one study (Dean 2000). The withdrawal rate for those studies reporting follow-up data was also less than 15\% for two studies (Green 2002; Wall 1987), but 33\% (two participants each from the experimental and control groups) for Dean 2000.

\section{Effects of interventions}

Comparison 1: Gait training versus control at end of treatment

For the primary variable of gait function, we found no statistically significant difference between the experimental gait training group and the control group at the end of the treatment period (Analysis 1.1). In contrast, there were statistically significant differences for the secondary variables of gait speed, TUG test, and 6MWT, but not for the variable of Barthel Index (Analysis 1.2). For gait speed, the gait training group walked an average of $0.07 \mathrm{~m} / \mathrm{sec}$ faster (95\% $\mathrm{Cl} 0.05$ to 0.10 ) than the control group, as shown in Analysis 1.3. For the TUG test, the gait training group moved 1.81 seconds faster $(95 \% \mathrm{Cl}-2.29$ to -1.33 ) than the control group (Analysis 1.4). Similarly, for the 6MWT, the gait training group walked an average of 26.06 metres further $(95 \% \mathrm{Cl} 7.14$ to 44.97$)$ than the control group, as shown in Analysis 1.5. Data for these comparisons came from three studies and 269 participants for gait function and the Barthel Index, from seven studies and 396 participants for gait speed, from three studies and 118 participants for the TUG test, and from four studies and 181 participants for the 6MWT. There was no evidence of substantial heterogeneity for any of the variables as shown by $\mathrm{I}^{2}$ values below $50 \%$. Moreover, none of the results changed notably when we ran the analyses using a random-effects model.

\section{Comparison 2: Gait training versus control at three-month follow up}

At the end of the three-month follow-up period, we found a statistically significant difference between the experimental and control interventions for the primary variable of gait function. The gait training group improved their gait function by a standardised mean difference of 0.34 units (95\% 0.01 to 0.66 ) compared with the control group (Analysis 2.1), but this was based on results from only one study with 150 participants. We found no significant differences for the variables of Barthel Index (Analysis 2.2), gait speed (Analysis 2.3), TUG test (Analysis 2.4), or 6MWT (Analysis 2.5). Data for the secondary variables were derived from one study and 150 participants for the Barthel Index, three studies and 165 participants for gait speed, one study with eight participants for the TUG test, and one study of 34 participants for the 6MWT. The $1^{2}$ values for all variables were below $50 \%$ indicating no substantial amount of heterogeneity. Additionally, results did not change substantially when we ran the analyses using a random-effects model.

\section{Other outcomes}

We analysed adverse events only in terms of 'death or dependency' and 'other adverse effects'. We did not analyse 'death or institutionalisation' since none of the included studies reported new instances of dependency or institutionalisation, and thus 'death or dependency' became equivalent to 'death or institutionalisation'. A total of four deaths occurred within the intervention period and these all occurred in the control groups, as shown in Analysis 1.6. During the three-month followup period, three deaths occurred in one study, as shown in Analysis 2.6. However, the odds ratio did not differ significantly from one either at the end of treatment or at follow up. Two adverse effects occurred within the experimental groups during the intervention period, but this did not result in a significant risk for the experimental condition (Analysis 1.6). One participant from Pang 2005 dropped out because he found the exercise too fatiguing, and one participant from Salbach 2004 dropped out due to groin 
pain. No other injuries or medical complications that could be plausibly linked to the intervention occurred in any study either during the intervention or follow-up periods (Analysis 1.7; Analysis 2.7). Five falls that related to study procedures were reported in one study (Pang 2005) though none of them led to injury.

\section{Subgroup analyses}

We planned to do three subgroup analyses.

1. Effect of initial ability to walk independently as defined in Moseley (Moseley 2003).

2. Effect of type of gait training (full-gait activities only versus a combination of full-gait and pre-gait activities versus pre-gait activities only).

3. Extent of intervention (more than or less than 29 hours).

For the first subgroup analysis, insufficient data were available within the included trials to determine which participants met the definition of walking dependency. Only two studies reported scales that could be used to determine the level of walking dependency among participants (Green 2002; Wade 1992), and data on gait function for dependent walkers could not be effectively separated from data for independent walkers for those studies. Moreover, very few participants met the definition for walking dependency even in these two studies - just 14\% in the Wade study, and less than $1 \%$ in the Green study. Given these impediments, we did not conduct a formal statistical analysis of the subgroups.

For the subgroup analysis on the type of gait training, one study used full-gait activities only (Yang 2007), six studies used a combination of full-gait and pre-gait activities (Dean 2000; Green 2002; Pang 2005; Salbach 2004; Wade 1992; Wall 1987), and one study used only pre-gait activities (Yang 2006). For Comparison 1 , the only variables that showed significant effects overall were the secondary variables of gait speed, TUG test, and 6MWT. Hence, we conducted subgroup analyses for those secondary variables although results should be interpreted with caution since in each case only one of three subgroups was represented by multiple studies. For gait speed, a trend was evident between subgroups ( $\mathrm{Chi}^{2}=5.07, \mathrm{df}=2, \mathrm{P}=0.08$ ), suggesting that the pre-gait only subgroup and the full-gait only subgroup continued to show differences between experimental and control interventions, whereas the combination subgroup (pre-gait and full-gait activities) did not (Analysis 1.3). No subgroup differences were evident for the TUG test (Analysis 1.4) or the 6MWT (Analysis 1.5). For Comparison 2, no subgroup analyses could be tested since the only variable that showed an overall effect (gait function) had only one study contributing data.

We also conducted analysis of subgroups with regards to extent of intervention. The net amount of training ranged from 2.25 hours to 57 hours, and the studies were divided according to the mid point of the range of net intervention durations or 29 hours. Thus, the subgroup analysis compared the two long-duration studies (Pang 2005; Wall 1987) versus the seven short-duration studies (Dean 2000; Green 2002; Lin 2004; Salbach 2004; Wade 1992; Yang 2006; Yang 2007). For Comparison 1, the only variables that showed significant effects overall were gait speed, TUG test, and 6MWT. We could not conduct the subgroup analysis for TUG test, however, since all of the studies fell into the low-intensity subgroup. We found no significant subgroup differences for gait speed or 6MWT (Analysis 3.1; Analysis 3.2). These results should be interpreted with caution since the high-intensity group was represented by a single study in both subgroup analyses. At the end of the three-month follow-up period, the only variable that showed a significant effect overall was gait function, and insufficient data were available to perform the subgroup analysis.

\section{Sensitivity analysis}

We addressed a number of sensitivity analyses.

1. True versus unclear randomisation.

2. Concealed versus unconcealed allocation.

3. Acceptable versus unacceptable number of withdrawals.

4. Blinded versus unblinded outcomes.

Due to the small number of studies within each comparison, we examined sensitivity by performing post-hoc analyses that eliminated one or more potentially biased studies to confirm the robustness of the original results.

\section{True versus unclear randomisation}

Five studies used true randomisation and four studies did not report how randomisation was achieved (Lin 2004; Wall 1987; Yang 2006; Yang 2007). We analysed all variables again after eliminating the studies with unclear randomisation procedures for Comparisons 1 and 2. Results for the secondary variables at the end of treatment were altered (Table 5); in this analysis, we found no significant effects for gait speed, the TUG test, or the 6MWT at the end of treatment. The results for Comparison 2 remained as previously reported.

\section{Concealed versus unconcealed allocation}

Seven studies reported concealed allocation of participant assignment and two studies did not report the details of how participants were assigned to groups (Lin 2004; Wall 1987). No substantial changes to the existence, direction or extent of significant effects resulted from eliminating the two studies that lacked concealed allocation. Moreover, the changes to effect size were minimal for gait speed, TUG test, and 6MWT at the end of treatment and for gait function at the three-month follow up (Table 6).

\section{Acceptable versus unacceptable number of withdrawals}

Eight of the nine studies reported an acceptable number of withdrawals (less than $15 \%$ of the total). As a result, we did a sensitivity analysis after removing the one study with a large number of withdrawals (Dean 2000). In the Dean study, $25 \%$ of participants were unavailable for the post-test, and 33\% withdrew prior to follow up. When the Dean study was removed from the analyses for which it had reported data, no substantial changes in the existence, direction or extent of significant effects occurred (Table 7); however the TUG test and the 6MWT could no longer be evaluated at follow up as only the Dean study contributed to those analyses.

\section{Blinded versus unblinded outcomes}

Seven of the nine studies reported that evaluators were blind to group allocation. The Dean study noted that one evaluator may have become partially exposed to group allocation part way through the study (Dean 2000), and the Wall study did not report on blinding (Wall 1987). Hence, we ran a sensitivity analysis removing 
the Dean and Wall studies, and no substantial changes in the existence, direction or extent of results occurred either at the end of treatment or at follow up (Table 8).

\section{DISCUSSION}

The primary aim of this review was to evaluate the effect of overground physical therapy gait training on the gait function of chronic stroke patients with mobility deficits. Results were mixed, with no significant effect for the primary variable at the end of treatment but small effects for several secondary variables. Our mixed findings may be due to the small number of studies that met the inclusion criteria, the small number of enrolled participants, and the lack of consistent outcome measures used in the included studies.

For the primary variable of gait function, meta-analysis revealed that gait training (as compared to the control intervention) did not have a significant effect at the end of treatment. At follow up, there was a significant effect for the one study that measured gait function. Since the effect size at follow up $(0.34,95 \% \mathrm{Cl} 0.01$ to 0.66) was a value generally considered to be small (Cohen 1988), and it was based on a single study, this result should be interpreted with caution. The lack of a sufficient number of trials precludes the review authors from making a conclusive statement about the effect of overground physical therapy gait training on gait function in patients with chronic stroke.

Results for the secondary variables of Barthel Index, gait speed, TUG, and 6MWT were mixed. Meta-analysis revealed statistically significant effects for gait speed, TUG test, and 6MWT immediately after treatment. These effects can be compared to the 'smallest real difference' values derived for chronic stroke patients with hemiparesis (Flansbjer 2005). The smallest real difference provides a $95 \% \mathrm{Cl}$ around the standard error of the measurement, showing how large a change is needed to have $95 \%$ confidence that observed changes are not due to measurement error. Flansbjer and colleagues report smallest real difference intervals of 0.15 to 0.25 $\mathrm{m} / \mathrm{sec}$ for gait speed, 2.59 to 3.75 seconds for the TUG test, and 37.3 to 66.0 metres for the 6MWT. The effect sizes from our meta-analysis did not reach the lower end of these smallest real difference ranges, suggesting that while these secondary variables show statistically significant effects, the observed changes are unlikely to translate into reliable and important clinical improvements. For the variable Barthel Index, no significant effects were evident. At the threemonth follow up, no significant effects were evident among the secondary variables. Taken together, the observed effects for gait speed, TUG, and 6MWT are limited but may suggest a promising area for future work. The results for the TUG test and the 6MWT especially reflect recent research focused on well-documented, specific, therapeutic protocols for overground gait training (Dean 2000; Pang 2005; Salbach 2004; Yang 2007; Yang 2007), some of which used methodologically rigorous placebo conditions but still included fewer than 100 participants each (Dean 2000; Pang 2005; Salbach 2004).

Very few adverse events or adverse effects were reported in the included studies. These results appear to reflect the relative safety of the experimental intervention in these studies as information on adverse events was obtained for all of the included studies either from the published article or from personal communication. Additional adverse events that did not lead to injury or medical complications or that appeared to be unrelated to the experimental procedures (new strokes, cancer diagnoses, falls in participants on a waiting list) may not have been recorded however, as they were not reported systematically.

Subgroup analyses on type of intervention (real-time cueing only versus mixed types versus pre-gait training only) and on extent of intervention (less than 29 hours versus more than 29 hours) revealed no significant effects. However, the results must be interpreted cautiously due to the small number of studies contributing.

Sensitivity analyses generated only one substantial change from the primary analyses. When studies with unclear randomisation procedures were eliminated, the secondary variables (gait speed, TUG test, and 6MWT) no longer showed significant effects at the end of the treatment phase. This lends additional caution to interpretation of the results, especially given that at most four studies contributed to the remaining analyses. Sensitivity analyses addressing unconcealed allocation, a large number of withdrawals, or unblinded evaluators did not change either the existence or size of effects notably.

Along with the relative paucity of large, high quality, randomised controlled trials on the effectiveness of overground gait training, limitations of this review include the large variability in the disability status of chronic stroke patients with mobility deficits, the slow rate of overall recovery for chronic stroke patients, the limited descriptions of the experimental interventions in studies focused on broadly-based community physical therapy services that included overground gait training, the blunt nature of the primary variable - gait function, the limited duration of follow up (generally no more than three months), and the diversity of outcome variables used by the included studies.

We are confident that our extensive search strategy across multiple databases identified all relevant trials. We made multiple contacts with investigators to obtain additional information on published studies or updated information on ongoing studies. We also had access to studies registered with the Cochrane Stroke Group and thoroughly reviewed the titles of studies included in the bibliography of relevant articles. We did not perform handsearching of conference proceedings because it has been shown to be ineffective in identifying relevant studies (Moseley 2003).

The effectiveness of overground gait training for improving gait function among patients with chronic stroke is crucial given the large number of chronic stroke patients with mobility deficits (Jorgensen 1995). The limited available evidence suggests that overground gait training has no significant effect on gait function although it may provide small benefits for the more unidimensional performance variables of gait speed, the TUG test and the 6MWT. Even there, however, the effects are small: they do not reach the level of smallest real difference, and they were no longer evident when studies with unclear randomisation were removed. Despite the lack of statistical significance, the importance of gait training for patients with chronic stroke may lie in its ability to educate the patient about ways to maintain safety during walking as the patient is encouraged to engage in related exercises and therapeutic approaches to increase strength and cardiovascular fitness, alter co-ordination or quality of gait, and achieve improved agility and efficiency. If that hypothesis holds true, overground gait training should not be expected to generate substantial changes in 
specific gait parameters or even broad measures of gait function by itself. Instead, overground gait training may create the most benefit in combination with other therapies or exercise protocols. This hypothesis is consistent with the finding that gait training is the most common physical therapy intervention provided to stroke patients (Jette 2005). It is also consistent with other systematic reviews that have considered the benefit of overground gait training in combination with treadmill training or high-technology approaches like body weight supported treadmill training (Moseley 2003), or both, or with exercise protocols (Saunders 2004) in acute and chronic stroke patients. These combination treatments appear to be more effective than overground gait training alone perhaps because they require larger amounts of practice on a single task than is generally available within overground gait training. In contrast with overground gait training, however, the combination therapies can be difficult to apply in community settings where resources are limited.

The studies reviewed here demonstrate a range of approaches to investigating overground gait training. Several studies investigated broadly-based interventions consisting of standard physical therapy treatment (Lin 2004; Green 2002; Wade 1992). In those studies, the interventions were defined to encompass standard practice and included a wide array of techniques and methods for performing gait training. The other included studies investigated a specific set of exercises aimed at task-oriented training (Dean 2000; Salbach 2004), cardiovascular fitness (Pang 2005), effective weight transfer, and increased duration during the support phase of the affected limb (Wall 1987), strength training (Yang 2006), or dual task performance (Yang 2007). These more focused interventions may generate benefits due to larger amounts of practice on a limited set of gait skills. This can be seen by the small and immediate effects of the focused protocols on the more uni-dimensional performance variables like gait speed, the TUG test, and the 6MWT. Recent work to develop additional performance variables that can be measured in contextually rich environments, such as the use of a functional obstacle course to measure task-oriented training (Means 2000) or multi-tasking situations to measure dual-task training (Yang 2007), may help to further clarify the specific effects of particular focused gait protocols. Most of these more focused protocols come from studies conducted in the last five years and hence show promise of producing additional data on the effectiveness of overground gait training.

Despite the plethora of clinically relevant studies on stroke patients, and the fact that overground gait training is a mainstay of physical therapy rehabilitation for chronic stroke patients, very few studies have investigated its effectiveness as a unique intervention. The literature search for this review suggests that a larger number of studies examining the effectiveness of overground gait training may be available for acute or subacute patients with stroke. Focusing on the effects in subacute patients may also be fruitful given the limited data available for chronic stroke patients. This review found insufficient evidence to determine whether overground gait training directly benefits broad measures of gait function, though it does suggest that specific training protocols provide limited benefits for more uni-dimensional measures of gait performance such as gait speed and the 6MWT. Additional evidence is needed to determine whether any type of overground gait training intervention by itself is sufficient to substantially affect broad measures of gait function in chronic stroke patients.

\section{AUTHORS' CONCLUSIONS}

\section{Implications for practice}

The literature lacks research-based evidence to support the use of overground gait training to improve mobility deficits in people with chronic stroke. This systematic review found no clear evidence that overground physical therapy gait training is associated with improvements in general gait function in people with chronic stroke, though limited evidence showed preliminary support for improvements on more uni-dimensional measures of gait performance, such as gait speed or the 6MWT, immediately after the intervention.

\section{Implications for research}

The findings of this study demonstrate a clear need for well-designed randomised controlled studies examining the effectiveness of overground physical therapy gait training for people with chronic stroke. Future studies should give a detailed description of a well-defined therapeutic protocol used for the intervention, include large sample sizes so they can be adequately powered, ensure that randomisation procedures are adequate and clearly outlined and that the assessors who perform outcome measures are blind to group assignment, and include outcome variables that measure quality of life, function, and adverse events as well as more uni-dimensional performance variables like gait speed and the 6MWT. Investigators should consider the findings of this Cochrane Review when designing trials and attempt to overcome the limitations of the studies presented.

\section{ACK N O WLEDGEMEN TS}

We greatly appreciate the efforts of Jill Lucas-Findley and Mariya Shiyko who reviewed the statistical analysis and provided suggestions on reporting results. Limited amounts of article retrieval and archival help were provided by graduate assistants supported by Long Island University, Brooklyn Campus. 
R E F E R E N C E S

\section{References to studies included in this review}

Dean 2000 \{published data only\}

Dean CM. Personal communication 1 May 2007.

Dean CM. Personal communication 25 October 2006.

* Dean CM, Richards CL, Malouin F. Task-related circuit training improves performance of locomotor tasks in chronic stroke: a randomized, controlled pilot trial. Archives of Physical Medicine and Rehabilitation 2000;81(4):409-17.

\section{Green 2002 \{published data only\}}

Green J, Forster A, Bogle S, Young J. Physiotherapy for patients with mobility problems more than 1 year after stroke: a randomised controlled trial. Lancet 2002;359(9302):199-203.

Lin 2004 \{published data only\}

Lin J-H, Hsieh C-L, Lo SK, Chai H-M, Liao L-F. Preliminary study of the effect of low-intensity home-based physical therapy in chronic stroke patients. Kaohsiung Journal of Medical Sciences 2004;20:18-23.

Pang 2005 \{published data only\}

Eng J. Personal communication 21 April 2007.

Eng J. Personal communication 30 May 2007.

* Pang MY, Eng JJ, Dawson AS, McKay HA, Harris JE. A community-based fitness and mobility exercise program for older adults with chronic stroke: a randomized, controlled trial. Journal of the American Geriatrics Society 2005;53(10):1667-74.

Salbach 2004 \{published data only\}

Salbach NM. Personal communication 19 July 2006.

Salbach NM. Individual patient data (supplied 27 March 2007). Data on file.

Salbach NM, Mayo NE, Robichaud-Ekstrand S, Hanley JA, Richards CL, Wood-Dauphinee S. The effect of a task-oriented walking intervention on improving balance self-efficacy poststroke: a randomized, controlled trial (corrected) (published erratum appears in Journal of the American Geriatrics Society 2005;53(8):1450). Journal of the American Geriatrics Society 2005;53(4):576-82.

* Salbach NM, Mayo NE, Wood-Dauphinee S, Hanley JA, Richards CL, Cote R. A task-orientated intervention enhances walking distance and speed in the first year post stroke: a randomized controlled trial. Clinical Rehabilitation 2004;18(5):509-19.

Wade 1992 \{published data only\}

Robertson F. Personal communication 12 June 2007.

Robertson F. Personal communication 4 June 2007.

* Wade DT, Collen FM, Robb GF, Warlow CP. Physiotherapy intervention late after stroke and mobility. $B M J$ 1992;304(6827):609-13.
Wall 1987 \{published data only\}

Turnbull G. Personal communication 14 June 2007.

* Wall JC, Turnbull GI. Evaluation of out-patient physiotherapy and a home exercise program in the management of gait asymmetry in residual stroke. Journal of Neurologic Rehabilitation 1987;3:115-23.

Yang 2006 \{published data only\}

Yang YR, Wang RY, Lin KH, Chu JY, Chan RC. Task-oriented progressive resistance strength training improves muscle strength and functional performance in individuals with stroke. Clinical Rehabilitation 2006;20:860-70.

\section{Yang 2007 \{published data only\}}

Yang Y-R, Wang R-Y, Chen Y-C, Kao M-J. Dual-task exercise improves walking ability in chronic stroke: a randomized controlled trial. Archives of Physical Medicine and Rehabilitation 2007;88:1236-40.

\section{References to studies excluded from this review}

Ada 2003 \{published and unpublished data\} Ada L. Personal communication 22 April 2007.

* Ada L, Dean CM, Hall JM, Bampton J, Crompton S. A treadmill and overground walking program improves walking in persons residing in the community after stroke: a placebocontrolled randomized trial. Archives of Physical Medicine and Rehabilitation 2003;84(10):1486-91.

\section{Andersen 2000 \{published data only\}}

Andersen H, Schultz-Larsen K, Kreiner S, Forchhammer B, Eriksen $\mathrm{K}$, Brown. Can readmission after stroke be prevented? Results of a randomized clinical study: a postdischarge followup service for stroke survivors. Stroke 2000;31(5):1038-45.

Caldwell 2000 \{published data only\}

Caldwell C, Medley A. Effects of bicycling, treadmill, and variable surfaces on gait in people following a CVA. Neurology Report 2000;24:203.

\section{Ceceli 1996 \{published data only\}}

Ceceli E, Dursun E, Cakci A. Comparison of joint-position biofeedback and overground therapy methods in genu recurvatum after stroke - 6 months' follow-up. European Journal of Physical Medicine \& Rehabilitation 1996;6(5):141-4.

\section{Chen 2006 \{published data only\}}

Chen XF. Effect of community-based-rehabilitation on activities of daily life and cognitive function in stroke patients. Chinese Journal of Clinical Rehabilitation 2006;10:4-6.

\section{DePaul 2007 \{unpublished data only\}}

DePaul VG. A comparison of two intensive walking training interventions in community dwelling individuals with history of stroke. www.clinicaltrials.gov (accessed May 2008). 
Dickstein 1986 \{published data only\}

Dickstein R, Hocherman S, Pillar T, Shaham R. Stroke rehabilitation. Three exercise therapy approaches. Physical Therapy 1986;66(8):1233-8.

\section{Duncan 2003 \{published data only\}}

Duncan P, Studenski S, Richards L, Gollub S, Lai SM, Reker D, et al. Randomized clinical trial of therapeutic exercise in subacute stroke. Stroke 2003;34(9):2173-80.

\section{Duncan 2007 \{published data only\}}

Duncan PW, Sullivan KJ, Behrman AL, Azen SP, Wu SS, Nadeau SE, et al. Protocol for the locomotor experience applied post-stroke (LEAPS) trial: a randomized controlled trial. BMC Neurology 2007;7:39.

\section{Eich 2004 \{published data only\}}

Eich HJ, Mach H, Werner C, Hesse S. Aerobic treadmill plus Bobath walking training improves walking in subacute stroke: a randomized controlled trial. Clinical Rehabilitation 2004;18(6):640-51.

\section{Flansbjer 2008 \{published data only\}}

Flansbjer U-B, Miller M, Downham D, Lexell J. Progressive resistance training after stroke: effects on muscle strength, muscle tone, gait performance and perceived participation. Journal of Rehabilitation Medicine 2008;40(1):42-8.

\section{Ford 2007 \{published data only\}}

Ford MP, Wagenaar RC, Newell KM. The effects of auditory rhythms and instruction on walking patterns in individuals post stroke. Gait \& Posture 2007;26(1):150-5.

\section{GAPS 2004 \{published data only\}}

The Glasgow Augmented Physiotherapy Study Group (GAPS). Can augmented physiotherapy input enhance recovery of mobility after stroke? A randomized controlled trial. Clinical Rehabilitation 2004;18:529-37.

\section{Green 2004 \{published data only\}}

Green J, Young J, Forster A, Collen F, Wade D. Combined analysis of two randomized trials of community physiotherapy for patients more than one year post stroke. Clinical Rehabilitation 2004;18(3):249-52.

\section{Hesse 1994 \{published data only\}}

Hesse SA, Jahnke MT, Bertelt CM, Schreiner C, Lucke D, Mauritz KH. Gait outcome in ambulatory hemiparetic patients after a 4-week comprehensive rehabilitation program and prognostic factors. Stroke 1994;25(10):1999-2004.

\section{Hesse 1995 \{published data only\}}

Hesse S, Bertelt C, Jahnke MT, Schaffrin A, Baake P, Malezic M, et al. Treadmill training with partial body-weight support compared with physiotherapy in nonambulatory hemiparetic patients. Stroke 1995;26(6):976-81.

\section{Hesse 1998 \{published data only\}}

Hesse S, Jahnke MT, Schaffrin A, Lucke D, Reiter F, Konrad M. Immediate effects of therapeutic facilitation on the gait of hemiparetic patients as compared with walking with and without a cane. Electromyography \& Motor Control 1998;109(6):515-22.

Hesse 1999 \{published data only\}

Hesse S. Treadmill training with partial body weight support in hemiparetic patients - further research needed. Neurorehabilitation and Neural Repair 1999;13(3):179-81.

\section{Hesse 2001 \{published data only\}}

Hesse S, Staats M, Werner C, Bestmann A, Lingnau ML. Ambulatory rehabilitation exercises for stroke patients at home. Preliminary results of scope, methods and effectiveness. Nervenarzt 2001;72(12):950-4.

\section{Hesse 2003 \{published data only\}}

Hesse S, Werner C, von Frandenberg S, Bardeleben A. Treadmil training with partial body weight support after stroke. Physical Medicine and Rehabilitation Clinics of North America 2003;14 Suppl 1:S111-23.

\section{Hesse 2005 \{published data only\}}

Hesse S, Eich HJ, Mach H, Parchmann H, Werner C. Aerobic treadmill training plus physiotherapy improves walking speed and capacity in subacute, moderately affected patients after stroke. Neurologie und Rehabilitation 2005;11(1):7-12.

\section{Horn 2005 \{published data only\}}

Horn SD, DeJong G, Smout RJ, Gassaway J, James R, Conroy B. Stroke rehabilitation patients, practice, and outcomes: is earlier and more aggressive therapy better?. Archives of Physical Medicine and Rehabilitation 2005;86(12):S101-14.

\section{Ivey 2007 \{published data only\}}

Ivey FM, Ryan AS, Hafer-Macko CE, Goldberg AP, Macko RF. Treadmill aerobic training improves glucose terlance and indices of insulin sensitivity in disabled stroke survivors - a preliminary report. Stroke 2007;38:2752-8.

Kalra 1993 \{published data only\}

Kalra L, Dale P, Crome P. Improving stroke rehabilitation. A controlled study. Stroke 1993;24(10):1462-7.

\section{Kilbreath 2006 \{published data only\}}

Kilbreath SL, Perkins S, Crosbie J, McConnell J. Gluteal taping improves hip extension during stance phase of walking following stroke. Australian Journal of Physiotherapy 2006;52(1):53-6.

\section{Kilbreath 2006b \{published data only\}}

Kilbreath SL. PBWST (partial body-weight supported treadmill training) and muscle power training after sub-acute stroke. www.ClinicalTrials.gov (accessed May 2008).

\section{Kollen 2005 \{published data only\}}

Kollen B, van de Port I, Lindeman E, Twisk J, Kwakkel G. Predicting improvement in gait after stroke - a longitudinal prospective study. Stroke 2005;36(12):2676-80.

Kwakkel 1999 \{published data only\}

Kwakkel G, Wagenaar RC, Twisk JWR, Lankhorst GJ, Koetsier JC. Intensity of leg and arm training after primary middle-cerebral- 
artery stroke: a randomised trial. Lancet 1999;354(9174):191-6, 176-7.

\section{Kwakkel 2002 \{published data only\}}

Kwakkel G, Kollen BJ, Wagenaar RC. Long term effects of intensity of upper and lower limb training after stroke: a randomised trial. Journal of Neurology, Neurosurgery and Psychiatry 2002;72(4):473-9.

\section{Langhammer 2000 \{published data only\}}

Langhammer B, Stanghelle JK. Bobath or motor relearning programme? A comparison of two different approaches of physiotherapy in stroke rehabilitation: a randomized controlled study. Clinical Rehabilitation 2000;14:361-9.

\section{Langhammer 2007 \{published data only\}}

Langhammer B, Kindmark B, Stanghell JK. Stroke patients and long-term training: is it worthwhile? A randomized comparison of two different training strategies after rehabilitation. Clinical Rehabilitation 2007;21(6):495-510.

\section{Langhammer 2008 \{published data only\}}

Langhammer B, Stanghelle JK, Lindmark B. Exercise and healthrelated quality of life during the first year following acute stroke. A randomized controlled trial. Brain Injury 2008;22(2):135-45.

\section{Latham 2005 \{published data only\}}

Latham NK, Jette DU, Slavin M, Richards LG, Procino A, Smout RJ, et al. Physical therapy during stroke rehabilitation for people with different walking abilities. Archives of Physical Medicine and Rehabilitation 2005;86(12 Suppl 2):S41-50.

\section{Laufer 2001 \{published data only\}}

Laufer Y, Dickstein R, Chefez Y, Marcovitz E. The effect of treadmill training on the ambulation of stroke survivors in the early stages of rehabilitation: a randomized study. Journal of Rehabilitation Research and Development 2001;38(1):69-78.

\section{Lee 2008 \{published data only\}}

Lee MJ, Kilbreath SL, Singh MF, Zeman B, Lord SR, Raymond J, et al. Comparison of effect of aerobic cycle training and progressive resistance training on walking ability after stroke: a randomized sham exercise-controlled study. Journal of the American Geriatrics Society 2008;56(6):976-85.

\section{Lennon 2006 \{published data only\}}

Lennon S, Ashburn A, Baxter D. Gait outcome following outpatient physiotherapy based on the Bobath concept in people post stroke. Disability and Rehabilitation 2006;28(13-14):873-81.

\section{Liston 2000 \{published data only\}}

Liston R, Mickelborough J, Harris B, Hann AW, Tallis RC. Overground physiotherapy and treadmill re-training for higherlevel gait disorders in cerebrovascular disease. Age and Ageing 2000;29(4):311-8.

\section{Logigian 1983 \{published data only\}}

Logigian MK, Samuels MA, Falconer J, Zagar R. Clinical exercise trial for stroke patients. Archives of Physical Medicine and Rehabilitation 1983;64(8):364-7.

\section{Luft 2008 \{unpublished data only\}}

Luft AR. Structural neuroplasticity associated with aerobic treadmill training in geriatric chronic stroke survivors. www.clinicaltrials.gov (accessed May 2008).

Lynch 2007 \{published data only\}

Lynch EA, Hillier S L, Stiller K, Campanella RR, Fisher PH. Sensory retraining of the lower limb after acute stroke: a randomized controlled pilot trial. Archives of Physical Medicine and Rehabilitation 2007;88(9):1101-7.

Macko 2005 \{published data only\}

Macko RF, Ivey FM, Forrester LW, Hanley D, Sorkin JD, Katzel LI, et al. Treadmill exercise rehabilitation improves ambulatory function and cardiovascular fitness in patients with chronic stroke - a randomized, controlled trial. Stroke 2005;36(10):2206-11.

\section{Mandel 1990 \{published data only\}}

Mandel AR, Nymark JR, Balmer SJ, Grinnell DM, Oriain MD. Electromyographic versus rhythmic positional biofeedback in computerized gait retraining with stroke patients. Archives of Physical Medicine and Rehabilitation 1990;71(9):649-54.

\section{Mauritz 2004 \{published data only\}}

Mauritz KH. Gait training in hemiparetic stroke patients. Europa Medicophysica 2004;40(3):165-78.

\section{Mayr 2007 \{published data only\}}

Mayr A, Kofler M, Quirbach E, Matzak H, Frohlich K, Saltuaryi L. Prospective, blinded, randomized crossover study of gait rehabilitation in stroke patients using the Lokomat gait orthosis. Neurorehabilitation and Neural Repair 2007;21(4):307-14.

\section{McClellan 2004 \{published data only\}}

McClellan R, Ada L. A six-week, resource-efficient mobility program after discharge from rehabilitation improves standing in people affected by stroke: placebo-controlled, randomised trial. Australian Journal of Physiotherapy 2004;50(3):163-7.

\section{Mead 2007 \{published data only\}}

Mead GE, Greig CA, Cunningham I, Lewis SJ, Dinan S, Saunders DH, et al. Stroke: a randomized trial of exercise or relaxation. Journal of the American Geriatrics Society 2007;55(6):892-9.

\section{Montoya 1994 \{published data only\}}

Montoya R, Dupui P, Pages B, Bessou P. Step-length biofeedback device for walk rehabilitation. Medical \& Biological Engineering \& Computing 1994;32(4):416-20.

\section{Morris 1992 \{published data only\}}

Morris ME, Matyas TA, Bach TM, Goldie PA. Electrogoniometric feedback: its effect on genu recurvatum in stroke. Archives of Physical Medicine and Rehabilitation 1992;73(12):1147-54.

\section{Olney 1991 \{published data only\}}

Olney SJ, Colborne GR. Assessment and treatment of gait dysfunction in the geriatric stroke patient. Topics In Geriatric Rehabilitation 1991;7(1):70-8. 


\section{Olney 2006 \{published data only\}}

Olney SJ, Nymark J, Brouwer B, Culham E, Day A, Heard J, et al. A randomized controlled trial of supervised versus unsupervised exercise programs for ambulatory stroke survivors. Stroke 2006;37(2):476-81.

\section{Peurala 2007 \{published data only\}}

Peurala SH, Airaksinen O, Jakala P, Tarkka IM, Sivenius J. Effects of intensive gait-oriented physiotherapy during early acute phase of stroke. Journal of Rehabilitation Research and Development 2007;44(5):637-48.

\section{Plummer 2007 \{published data only\}}

Plummer P, Behrman AL, Duncan PW, Spigel P, Saracino D, Martin J, et al. Effects of stroke severity and training duration on locomotor recovery after stroke: a pilot study. Neurorehabilitation and Neural Repair 2007;21(2):137-51.

\section{Pohl 2002 \{published data only\}}

Pohl M, Mehrholz J, Ritschel C, Ruckriem S. Speed-dependent treadmill training in ambulatory hemiparetic stroke patients - a randomized controlled trial. Stroke 2002;33(2):553-8.

\section{Pohl 2007 \{published data only\}}

Pohl M, Werner C, Holzgraefe M, Kroczek G, Mehrholz J, Wingendorf I, et al. Repetitive locomotor training and physiotherapy improve walking and basic activities of daily living after stroke: a single-blind, randomized multicentre trial (DEutsche GAngtrainerStudie, DEGAS). Clinical Rehabilitation 2007;21(1):17-27.

\section{Pyoria 2007 \{published data only\}}

Pyoria O, Talvitie U, Nyrkko H, Kautiainen H, Pohjolainen T, Kasper $\mathrm{V}$. The effect of two physiotherapy approaches on physical and cognitive functions and independent coping at home in stroke rehabilitation. A preliminary follow-up study. Disability \& Rehabilitation 2007;29(6):503-11.

\section{Rimmer 2000 \{published data only\}}

Rimmer JH, Riley B, Creviston T, Nicola T. Exercise training in a predominantly African-American group of stroke survivors. Medicine \& Science in Sports \& Exercise 2000;32(12):1990-6.

\section{Rodriquez 1996 \{published data only\}}

Rodriquez AA, Black PO, Kile KA, Sherman J, Stellberg B, McCormick J, et al. Gait training efficacy using a home-based practice model in chronic hemiplegia. Archives of Physical Medicine and Rehabilitation 1996;77(8):801-5.

\section{Roerdink 2007 \{published data only\}}

Roerdink M, Lamoth CJC, Kwakkel G, van Wieringen PCW, Beek PJ. Gait coordination after stroke: benefits of acoustically paced treadmill walking. Physical Therapy 2007;87(8):1009-22.

\section{Schauer 2003 \{published data only\}}

Schauer M, Mauritz KH. Musical motor feedback (MMF) in walking hemiparetic stroke patients: randomized trials of gait improvement. Clinical Rehabilitation 2003;17(7):713-22.
Smith 1981 \{published data only\}

Smith D, Goldenberg E, Ashburn A, Kinsella GJ, Sheikh K, Brennan $P$, et al. Remedial therapy after stroke: a randomised controlled trial. BMJ 1981;282(6263):517-20.

Smith 1982 \{published data only\}

Smith ME, Garraway WM, Smith DL, Akhtar AJ. Therapy impact on functional outcome in a controlled trial of stroke rehabilitation. Archives of Physical Medicine \& Rehabilitation 1982;63(1):21-4.

\section{Stephenson 2000 \{published data only\}}

Stephenson S, Wiles R. Advantages and disadvantages of the home setting for therapy: views of patients and therapists. British Journal of Occupational Therapy 2000;63(2):59-64.

\section{Stern 1970 \{published data only\}}

Stern PH, McDowell F, Miller JM, Robinson. Effects of facilitation exercise techniques in stroke rehabilitation. Archives of Physical Medicine and Rehabilitation 1970;51(9):526-31.

\section{Stibrant Sunnerhagen 2007 \{published data only\}}

Stibrant Sunnerhagen K. Circuit training in communityliving "younger" men after stroke. Journal of Stroke and Cerebrovascular Disease 2007;16(3):112-9.

\section{Sullivan 2007 \{published data only\}}

Sullivan KJ, Brown DA, Klassen T, Mulroy S, Ge T, Azen SP, et al. Effects of task-specific locomotor and strength training in adults who were ambulatory after stroke: results of the STEPS randomized clinical trial. Physical Therapy 2007;87(12):1580-602.

\section{Sutbeyaz 2007 \{published data only\}}

Sutbeyaz S, Yavuzer G, Sezer N, Koseoglu BF. Mirror therapy enhances lower-extremity motor recovery and motor functioning after stroke: a randomized controlled trial. Archives of Physical Medicine and Rehabilitation 2007;88(5):555-9.

Tangeman 1990 \{published data only\}

Tangeman P, Banaitis D, Williams A. Rehabilitation of chronic stroke patients: changes in functional performance. Archives of Physical Medicine \& Rehabilitation 1990;71(11):876-80.

Teixeira 1999 \{published data only\}

Teixeira-Salmela LF, Olney SJ, Nadeau S, Brouwer B. Muscle strengthening and physical conditioning to reduce impairment and disability in chronic stroke survivors. Archives of Physical Medicine and Rehabilitation 1999;80(10):1211-8.

Teixeira 2001 \{published data only\}

Teixeira-Salmela LF, Nadeau S, McBride I, Olney SJ. Effects of muscle strengthening and physical conditioning training on temporal, kinematic and kinetic variables during gait in chronic stroke survivors. Journal of Rehabilitation Medicine 2001;33(2):53-60

Thaut 1997 \{published data only\}

Thaut MH, McIntosh GC, Rice RR. Rhythmic facilitation of gait training in hemiparetic stroke rehabilitation. Journal of the Neurological Sciences 1997;151(2):207-12. 
Treger 2004 \{published data only\}

Treger I, Rofe K, Hutzler Y, Ring H. Self-managed walking program after stroke patients hospital rehabilitation. International Journal of Rehabilitation Research 2004;27:116-7.

\section{van Vliet 2005 \{published data only\}}

van Vliet PM, Lincoln NB, Foxall A. Comparison of Bobath based and movement science based treatment for stroke: a randomised controlled trial. Journal of Neurology, Neurosurgery and Psychiatry 2005;76(4):503-8.

\section{Waagfjord 1990 \{published data only\}}

Waagfjord J, Levangie PK, Certo CME. Effects of treadmill training on gait in a hemiparetic patient. Physical Therapy 1990;70(9):549-58.

\section{Wagenaar 1990 \{published data only\}}

Wagenaar RC, Meijer OG, van Wieringen PC, Kuik DJ, Hazenberg GJ, Lindeboom J, et al. The functional recovery of stroke: a comparison between neuro-developmental treatment and the Brunnstrom method. Scandinavian Journal of Rehabilitation Medicine 1990;22(1):1-8.

Weng 2006 \{published data only\} Weng CS, Wang J, Pan XY, Yu ZZ, Wang G, Gao LP, et al. Effectiveness of backward walking treadmill training in lower extremity function after stroke. Zhonghua Yi Xue Za Zi 2006;86:2635-8.

\section{Werner 1996 \{published data only\}}

Werner R, Kessler S. Effectiveness of an intensive outpatient rehabilitation program for postacute stroke patients. American Journal of Physical Medicine \& Rehabilitation 1996;75(2):114-20.

\section{Werner 2007 \{published data only\}}

Werner C, Lindquist AR, Bardeleben A, Hesse S. The influence of treadmill inclination on the gait of ambulatory hemiparetic subjects. Neurorehabilitation \& Neural Repair 2007;21(1):76-80.

\section{Wolfe 2000 \{published data only\}}

Wolfe C, Tilling K, Rudd AG. The effectiveness of communitybased rehabilitation for stroke patients who remain at home: a pilot randomized trial. Clinical Rehabilitation 2000;14:563-9.

\section{Yang 2005 \{published data only\}}

Yang YR, Yen JG, Yen LL, Lieu FK. Gait outcomes after additional backward walking training in patients with stroke: a randomized controlled trial. Clinical Rehabilitation 2005;19(3):264-73.

\section{Yavuzer 2007 \{published data only\}}

Yavuzer G, Oken O, Atay MB, Stam HJ. Effect of sensoryamplitude electric stimulation on motor recovery and gait kinematics after stroke: a randomized controlled study. Archives of Physical Medicine and Rehabilitation 2007;88(6):710-4.

\section{Yen 2008 \{published data only\}}

Yen C-L, Wang R-Y, Liao K-K, Huang C-C, Yang Y-R. Gait training induced change in corticomotor excitability in patients with chronic stroke. Neurorehabilitation \& Neural Repair 2008;22(1):22-30.
Young 1992 \{published data only\}

Young JB, Forster A. The Bradford community stroke trial: results at six months. BMJ 1992;304(6834):1085-9.

\section{References to ongoing studies}

Macko 2007 \{unpublished data only\}

Macko RF. Treadmill exercise prescriptions to improve fitness versus ambulatory function after stroke. www.ClinicalTrials.gov (accessed May 2008).

\section{Additional references \\ AHA 2005}

AHA (American Heart Association). Statistical Highlights. Heart Disease and Stroke Statistics - 2005 Update. Dallas, TX: American Heart Association, 2005.

\section{Bates 2005}

Bates B, Choi JY, Duncan PW, Glasberg JJ, Graham GD, Katz RC et al. Veterans Affairs/Department of Defense clinical practice guideline for the management of adult stroke rehabilitation care: executive summary. Stroke 2005;36(9):2049-56.

\section{Butland 1982}

Butland RJA, Pang J, Gross ER, Woodcock AA, Geddes DM. Two-, six-, and twelve-minute walking tests in respiratory disease. BMJ 1982;284:1607-8.

\section{Carr 1985}

Carr JH, Shepherd RB, Nordholm L, Lynne D. Investigation of a new motor assessment scale for stroke patients. Physical Therapy 1985;65:175-80.

\section{Cohen 1988}

Cohen J. Statistical Power Analysis in the Behavioral Sciences. 2nd Edition. Hillsdale, NJ: Lawrence Erlbaum Associates, Inc., 1988.

\section{Collen 1991}

Collen FM, Wade DT, Robb GF, Bradshaw CM. Mobility after stroke: the Rivermead mobility index: a further development of the Rivermead motor assessment. International Disability Studies 1991;13(2):50-4.

\section{Daley 1997}

Daley K, Mayo NE, Wood-Dauphinee S, Danys I, Cabot R. Verification of the STroke REhabilitation Assessment of Movement (STREAM). Physiotherapy Canada 1997;49:269-78.

\section{Deeks 2008}

Deeks JJ, Higgins JPT, Altman DG (editors). Chapter 9: Analysing data and undertaking meta-analyses. In: Higgins JPT, Green $\mathrm{S}$ (editors). Cochrane Handbook for Systematic Reviews of Interventions Version 5.0.1 (updated September 2008). The Cochrane Collaboration, 2008. Available from www.cochranehandbook.org. 


\section{Duncan 2002}

Duncan PW, Horner RD, Reker DM, Samsa GP, Hoening H, Hamilton B, et al. Adherence to postacute rehabilitation guidelines is associated with functional recovery in stroke. Stroke 2002;33(1):167-77.

\section{Duncan 2005}

Duncan PW, Zorowitz R, Bates B, Choi JY, Glasberg JJ, Graham GD, et al. AHA/ASA-endorsed practice guidelines: management of acute stroke rehabilitation care: a clinical practice guideline. Stroke 2005;36:2049-56.

\section{Finch 2002}

Finch E, Brooks D, Stratford PW, Mayo NE. Physical rehabilitation outcome measures: a guide to enhanced clinical decision making. 2nd Edition. Baltimore, MD: Lippincott, William \& Wilkins, 2002:292. [0-7817-4241-2]

\section{Flansbjer 2005}

Flansbjer UB, Holmback AM, Downham D, Patten C, Lexell J. Reliability of gait performance tests in men and women with hemiparesis after stroke. Journal of Rehabilitation Medicine 2005;37:75-82.

\section{Higgins 2008}

Higgins JPT, Green S (editors). Cochrane Handbook for Systematic Reviews of Interventions Version 5.0.0 [updated February 2008]. The Cochrane Collaboration, 2008. Available from www.cochrane-handbook.org.

\section{Hsieh 2000}

Hsieh C, Hsueh I, Mao H. Validity and responsiveness of the Rivermead Mobility Index in stroke patients. Scandinavian Journal of Rehabilitation Medicine 2000;32(3):140-2.

\section{Jette 2005}

Jette DU, Latham NK, Smout RJ, Gassaway J, Slavin MD, Horn SD. Physical therapy interventions for patients with stroke in inpatient rehabilitation facilities. Physical Therapy 2005;85:238-48.

\section{Jorgensen 1995}

Jorgensen HS, Nakayama H, Raaschou HO, Olsen TS. Recovery of walking function in stroke patients - the Copenhagen stroke study. Archives of Physical Medicine and Rehabilitation 1995;76(1):27-32.

\section{Lincoln 1979}

Lincoln NB, Leadbitter D. Assessment of motor function in stroke patients. Physiotherapy 1979;65:48-51.

\section{Maher 2003}

Maher CG, Sherrington C, Herbert RD, Moseley A, Elkins M. Reliability of the PEDro scale for rating quality of randomized controlled trials. Physical Therapy 2003;83(8):713-21.

\section{Mahoney 1965}

Mahoney FI, Barthel DW. Functional evaluation: the Barthel Index. Maryland State Medical Journal 1965;14:61-5.

\section{Matthias 1986}

Matthias S, Nayak, US, Isaacs B. Balance in elderly patients: the "Get-Up and Go" test. Archives of Physical Medicine and Rehabilitation 1986;67:387-9.

\section{Mayo 1999}

Mayo NE, Wood-Dauphinee S, Ahmed S, Gordon C, Higgins J, McEwen S, et al. Disablement following stroke. Disability and Rehabilitation 1999;21(5-6):258-68.

\section{Mayo 2002}

Mayo NE, Wood-Dauphinee S, Cote R, Durcan L, Carlton J. Activity, participation, and quality of life 6 months poststroke. Archives of Physical Medicine and Rehabilitation 2002;83(8):1035-42.

\section{Means 2000}

Means KM, O'Sullivan PS. Modifying a functional obstacle course to test balance and mobility in the community. Journal of Rehabilitation Research and Development 2000;37(5):621-32.

\section{Moseley 2003}

Moseley A, Stark A, Cameron I, Pollock A. Treadmill training and body weight support for walking after stroke. Cochrane Database of Systematic Reviews 2003, Issue 3. [DOI: 10.1002/14651858.CD002840.pub2]

\section{Murray 1967}

Murray MP. Gait as a total pattern of movement. American Journal of Physical Medicine 1967;46:290-333.

\section{OST 2003}

Outpatient Service Trialists. Therapy-based rehabilitation services for stroke patients at home. Cochrane Database of Systematic Reviews 2003, Issue 1. [DOI: 10.1002/14651858.CD002925]

\section{Patel 2000}

Patel AT, Duncan PW, Lai S-M, Studenski S. The relation between impairments and functional outcomes poststroke. Archives of Physical Medicine and Rehabilitation 2000;81(10):1357-63.

\section{Podsiadlo 1991}

Podsiadlo D, Richardson S. The Timed "Up \& Go": a test of basic functional mobility for frail elderly persons. Journal of the American Geriatrics Society 1991;39:142-8.

\section{RevMan 2008 [Computer program]}

The Nordic Cochrane Centre, The Cochrane Collaboration. Review Manager (RevMan). The Cochrane Collaboration. Version 5.0. Copenhagen: The Nordic Cochrane Centre, The Cochrane Collaboration, 2008.

\section{Sandercock 2006}

Sandercock P. Subgroup analysis: pitfalls and perils. Evidencebased Neurology in Europe. Perugia, Italy, December 2006.

\section{Saunders 2004}

Saunders D, Greig C, Young A, Mead G. Physical fitness training for stroke patients. Cochrane Database of Systematic Reviews 2004, Issue 1. [DOI: 10.1002/14651858.CD003316.pub2] 


\section{Shaughnessy 2005}

Shaughnessy M, Michael KM, Sorkin JD, Macko RF. Steps after stroke - capturing ambulatory recovery. Stroke 2005;36:1305-7.

\section{Teasell 2005}

Teasell RW, Foley NC, Salter K, Bhogal SK, Bayona N, Jutai J, et al. Evidence-based review of stroke rehabilitation: Outcome measures in stroke rehabilitation. Evidence-based review of stroke rehabilitation (Edition 9). London, Ontario, Canada: Department of Physical Medicine and Rehabilitation, 2005.

\section{CHARACTERISTICS OF STUDIES}

Characteristics of included studies [ordered by study ID]

\section{Verhagen 1998}

Verhagen AP, de Vet HC, de Bie RA, Kessels AG, Boers M, Bouter LM, et al. The Delphi list: a criteria list for quality assessment of randomized clinical trials for conducting systematic reviews developed by Delphi consensus. Journal of Clinical Epidemiology 1998;51(12):1235-41.

* Indicates the major publication for the study

\section{Dean 2000}

\begin{tabular}{|c|c|}
\hline Methods & $\begin{array}{l}\text { RCT with placebo group (upper extremity functional tasks) } \\
\text { Randomised after pairing by gait speed } \\
\text { Exp }=6 ; \mathrm{Ctl}=6 \\
\text { Participants were not blind, but did not know the purpose of the study } \\
\text { Treating therapists were not blind } \\
\text { Evaluators may have been aware of assignment as they inadvertently viewed one training session }\end{array}$ \\
\hline Participants & $\begin{array}{l}\text { Number of participants }=12 \\
50 \text { to } 74 \text { years } \\
\text { Stroke }>6 \text { months } \\
\text { First stroke } \\
\text { Hemiplegia } \\
\text { Able to walk } 10 \text { metres with or without assistive device } \\
\text { Live in community }\end{array}$ \\
\hline Interventions & $\begin{array}{l}3 \text { sessions per week for } 4 \text { weeks; } 1 \text { hour per session } \\
\text { Group exercise class ( } 3 \text { participants per physical therapist) } \\
\text { Circuit programme } \\
\text { Strengthen leg muscles and practice locomotor tasks } \\
\text { The control group did the same but with upper extremity circuit training exercises } \\
\text { Both groups did intervention in rehabilitation centre }\end{array}$ \\
\hline Outcomes & $\begin{array}{l}\text { Gait speed (10 metres) } \\
\text { 6MWT } \\
\text { TUG } \\
\text { Outcomes measured at baseline, immediately after intervention ( } 4 \text { weeks), and } 2 \text { months after the end } \\
\text { of the intervention }\end{array}$ \\
\hline Notes & Quebec \\
\hline \multicolumn{2}{|l|}{ Risk of bias } \\
\hline Bias & Authors' judgement Support for judgement \\
\hline Allocation concealment? & A - Adequate \\
\hline
\end{tabular}

\section{Green 2002}

\section{Methods}

RCT with no treatment control group

Participants were randomised to groups using a random numbers table and 4-length permuted blocks $\operatorname{Exp}=85 ; \mathrm{Ctl}=85$ 
Green 2002 (Continued)

Participants and treating therapists were not blind

Evaluator was blind at 0 and 3 months, not blind for 6 and 9 months

\begin{tabular}{ll}
\hline Participants & Number of participants = 170 \\
& $50+$ years \\
& Stroke $>1$ year ago \\
& Mobility problems (slow speed, needed assistive device, having fallen within past 3 months, unable to \\
manage stairs independently) & Excluded patients with dementia, other gait problems, severe comorbidities, PT in past 6 months \\
& Living at home \\
\hline Interventions & Variable, at least 3 visits, up to 13 weeks \\
& Community PT \\
& Problem-solving approach \\
& Main interventions were gait re-education, therapeutic exercise, functional exercise, balance re-educa- \\
tion & The control group got no treatment \\
Interventions and outcome measures done in the participants' homes \\
Gait speed (10 metres) \\
RMI \\
Bl - locomotion score \\
Outcomes measured at 0, 3, 6, 9 months \\
\hline Outcomes \\
Did extensive assessment at baseline \\
Intervention varied by participant \\
Bradford, UK
\end{tabular}

\section{Risk of bias}

\begin{tabular}{lll}
\hline Bias & Authors' judgement & Support for judgement \\
\hline Allocation concealment? & Low risk & A - Adequate \\
\hline
\end{tabular}

Lin 2004

\begin{tabular}{|c|c|}
\hline Methods & $\begin{array}{l}\text { Randomised, cross-over trial, using the first period only } \\
\text { Control group got no treatment during first } 11 \text { weeks } \\
\text { Participants were randomised but no procedures are given } \\
\text { Exp }=10 ; \mathrm{Ctl}=10 \\
\text { Participants and treating therapists were not blind } \\
\text { Evaluators were blind to group assignment }\end{array}$ \\
\hline Participants & $\begin{array}{l}\text { Number of participants }=20 \\
\text { Average age }=62 \text { years (no range given) } \\
\text { Stroke }>1 \text { year ago } \\
\text { Live in community } \\
\text { Barthel Index score } 5 \text { to } 14 \\
\text { No rehabilitation in } 6 \text { months } \\
\text { Follow verbal commands }\end{array}$ \\
\hline Interventions & $\begin{array}{l}1 \text { session per week for } 10 \text { weeks; } 50 \text { to } 60 \text { minutes per session } \\
\text { Home-based PT programme: motor facilitation, posture training, functional ambulation training, ADL } \\
\text { training } \\
\text { Caregiver counselling } \\
\text { All treatments and outcome assessments were done at participants' homes }\end{array}$ \\
\hline
\end{tabular}


Lin 2004 (Continued)

Outcomes BI

STREAM - mobility item

Outcomes measured at baseline and after intervention (11 weeks)

Notes Nan-Tou County, Taiwan

\section{Risk of bias}

\begin{tabular}{lll}
\hline Bias & Authors' judgement & Support for judgement \\
\hline Allocation concealment? & Unclear risk & B - Unclear \\
\hline
\end{tabular}

\section{Pang 2005}

$\begin{array}{ll}\text { Methods } & \text { RCT with placebo group (upper extremity exercise training) } \\ & \text { Participants stratified by sex } \\ & \text { Each participant was randomised by drawing ballots by an investigator independent of assessment } \\ \text { and recruitment } & \text { Exp }=32 ; \mathrm{Ctl}=31 \\ & \text { Outcome assessors were blind to group allocation }\end{array}$

Number of participants =63
Inclusion criteria:
(1) 50 years or more
(2) stroke > 1 year ago
(3) first stroke
(4) able to walk 10 metres with or without walking aid
(5) live in community
Exclusion criteria:
(1) serious cardiac disease
(2) high blood pressure
(3) pain while walking
(4) other neurological conditions
(5) other serious diseases that precluded participation

Interventions 3 sessions per week for 19 weeks; 1 hour per session

The experimental group did cardiorespiratory and mobility exercise programme, which included brisk walking, various stepping and walking tasks, balance tasks, leg muscle strengthening

The control group did upper extremity programme to strengthen and improve co-ordination of shoulder, elbow, wrist, and hand

\begin{tabular}{ll}
\hline Outcomes & 6MWT \\
& Assessed at baseline and immediately after intervention (19 weeks) \\
\hline Notes & Vancouver, British Columbia, Canada \\
& Also assessed: \\
(1) VO $\mathrm{O}_{2}$ max during a maximal cycle ergometer exercise test \\
(2) level of perceived exertion (Borg Rating of Perceived Exertion Scale) \\
(3) isometric knee extension strength \\
(4) functional balance (Berg Balance Scale) \\
(5) activity participation - Physical Activity Scale for Individuals with Physical Disabilities \\
(6) femoral neck bone mineral density based on dual-energy x-ray absorptiometry
\end{tabular}

\section{Risk of bias}

Overground physical therapy gait training for chronic stroke patients with mobility deficits (Review) 
Pang 2005 (Continued)

\begin{tabular}{lll} 
Bias & Authors' judgement & Support for judgement \\
\hline Allocation concealment? & Low risk & A - Adequate \\
\hline
\end{tabular}

\section{Salbach 2004}

\begin{tabular}{|c|c|}
\hline Methods & $\begin{array}{l}\text { RCT with placebo group (upper extremity functional training) } \\
\text { Exp }=44 ; \mathrm{Ctl}=47 \\
\text { Stratified according to gait speed (slow, medium, fast) and then randomised } \\
\text { Participants and treating therapists were not blind but evaluators were blind }\end{array}$ \\
\hline Participants & $\begin{array}{l}\text { Number of participants }=91 \\
38 \text { to } 91 \text { years } \\
\text { ( } 62 \text { had stroke }>6 \text { months) } \\
\text { First or recurrent stroke no more than } 1 \text { year prior } \\
\text { Residual walking deficit ( } 6 \mathrm{MWT} \text { result must be less than age and gender norms) } \\
\text { Mental competency and ability to comprehend instructions } \\
\text { Ability to walk } 10 \text { metres independently with or without assistive device } \\
\text { Living in community } \\
\text { No comorbidities that precluded participation }\end{array}$ \\
\hline Interventions & $\begin{array}{l}3 \text { sessions per week for } 6 \text { weeks } \\
\text { Mobility intervention included } 10 \text { walking related tasks from Dean } 2000 \\
\text { The control group did upper extremity functional training }\end{array}$ \\
\hline Outcomes & $\begin{array}{l}\text { Gait speed ( } 5 \text { metres - comfortable pace) } \\
\text { 6MWT } \\
5 \text {-metre walk at maximum pace } \\
\text { TUG } \\
\text { Outcomes measured at baseline at end of intervention ( } 6 \text { weeks) }\end{array}$ \\
\hline Notes & Montreal and Quebec City, Canada \\
\hline \multicolumn{2}{|l|}{ Risk of bias } \\
\hline Bias & Authors' judgement Support for judgement \\
\hline Allocation concealment? & A - Adequate \\
\hline
\end{tabular}

\section{Wade 1992}

Methods

RCT using 3-month cross-over design with no treatment control group, first period only

"Randomisation was restricted; randomisation (permuted blocks of 10) with random number tables"

$\operatorname{Exp}=49 ; \mathrm{Ctl}=45$

Patients and treating therapists were not blind to their treatment group

Evaluators were blind to treatment group

Pumber of participants $=94$
Average age $=72$ years
Stroke $>1$ year and $<7$ years
Mobility problems (needed walking aid, had fallen in previous 3 months, unable to manage stairs, or
slow gait speed)
No other inclusion/exclusion criteria


Wade 1992 (Continued)

It is not known if participants were living in the community

\begin{tabular}{ll}
\hline Outcomes & Gait speed (10 metres) \\
& Functional Ambulation Category (at baseline only) \\
& $\mathrm{BI}$ - number walking independently \\
$\mathrm{RMI}$ (sometimes an early version of it) \\
Nottingham Extended ADL Index - mobility subscale \\
Outcomes measured at baseline (x 2), 6 weeks and 3.5 months \\
\hline Notes & Oxfordshire, UK \\
\hline
\end{tabular}

\section{Risk of bias}

\begin{tabular}{lll}
\hline Bias & Authors' judgement & Support for judgement \\
\hline Allocation concealment? & Low risk & A-Adequate \\
\hline
\end{tabular}

Wall 1987

\begin{tabular}{|c|c|}
\hline Methods & $\begin{array}{l}\text { RCT with } 4 \text { groups } \\
\text { Randomly assigned to } 1 \text { of } 4 \text { groups for } 6 \text { months }+3 \text {-month follow up } \\
A=5 ; B=5 ; C=5 \text {; Control }=5 \\
\text { Does not report if participants, treating therapists, or evaluators were blind }\end{array}$ \\
\hline Participants & $\begin{array}{l}\text { Number of participants }=20 \\
45 \text { to } 70 \text { years } \\
\text { Stroke }>18 \text { months }<10 \text { years } \\
\text { Participants excluded if serious or unstable medial conditions, cognitive disturbances, incontinence } \\
\text { Had to be able to walk with or without cane }\end{array}$ \\
\hline Interventions & $\begin{array}{l}2 \text { sessions per week for } 6 \text { months; } 1 \text { hour per session } \\
\text { A: both exercise sessions at PT clinic, with physical therapist } \\
\text { B: both exercise sessions at home } \\
\text { C: } 1 \text { exercise session at PT clinic, one at home } \\
\text { D: No treatment control group } \\
\text { Series of } 10 \text { exercises that were progressed at each month (easiest dropped, harder one added) } \\
\text { Exercises were designed to improve the gait pattern by increasing the ability of the participant to } \\
\text { transfer weight through the hemiplegic limb } \\
\text { Also designed to increase the time spent on the affected limb in single support }\end{array}$ \\
\hline Outcomes & $\begin{array}{l}\text { Gait speed (normalised to stature) } \\
\text { Outcomes measured at baseline, monthly for months } 1 \text { to } 9\end{array}$ \\
\hline Notes & Halifax, Nova Scotia, Canada \\
\hline
\end{tabular}


Wall 1987 (Continued)

Risk of bias

\begin{tabular}{lll}
\hline Bias & Authors' judgement & Support for judgement \\
\hline Allocation concealment? & Unclear risk & B - Unclear \\
\hline
\end{tabular}

Yang 2006

\begin{tabular}{|c|c|c|}
\hline Methods & \multicolumn{2}{|c|}{$\begin{array}{l}\text { RCT with no treatment control group } \\
\text { Participants were randomised by independent person using sealed envelopes } \\
\text { The evaluator was blind to group assignment } \\
\text { Participants and treating therapist were not reported to be blind to group assignment }\end{array}$} \\
\hline Participants & \multicolumn{2}{|c|}{$\begin{array}{l}\text { Number of participants }=48 \\
\text { Stroke }>1 \text { year } \\
\text { First stroke } \\
\text { Limited gait velocity } \\
\text { Hemiparesis } \\
\text { Able to walk } 10 \text { metres without an assistive devices } \\
\text { Not presently receiving rehabilitation } \\
\text { Stable medical condition } \\
\text { Able to understand commands and follow directions }\end{array}$} \\
\hline Interventions & \multicolumn{2}{|c|}{$\begin{array}{l}3 \text { sessions per week for } 4 \text { weeks; } 30 \text { minutes per session } \\
\text { Task-oriented progressive resistance strength training within the context of a circuit training class. Sta- } \\
\text { tions included standing and reaching in different directions; sit to stand from various chair heights; } \\
\text { stepping forward, backwards, and sideways onto and off of blocks; heel rise and lowering } \\
\text { The control group received no intervention }\end{array}$} \\
\hline Outcomes & \multicolumn{2}{|c|}{$\begin{array}{l}\text { Gait speed ( } 3.7 \text { metres) } \\
\text { TUG } \\
\text { 6MWT } \\
\text { Outcomes measured at baseline and immediately after intervention (4 weeks) }\end{array}$} \\
\hline Notes & \multicolumn{2}{|c|}{$\begin{array}{l}\text { Taipei, Taiwan } \\
\text { Also assessed: cadence, stride length, 15-second step test, lower extremity muscle strength }\end{array}$} \\
\hline \multicolumn{3}{|l|}{ Risk of bias } \\
\hline Bias & Authors' judgement & Support for judgement \\
\hline Allocation concealment? & Unclear risk & B - Unclear \\
\hline
\end{tabular}

\section{Yang 2007}

\begin{tabular}{ll} 
Methods & RCT with no treatment control group \\
& Participants were randomised by independent person using sealed envelopes \\
& The evaluator was blind to group assignment \\
& Participants and treating therapist were not reported to be blind to group assignment \\
\hline Participants & Number of participants $=25$ \\
& 45 to 80 years \\
& Stroke $>1$ year \\
& First stroke
\end{tabular}


Yang 2007 (Continued)

Hemiparesis

Limited gait velocity

Able to walk 10 metres without an assistive devices

Functional use of the upper extremities

Not presently receiving rehabilitation

Stable medical condition

Able to understand commands and follow directions

\begin{tabular}{ll}
\hline Interventions & 3 sessions per week for 4 weeks; 30 minutes per session \\
& Dual task training including walking activities while carrying or bouncing 1 or 2 balls \\
Ctl received no treatment
\end{tabular}

\begin{tabular}{|c|c|c|}
\hline Outcomes & \multicolumn{2}{|c|}{$\begin{array}{l}\text { Gait speed } \\
\text { Outcomes measured at baseline and immediately after intervention ( } 4 \text { weeks) }\end{array}$} \\
\hline Notes & \multicolumn{2}{|c|}{$\begin{array}{l}\text { Taipei, Taiwan } \\
\text { Also assessed: cadence, stride time, stride length, single support time, and temporal symmetry index }\end{array}$} \\
\hline \multicolumn{3}{|l|}{ Risk of bias } \\
\hline Bias & Authors' judgement & Support for judgement \\
\hline Allocation concealment? & Unclear risk & B - Unclear \\
\hline
\end{tabular}

6MWT: six-minute-walk test

ADL: activities of daily living

BI: Barthel Index

Ctl: control

Exp: experimental

PT: physical therapy

$\mathrm{RCT}$ : randomised controlled trial

RMI: Rivermead Mobility Index

STREAM: Stroke Rehabilitation Assessment of Movement

TUG: timed up-and-go test

$\mathrm{VO}_{2}$ max: a measure of the maximum volume of oxygen that a person can use

Characteristics of excluded studies [ordered by study ID]

\begin{tabular}{ll}
\hline Study & Reason for exclusion \\
\hline Ada 2003 & $\begin{array}{l}\text { The intervention included more than } 50 \% \text { training on the treadmill, so that overground gait train- } \\
\text { ing was not a majority of the treatment }\end{array}$ \\
\hline Andersen 2000 & Participants had a stroke within previous 6 months \\
\hline Caldwell 2000 & Not a RCT (case series with 1 or 2 participants per group) \\
\hline Ceceli 1996 & $\begin{array}{l}\text { The intervention included high-technology equipment not readily available in a community PT set- } \\
\text { ting }\end{array}$ \\
\hline Chen 2006 & $\begin{array}{l}\text { The intervention included numerous components and overground gait training was only one of } \\
\text { them, less than } 50 \% \text { of the total }\end{array}$ \\
\hline DePaul 2007 & $\begin{array}{l}\text { Some participants had a stroke within previous } 6 \text { months } \\
\text { All groups participated in walking exercises }\end{array}$ \\
\hline
\end{tabular}




\begin{tabular}{|c|c|}
\hline Study & Reason for exclusion \\
\hline Dickstein 1986 & Participants had a stroke within previous 6 months \\
\hline Duncan 2003 & Participants had a stroke within previous 6 months \\
\hline Duncan 2007 & $\begin{array}{l}\text { Not a RCT (protocol for a RCT; intervention used body weight supported treadmill training, not } \\
\text { overground gait training) }\end{array}$ \\
\hline Eich 2004 & $\begin{array}{l}\text { Participants had a stroke within previous } 6 \text { months } \\
\text { All groups participated in walking exercises }\end{array}$ \\
\hline Flansbjer 2008 & $\begin{array}{l}\text { Experimental intervention consisted of strength training and stretching; did not include over- } \\
\text { ground gait training }\end{array}$ \\
\hline Ford 2007 & Not a RCT (no control group) \\
\hline GAPS 2004 & $\begin{array}{l}\text { Participants had a stroke within previous } 6 \text { months } \\
\text { All groups participated in walking exercises }\end{array}$ \\
\hline Green 2004 & This study combined the results of two other studies \\
\hline Hesse 1994 & Not a RCT (single group repeated measures design) \\
\hline Hesse 1995 & Not a RCT (single group repeated measures design) \\
\hline Hesse 1998 & Not a RCT (single group repeated measures design) \\
\hline Hesse 1999 & Not a RCT (single group repeated measures design) \\
\hline Hesse 2001 & Not a RCT (survey design) \\
\hline Hesse 2003 & Not a RCT (review) \\
\hline Hesse 2005 & $\begin{array}{l}\text { Participants had a stroke within previous } 6 \text { months } \\
\text { All groups participated in walking exercises }\end{array}$ \\
\hline Horn 2005 & Not a RCT (cohort design) \\
\hline Ivey 2007 & $\begin{array}{l}\text { Experimental intervention was a fitness programme and did not include overground gait training } \\
\text { Measured physiological variables such as insulin response and glucose tolerance }\end{array}$ \\
\hline Kalra 1993 & $\begin{array}{l}\text { Intervention was placement into stroke unit or general hospital setting, not a specific therapeutic } \\
\text { protocol }\end{array}$ \\
\hline Kilbreath 2006 & Not a RCT (repeated measures cohort design) \\
\hline Kilbreath 2006b & Intervention included high-technology equipment not readily available in a community PT setting \\
\hline Kollen 2005 & Not a RCT (cohort design) \\
\hline Kwakkel 1999 & Participants had a stroke within previous 6 months \\
\hline Kwakkel 2002 & Participants had a stroke within previous 6 months \\
\hline Langhammer 2000 & $\begin{array}{l}\text { Participants had a stroke within previous } 6 \text { months } \\
\text { All groups participated in walking exercises }\end{array}$ \\
\hline
\end{tabular}




\section{Study}

Langhammer 2007

\section{Reason for exclusion}

All groups participated in walking exercises

The experimental treatment was focused on high intensity exercise for endurance, strength, and balance rather than on overground gait training per se

The control group received functional task-oriented training during the first 3 months and standard PT treatment for the remaining 9 months as needed

\begin{tabular}{ll}
\hline Langhammer 2008 & Participants had acute stroke \\
\hline Latham 2005 & Not a RCT (survey design) \\
\hline Laufer 2001 & $\begin{array}{l}\text { Participants had a stroke within previous } 6 \text { months } \\
\text { The control group participated in walking exercises }\end{array}$
\end{tabular}

\begin{tabular}{ll}
\hline Lee 2008 & $\begin{array}{l}\text { Intervention consisted of progressive resistance training or aerobic cycling, not overground gait } \\
\text { training }\end{array}$
\end{tabular}
training

\begin{tabular}{|c|c|}
\hline Lennon 2006 & $\begin{array}{l}\text { Participant had acute stroke } \\
\text { No control group }\end{array}$ \\
\hline Liston 2000 & Not a RCT (single group cross-over trial) \\
\hline Logigian 1983 & $\begin{array}{l}\text { Included only participants with acute stroke } \\
\text { The control group participated in walking exercises }\end{array}$ \\
\hline Luft 2008 & All groups participated in walking exercises \\
\hline Lynch 2007 & Intervention consisted of sensory retraining, not overground gait training \\
\hline Macko 2005 & All groups participated in walking exercises \\
\hline Mandel 1990 & $\begin{array}{l}\text { Intervention for experimental group included high-technology equipment not available in a typical } \\
\text { community PT setting }\end{array}$ \\
\hline Mauritz 2004 & Not a RCT (review paper) \\
\hline Mayr 2007 & $\begin{array}{l}\text { All but one participant had a stroke less than } 6 \text { months prior to the study beginning } \\
\text { Both groups received physical therapy gait training }\end{array}$ \\
\hline McClellan 2004 & The experimental treatment was primarily a home exercise programme \\
\hline Mead 2007 & $\begin{array}{l}\text { The experimental treatment focused on progressive endurance and resistance training and did not } \\
\text { involve overground gait training }\end{array}$ \\
\hline Montoya 1994 & $\begin{array}{l}\text { Intervention for experimental group included high technology equipment not available in a typical } \\
\text { community PT setting }\end{array}$ \\
\hline Morris 1992 & $\begin{array}{l}\text { Intervention for experimental group included high technology equipment not available in a typical } \\
\text { community PT setting }\end{array}$ \\
\hline Olney 1991 & Not a RCT (review paper) \\
\hline Olney 2006 & $\begin{array}{l}\text { The experimental treatment provided strength and conditioning training rather than a overground } \\
\text { gait training } \\
\text { The control group participated in walking exercises at home }\end{array}$ \\
\hline Peurala 2007 & Not a RCT (cohort design) \\
\hline
\end{tabular}




\begin{tabular}{|c|c|}
\hline Study & Reason for exclusion \\
\hline Plummer 2007 & Not a RCT (feasibility study with 7 participants) \\
\hline Pohl 2002 & $\begin{array}{l}\text { Participants had a stroke within previous } 6 \text { months } \\
\text { All groups participated in walking exercises }\end{array}$ \\
\hline Pohl 2007 & $\begin{array}{l}\text { Participants had a stroke within previous } 6 \text { months } \\
\text { All groups participated in walking exercises }\end{array}$ \\
\hline Pyoria 2007 & $\begin{array}{l}\text { The control group received overground physical therapy treatment and thus included a substantial } \\
\text { amount of gait training }\end{array}$ \\
\hline Rimmer 2000 & $\begin{array}{l}\text { The experimental treatment provided strength and conditioning training rather than providing } \\
\text { overground gait training }\end{array}$ \\
\hline Rodriquez 1996 & Not a RCT (case series) \\
\hline Roerdink 2007 & Not a RCT (compared stroke patients to healthy controls) \\
\hline Schauer 2003 & $\begin{array}{l}\text { The intervention included high-technology equipment not readily available in a community PT set- } \\
\text { ting }\end{array}$ \\
\hline Smith 1981 & $\begin{array}{l}\text { Participants had a stroke within previous } 6 \text { months } \\
\text { The experimental treatment compared placement into a stroke unit or a general medical unit }\end{array}$ \\
\hline Smith 1982 & $\begin{array}{l}\text { Participants had a stroke within previous } 6 \text { months } \\
\text { The experimental treatment compared placement into a stroke unit or a general medical unit }\end{array}$ \\
\hline Stephenson 2000 & Not a RCT (survey study) \\
\hline Stern 1970 & Participants had a stroke within previous 6 months \\
\hline Stibrant Sunnerhagen 2007 & $\begin{array}{l}\text { Experimental intervention focused on muscle strengthening and muscle endurance using a circuit } \\
\text { training methods, and did not involve overground gait training } \\
\text { Measured physiological variables like oxygen consumption and muscle enzymes }\end{array}$ \\
\hline Sullivan 2007 & $\begin{array}{l}\text { All } 3 \text { interventions included high-technology equipment (body weight supported treadmill training) } \\
\text { not readily available in a community PT setting }\end{array}$ \\
\hline Sutbeyaz 2007 & Both groups performed ankle dorsiflexion movements, not overground gait training \\
\hline Tangeman 1990 & Not a RCT (single group repeated measures design) \\
\hline Teixeira 1999 & $\begin{array}{l}\text { The experimental treatment was a strength and conditioning programme rather overground gait } \\
\text { training }\end{array}$ \\
\hline Teixeira 2001 & Not a RCT (single group repeated measures design) \\
\hline Thaut 1997 & $\begin{array}{l}\text { Participants had a stroke within previous } 6 \text { months } \\
\text { Neither group acted as a non-gait control group }\end{array}$ \\
\hline Treger 2004 & The experimental treatment was a home-based walking programme rather than gait training \\
\hline van Vliet 2005 & Participants had a stroke within previous 6 months \\
\hline Waagfjord 1990 & Not a RCT (case series) \\
\hline
\end{tabular}




\begin{tabular}{ll}
\hline Study & Reason for exclusion \\
\hline Wagenaar 1990 & Not a RCT (case series) \\
\hline Weng 2006 & Neither group acted as a non-gait control group \\
\hline Werner 1996 & $\begin{array}{l}\text { The experimental treatment included 50\% OT and 50\% PT } \\
\text { Of the PT services, gait training accounted for only a portion } \\
\text { Thus, overall, gait training did not account for 50\% of the experimental treatment }\end{array}$ \\
\hline Werner 2007 & Not a RCT (cohort design) \\
\hline Wolfe 2000 & $\begin{array}{l}\text { The experimental treatment was home-based intervention by a rehabilitation team } \\
\text { Fewer than } 50 \% \text { of the participants received gait training or physical therapy services }\end{array}$ \\
\hline Yang 2005 & All groups participated in walking exercises \\
\hline Yavuzer 2007 & $\begin{array}{l}\text { Participants had a stroke within previous } 6 \text { months, and the experimental treatment did not con- } \\
\text { sist of overground gait training }\end{array}$ \\
\hline Yen 2008 & $\begin{array}{l}\text { No non-gait control group } \\
\text { Both groups received general physical therapy }\end{array}$ \\
\hline & Participants had a stroke within previous 6 months \\
\hline
\end{tabular}

OT: occupational therapy

PT: physical therapy

$\mathrm{RCT}$ : randomised controlled trial

Characteristics of ongoing studies [ordered by study ID]

Macko 2007

\begin{tabular}{ll}
\hline Trial name or title & Treadmill exercise prescriptions to improve fitness versus ambulatory function after stroke \\
\hline Methods & - \\
\hline Participants & $\begin{array}{l}\text { Recruiting } 120 \\
40 \text { to } 85 \text { years } \\
\text { Stroke at least } 6 \text { months prior } \\
\text { Hemiparetic gait deficits } \\
\text { Completed inpatient and outpatient PT } \\
\text { Adequate language and neurocognitive function }\end{array}$ \\
\hline Interventions & Type of exercise (stretching, intense walking, long walking) \\
\hline Outcomes & Cardiovascular fitness (VO 2 peak), 10-metre walk time, 6-minute walk distance + secondary out- \\
comes
\end{tabular}

Notes

PT: physical therapy 


\section{DATA AND ANALYSES}

\section{Comparison 1. Gait training versus control at end of treatment}

\begin{tabular}{|c|c|c|c|c|}
\hline Outcome or subgroup title & $\begin{array}{l}\text { No. of } \\
\text { studies }\end{array}$ & $\begin{array}{l}\text { No. of } \\
\text { partici- } \\
\text { pants }\end{array}$ & Statistical method & Effect size \\
\hline 1 Gait function (\%) & 3 & 269 & $\begin{array}{l}\text { Std. Mean Difference (IV, Fixed, } \\
95 \% \mathrm{Cl})\end{array}$ & $0.19[-0.05,0.43]$ \\
\hline 1.1 Pre-gait and full-gait activities & 3 & 269 & $\begin{array}{l}\text { Std. Mean Difference (IV, Fixed, } \\
95 \% \mathrm{Cl} \text { ) }\end{array}$ & $0.19[-0.05,0.43]$ \\
\hline 2 Barthel Index (unitless) & 3 & 269 & $\begin{array}{l}\text { Mean Difference (IV, Fixed, 95\% } \\
\mathrm{CI})\end{array}$ & $-0.07[-0.68,0.53]$ \\
\hline 2.1 Pre-gait and other activities & 3 & 269 & $\begin{array}{l}\text { Mean Difference (IV, Fixed, 95\% } \\
\mathrm{CI})\end{array}$ & $-0.07[-0.68,0.53]$ \\
\hline 3 Gait speed (m/s) & 7 & 396 & $\begin{array}{l}\text { Mean Difference (IV, Fixed, 95\% } \\
\mathrm{CI})\end{array}$ & $0.07[0.05,0.10]$ \\
\hline 3.1 Pre-gait activities only & 1 & 48 & $\begin{array}{l}\text { Mean Difference (IV, Fixed, 95\% } \\
\mathrm{CI})\end{array}$ & $0.09[0.05,0.12]$ \\
\hline 3.2 Pre-gait and full-gait activities & 5 & 323 & $\begin{array}{l}\text { Mean Difference (IV, Fixed, 95\% } \\
\mathrm{CI})\end{array}$ & $0.03[-0.01,0.08]$ \\
\hline 3.3 Full-gait activities only & 1 & 25 & $\begin{array}{l}\text { Mean Difference (IV, Fixed, 95\% } \\
\mathrm{CI})\end{array}$ & $0.17[0.02,0.32]$ \\
\hline 4 Timed-up-and-go test (s) & 3 & 118 & $\begin{array}{l}\text { Mean Difference (IV, Fixed, 95\% } \\
\mathrm{CI} \text { ) }\end{array}$ & $-1.81[-2.29,-1.33]$ \\
\hline 4.1 Pre-gait and full-gait activities & 2 & 70 & $\begin{array}{l}\text { Mean Difference (IV, Fixed, 95\% } \\
\mathrm{CI} \text { ) }\end{array}$ & $-3.59[-10.40,3.22]$ \\
\hline 4.2 Full-gait activities only & 1 & 48 & $\begin{array}{l}\text { Mean Difference (IV, Fixed, 95\% } \\
\mathrm{CI})\end{array}$ & $-1.8[-2.28,-1.32]$ \\
\hline 5 Six-minute-walk test (m) & 4 & 181 & $\begin{array}{l}\text { Mean Difference (IV, Fixed, 95\% } \\
\mathrm{CI})\end{array}$ & $26.06[7.14,44.97]$ \\
\hline 5.1 Pre-gait activities only & 1 & 48 & $\begin{array}{l}\text { Mean Difference (IV, Fixed, 95\% } \\
\mathrm{CI} \text { ) }\end{array}$ & $34.30[7.42,61.18]$ \\
\hline 5.2 Pre-gait and full-gait activities & 3 & 133 & $\begin{array}{l}\text { Mean Difference (IV, Fixed, 95\% } \\
\mathrm{Cl} \text { ) }\end{array}$ & $17.96[-8.67,44.59]$ \\
\hline 6 Death or dependency (unitless) & 9 & 499 & $\begin{array}{l}\text { Odds Ratio (M-H, Fixed, 95\% } \\
\mathrm{Cl} \text { ) }\end{array}$ & $0.18[0.02,1.55]$ \\
\hline 7 Other adverse effects (unitless) & 9 & 499 & $\begin{array}{l}\text { Odds Ratio (M-H, Fixed, 95\% } \\
\mathrm{Cl})\end{array}$ & $3.0[0.30,29.64]$ \\
\hline
\end{tabular}


Analysis 1.1. Comparison 1 Gait training versus control at end of treatment, Outcome 1 Gait function (\%).

\begin{tabular}{|c|c|c|c|c|c|c|c|}
\hline \multirow[t]{2}{*}{ Study or subgroup } & \multicolumn{2}{|c|}{ Treatment } & \multicolumn{2}{|c|}{ Control } & \multirow{2}{*}{$\begin{array}{c}\text { Std. Mean Difference } \\
\text { Fixed, } 95 \% \mathrm{Cl}\end{array}$} & \multirow[t]{2}{*}{ Weight } & \multirow{2}{*}{$\begin{array}{c}\text { Std. Mean Difference } \\
\text { Fixed, } 95 \% \mathrm{Cl}\end{array}$} \\
\hline & $\mathbf{N}$ & $\operatorname{Mean}(S D)$ & $\mathbf{N}$ & $\operatorname{Mean}(S D)$ & & & \\
\hline \multicolumn{8}{|c|}{ 1.1.1 Pre-gait and full-gait activities } \\
\hline Green 2002 & 81 & $11(3)$ & 80 & $10(3)$ & & $59.8 \%$ & $0.34[0.03,0.65]$ \\
\hline Wade 1992 & 48 & $12.2(4.3)$ & 41 & $12.7(4.2)$ & $\rightarrow$ & $33.27 \%$ & $-0.12[-0.53,0.3]$ \\
\hline Lin 2004 & 9 & $12.3(7)$ & 10 & $9.4(5.4)$ & $\longrightarrow$ & $6.92 \%$ & $0.45[-0.47,1.36]$ \\
\hline Subtotal $\star \star \star ~$ & 138 & & 131 & & $\nabla$ & $100 \%$ & $0.19[-0.05,0.43]$ \\
\hline \multicolumn{8}{|c|}{ Test for overall effect: $Z=1.57(P=0.12)$} \\
\hline Total $* \star \star$ & 138 & & 131 & & 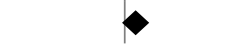 & $100 \%$ & $0.19[-0.05,0.43]$ \\
\hline \multicolumn{8}{|c|}{ Heterogeneity: $\mathrm{Tau}^{2}=0 ; \mathrm{Chi}^{2}=3.22, \mathrm{df}=2(\mathrm{P}=0.2) ; \mathrm{I}^{2}=37.96 \%$} \\
\hline Test for overall effect & & & & & & & \\
\hline
\end{tabular}

Analysis 1.2. Comparison 1 Gait training versus control at end of treatment, Outcome 2 Barthel Index (unitless).

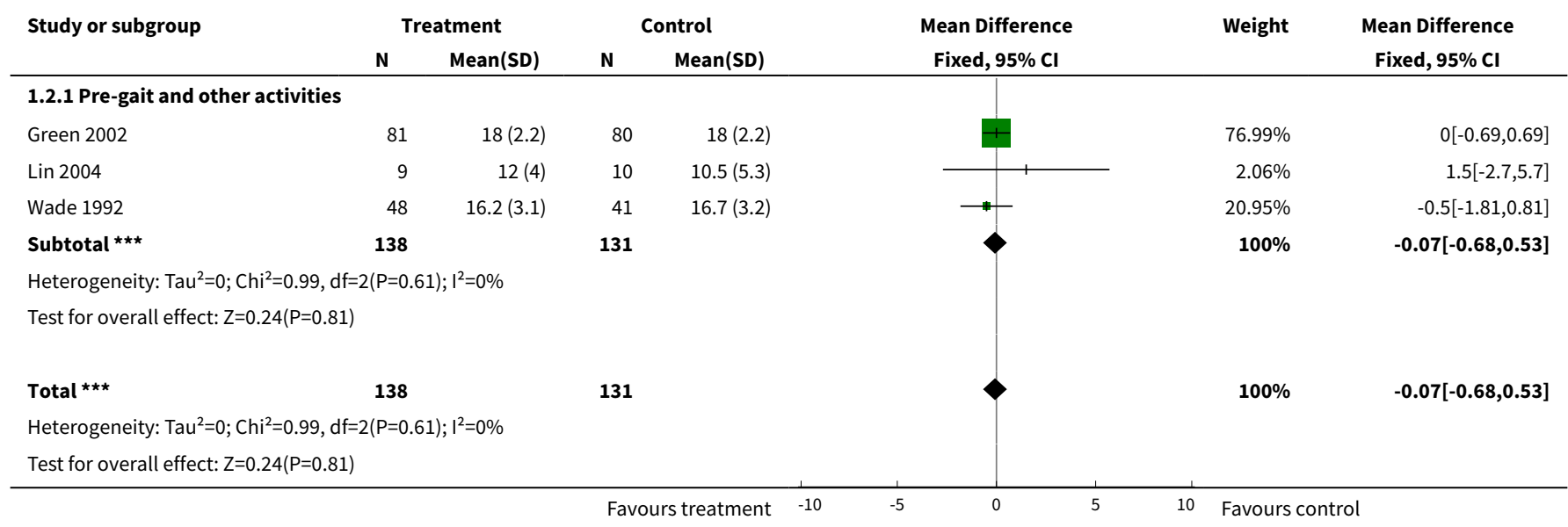

Analysis 1.3. Comparison 1 Gait training versus control at end of treatment, Outcome 3 Gait speed (m/s).

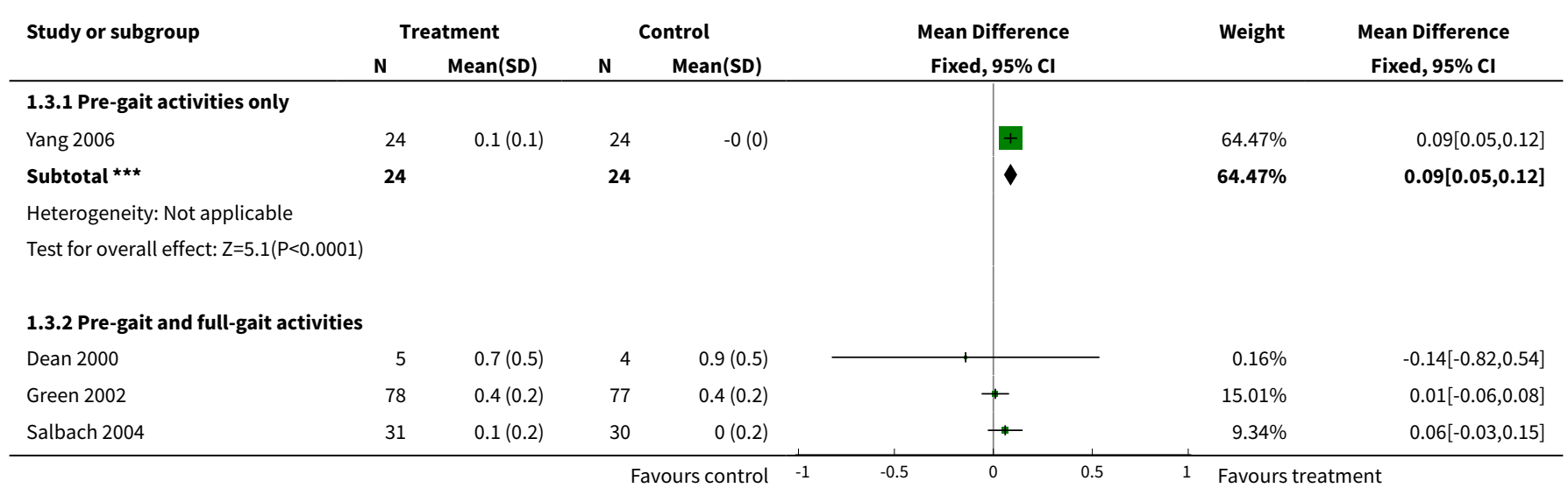




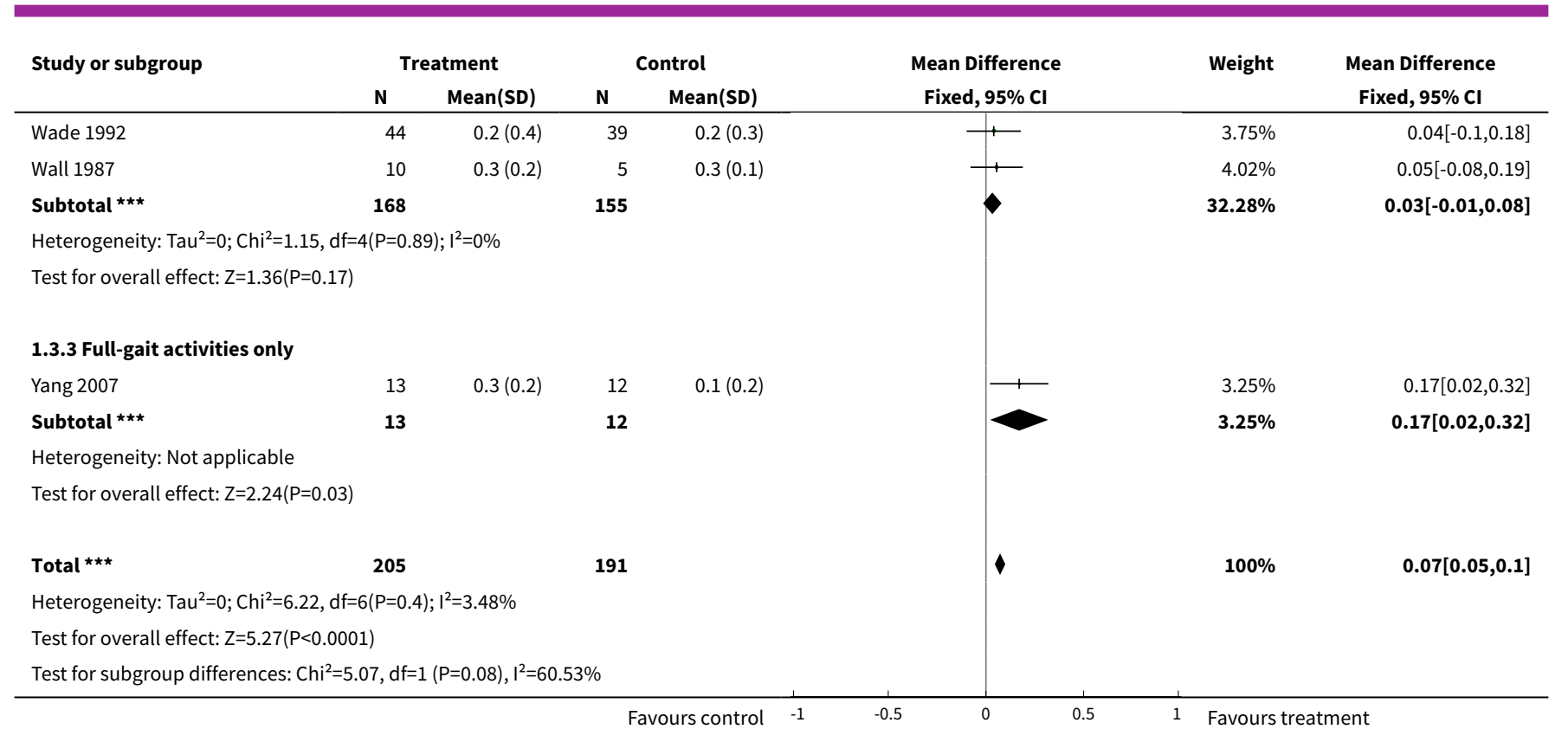

Analysis 1.4. Comparison 1 Gait training versus control at end of treatment, Outcome 4 Timed-up-and-go test (s).

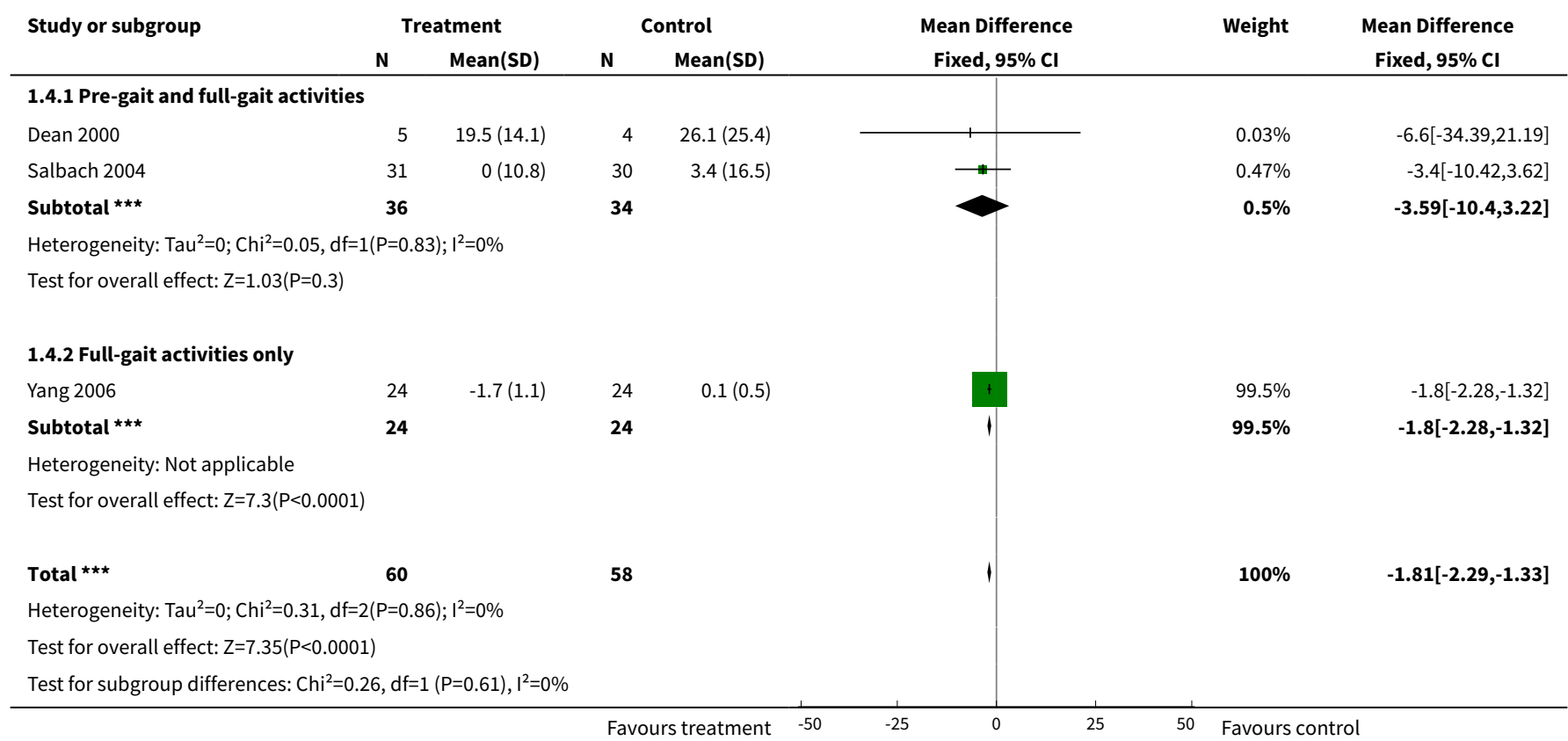

Analysis 1.5. Comparison 1 Gait training versus control at end of treatment, Outcome 5 Six-minute-walk test (m).

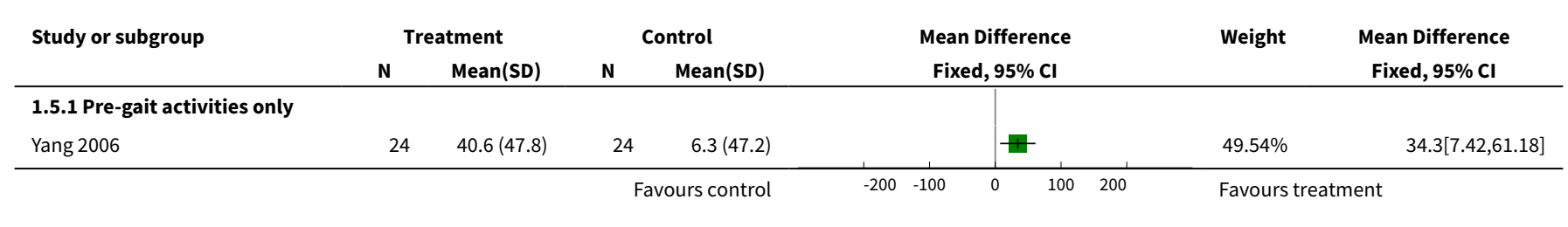




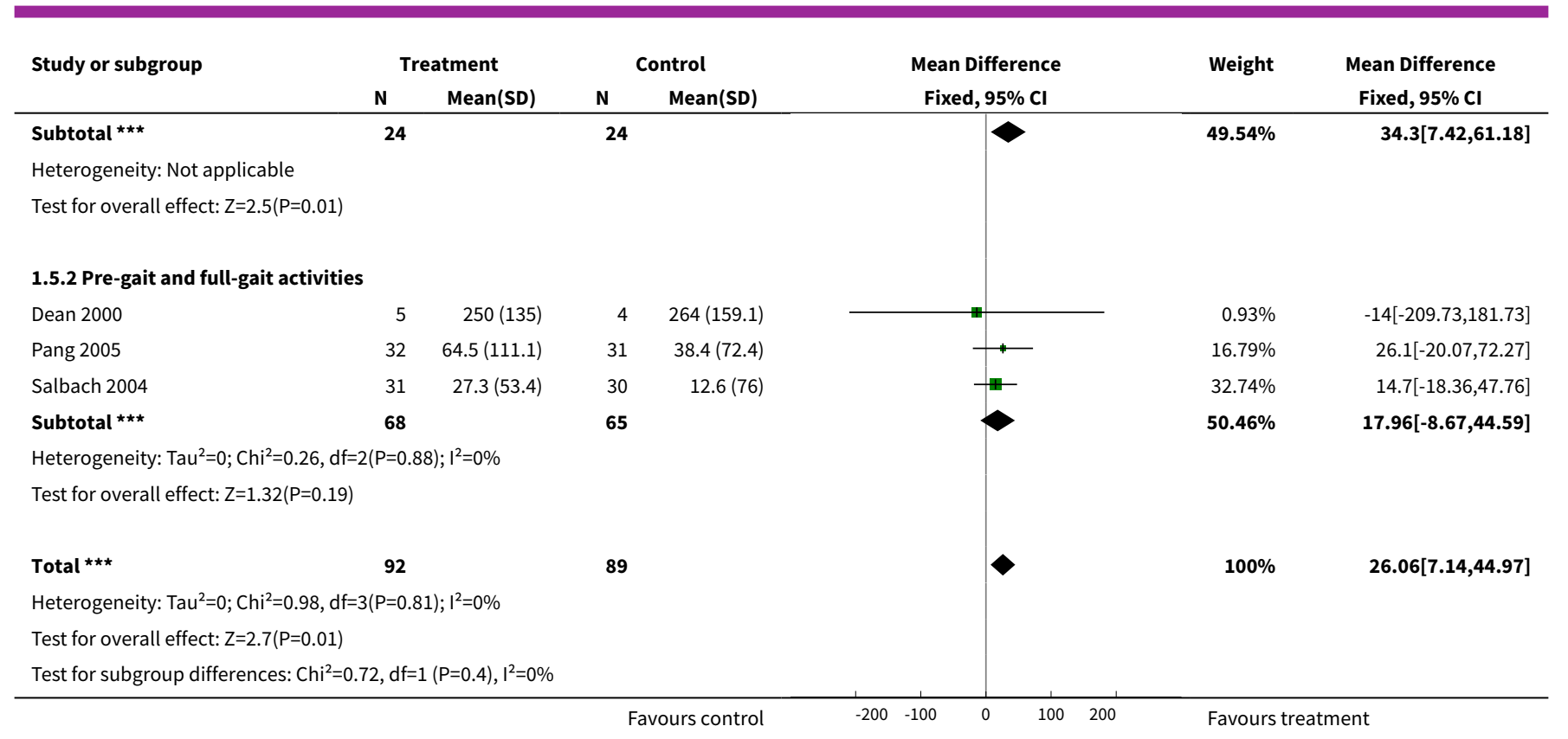

Analysis 1.6. Comparison 1 Gait training versus control at end of treatment, Outcome 6 Death or dependency (unitless).

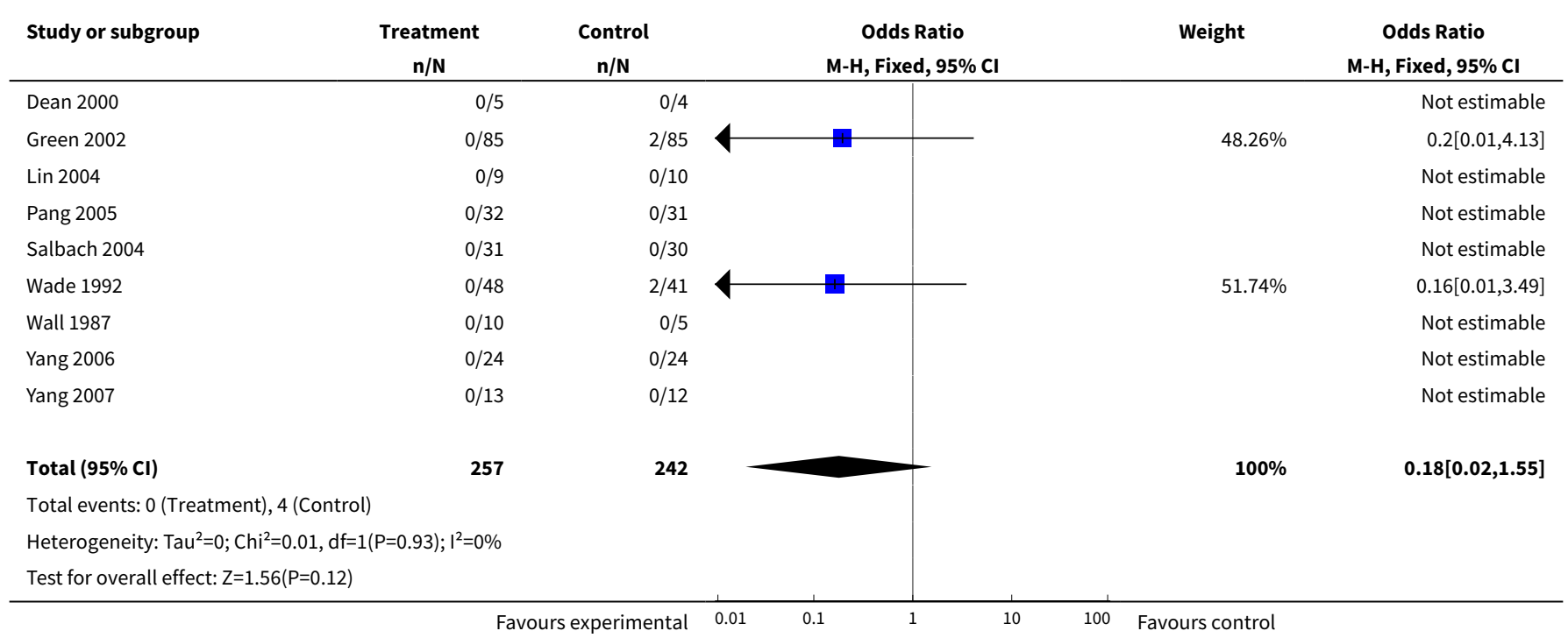

Analysis 1.7. Comparison 1 Gait training versus control at end of treatment, Outcome 7 Other adverse effects (unitless).

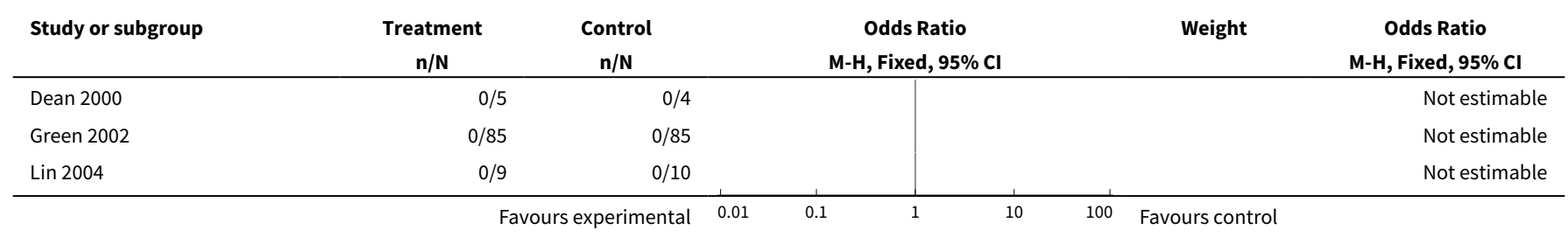




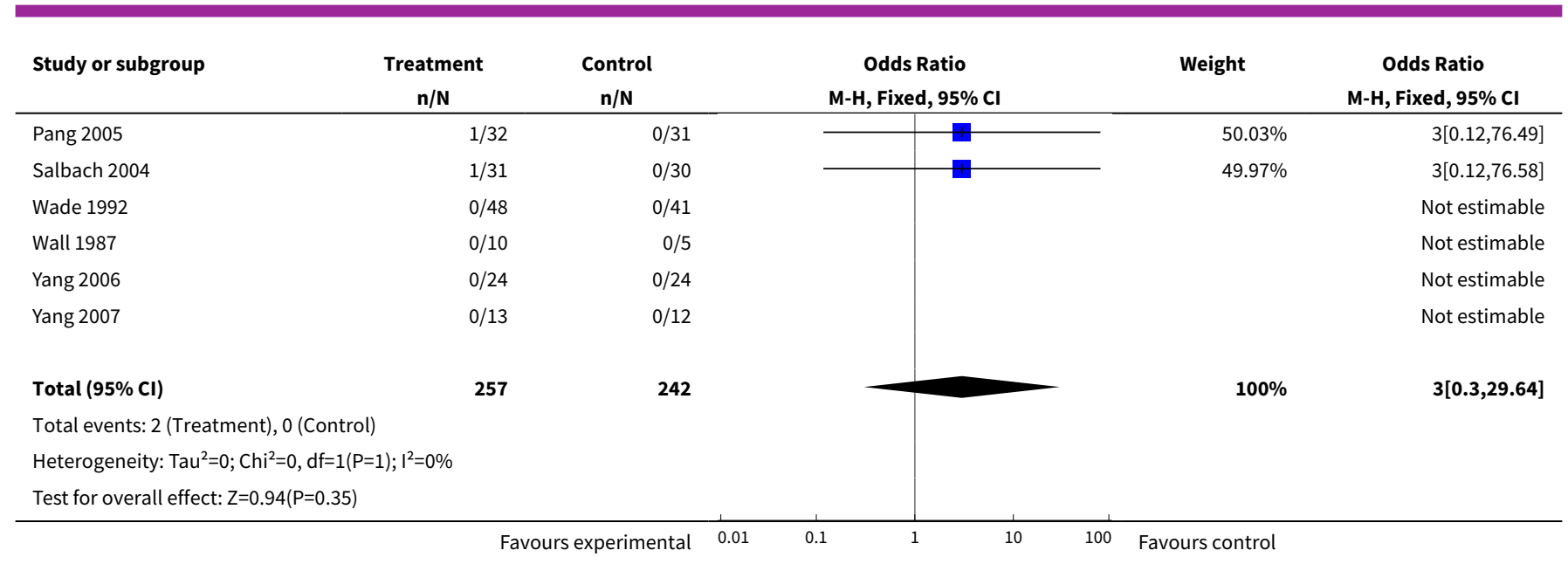

Comparison 2. Gait training versus control at three-month follow up

\begin{tabular}{|c|c|c|c|c|}
\hline Outcome or subgroup title & $\begin{array}{l}\text { No. of } \\
\text { studies }\end{array}$ & $\begin{array}{l}\text { No. of } \\
\text { partici- } \\
\text { pants }\end{array}$ & Statistical method & Effect size \\
\hline 1 Gait function (\%) & 1 & 150 & $\begin{array}{l}\text { Std. Mean Difference (IV, Fixed, } \\
95 \% \mathrm{CI})\end{array}$ & $0.34[0.01,0.66]$ \\
\hline 1.1 Pre-gait and full-gait activities & 1 & 150 & $\begin{array}{l}\text { Std. Mean Difference (IV, Fixed, } \\
95 \% \mathrm{CI} \text { ) }\end{array}$ & $0.34[0.01,0.66]$ \\
\hline 2 Barthel Index (unitless) & 1 & 150 & $\begin{array}{l}\text { Mean Difference (IV, Fixed, 95\% } \\
\mathrm{CI})\end{array}$ & $0.0[-0.83,0.83]$ \\
\hline 2.1 Pre-gait and full-gait activities & 1 & 150 & $\begin{array}{l}\text { Mean Difference (IV, Fixed, 95\% } \\
\text { Cl) }\end{array}$ & $0.0[-0.83,0.83]$ \\
\hline 3 Gait speed (m/s) & 3 & 165 & $\begin{array}{l}\text { Mean Difference (IV, Fixed, 95\% } \\
\text { CI) }\end{array}$ & $0.02[-0.05,0.08]$ \\
\hline 3.1 Pre-gait and full-gait activities & 3 & 165 & $\begin{array}{l}\text { Mean Difference (IV, Fixed, 95\% } \\
\mathrm{CI})\end{array}$ & $0.02[-0.05,0.08]$ \\
\hline 4 Timed-up-and-go test (m) & 1 & 8 & $\begin{array}{l}\text { Mean Difference (IV, Fixed, 95\% } \\
\mathrm{Cl} \text { ) }\end{array}$ & $-4.5[-41.10,32.10]$ \\
\hline 4.1 Pre-gait and full-gait activities & 1 & 8 & $\begin{array}{l}\text { Mean Difference (IV, Fixed, 95\% } \\
\mathrm{CI} \text { ) }\end{array}$ & $-4.5[-41.10,32.10]$ \\
\hline 5 Six-minute-walk test $(\mathrm{m})$ & 1 & 8 & $\begin{array}{l}\text { Mean Difference (IV, Fixed, 95\% } \\
\mathrm{CI})\end{array}$ & $16.20[-184.09,216.49]$ \\
\hline 5.1 Pre-gait and full-gait activities & 1 & 8 & $\begin{array}{l}\text { Mean Difference (IV, Fixed, 95\% } \\
\mathrm{CI})\end{array}$ & $16.20[-184.09,216.49]$ \\
\hline 6 Death or dependency (unitless) & 3 & 165 & Odds Ratio (M-H, Fixed, 95\% Cl) & $0.52[0.05,5.89]$ \\
\hline 7 Other adverse effects (unitless) & 3 & 165 & Odds Ratio (M-H, Fixed, 95\% Cl) & $0.0[0.0,0.0]$ \\
\hline
\end{tabular}


Analysis 2.1. Comparison 2 Gait training versus control at three-month follow up, Outcome 1 Gait function (\%).

\begin{tabular}{|c|c|c|c|c|c|c|c|}
\hline \multirow[t]{2}{*}{ Study or subgroup } & \multicolumn{2}{|c|}{ Treatment } & \multicolumn{2}{|c|}{ Control } & \multirow{2}{*}{$\begin{array}{c}\text { Std. Mean Difference } \\
\text { Fixed, } 95 \% \mathrm{Cl}\end{array}$} & \multirow[t]{2}{*}{ Weight } & \multirow{2}{*}{$\begin{array}{c}\text { Std. Mean Difference } \\
\text { Fixed, } 95 \% \mathrm{Cl}\end{array}$} \\
\hline & $\mathbf{N}$ & Mean(SD) & $\mathbf{N}$ & Mean(SD) & & & \\
\hline \multicolumn{8}{|c|}{ 2.1.1 Pre-gait and full-gait activities } \\
\hline Green 2002 & 73 & $11(3)$ & 77 & $10(3)$ & & $100 \%$ & $0.34[0.01,0.66]$ \\
\hline 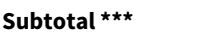 & 73 & & 77 & & & $100 \%$ & $0.34[0.01,0.66]$ \\
\hline \multicolumn{8}{|c|}{ Heterogeneity: Not applicable } \\
\hline \multicolumn{8}{|c|}{ Test for overall effect: $Z=2.04(P=0.04)$} \\
\hline Total ${ }^{\star \star \star}$ & 73 & & 77 & & & $100 \%$ & $0.34[0.01,0.66]$ \\
\hline \multicolumn{8}{|c|}{ Heterogeneity: Not applicable } \\
\hline Test for overall effect & & & & & & & \\
\hline
\end{tabular}

Analysis 2.2. Comparison 2 Gait training versus control at three-month follow up, Outcome 2 Barthel Index (unitless).

\begin{tabular}{|c|c|c|c|c|c|c|c|}
\hline \multirow[t]{2}{*}{ Study or subgroup } & \multicolumn{2}{|c|}{ Treatment } & \multicolumn{2}{|c|}{ Control } & \multirow{2}{*}{$\begin{array}{c}\text { Mean Difference } \\
\text { Fixed, } 95 \% \mathrm{Cl}\end{array}$} & \multirow[t]{2}{*}{ Weight } & \multirow{2}{*}{$\begin{array}{c}\text { Mean Difference } \\
\text { Fixed, } 95 \% \mathrm{Cl}\end{array}$} \\
\hline & $\mathbf{N}$ & $\operatorname{Mean}(S D)$ & $\mathbf{N}$ & $\operatorname{Mean}(S D)$ & & & \\
\hline \multicolumn{8}{|c|}{ 2.2.1 Pre-gait and full-gait activities } \\
\hline Green 2002 & 73 & $18(2.2)$ & 77 & $18(3)$ & & $100 \%$ & $0[-0.83,0.83]$ \\
\hline Subtotal ${ }^{\star \star \star}$ & 73 & & 77 & & & $100 \%$ & $0[-0.83,0.83]$ \\
\hline \multicolumn{8}{|c|}{ Heterogeneity: Not applicable } \\
\hline \multicolumn{8}{|c|}{ Test for overall effect: Not applicable } \\
\hline Total $\star \star \star$ & 73 & & 77 & & & $100 \%$ & $0[-0.83,0.83]$ \\
\hline \multicolumn{8}{|c|}{ Heterogeneity: Not applicable } \\
\hline \multicolumn{8}{|c|}{ Test for overall effect: Not applicable } \\
\hline & & & Favo & treatment -2 & 1 & Favours & \\
\hline
\end{tabular}

\section{Analysis 2.3. Comparison 2 Gait training versus control at three-month follow up, Outcome $3 \mathrm{Gait} s p e e d(\mathrm{~m} / \mathrm{s})$.}

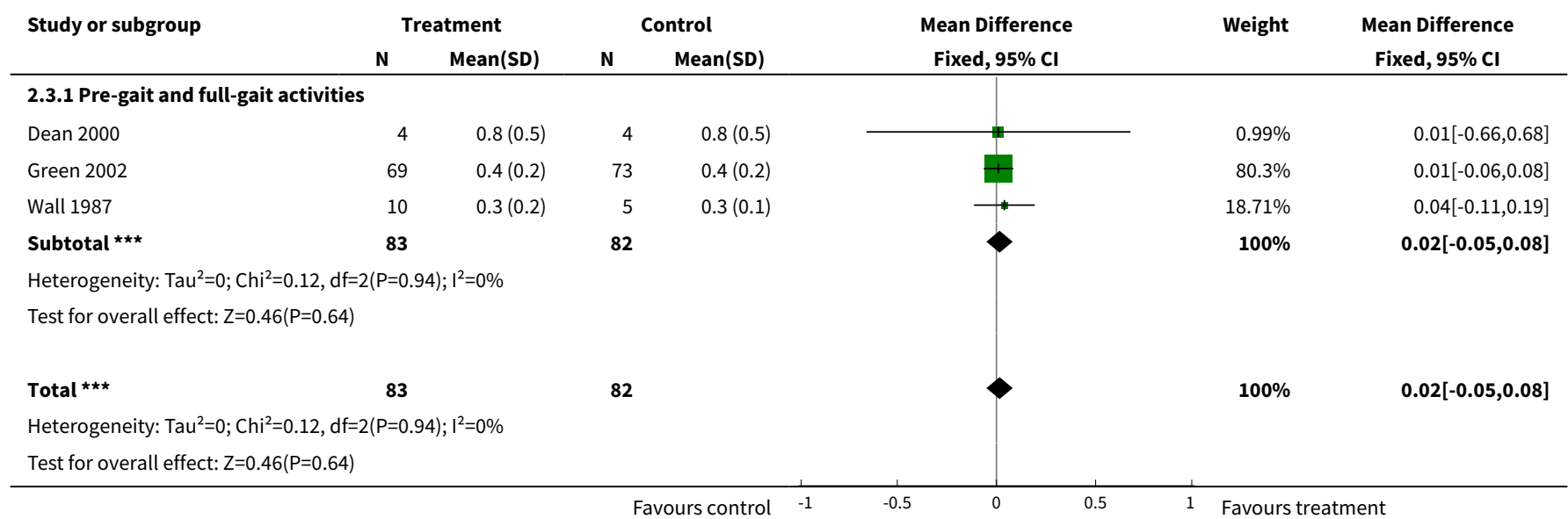


Analysis 2.4. Comparison 2 Gait training versus control at three-month follow up, Outcome 4 Timed-up-and-go test (m).

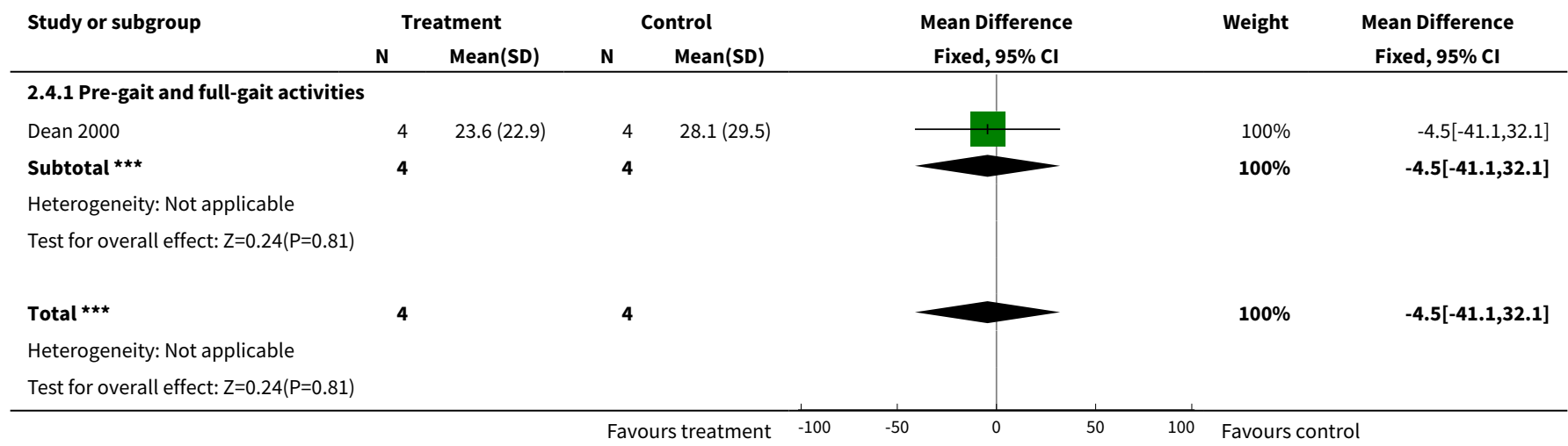

Analysis 2.5. Comparison 2 Gait training versus control at three-month follow up, Outcome 5 Six-minute-walk test (m).

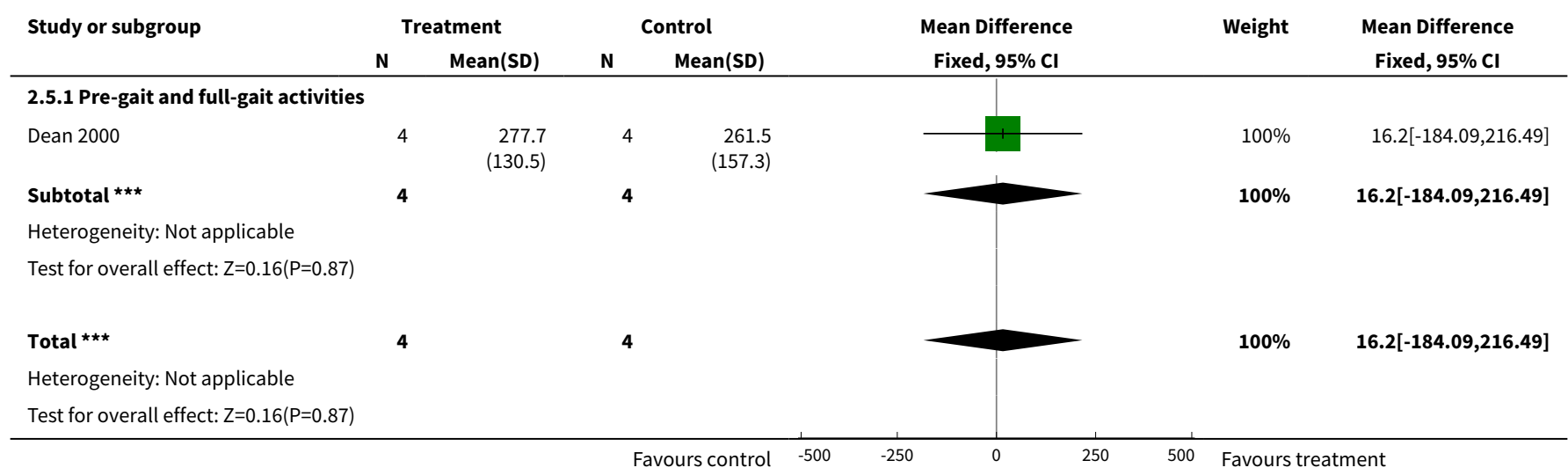

Analysis 2.6. Comparison 2 Gait training versus control at threemonth follow up, Outcome 6 Death or dependency (unitless).

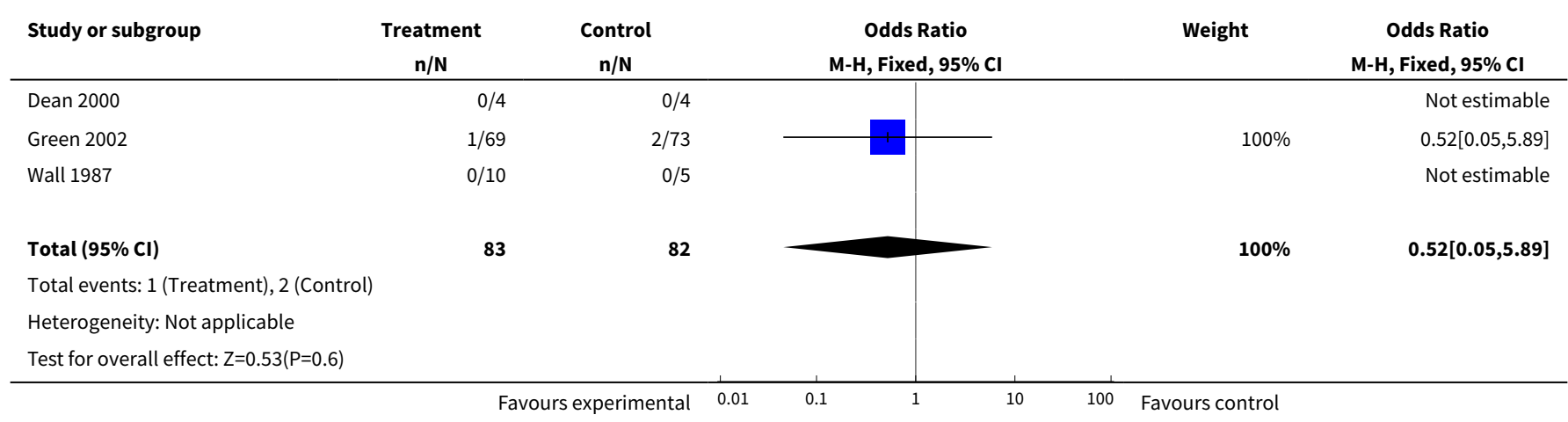


Analysis 2.7. Comparison 2 Gait training versus control at threemonth follow up, Outcome 7 Other adverse effects (unitless).

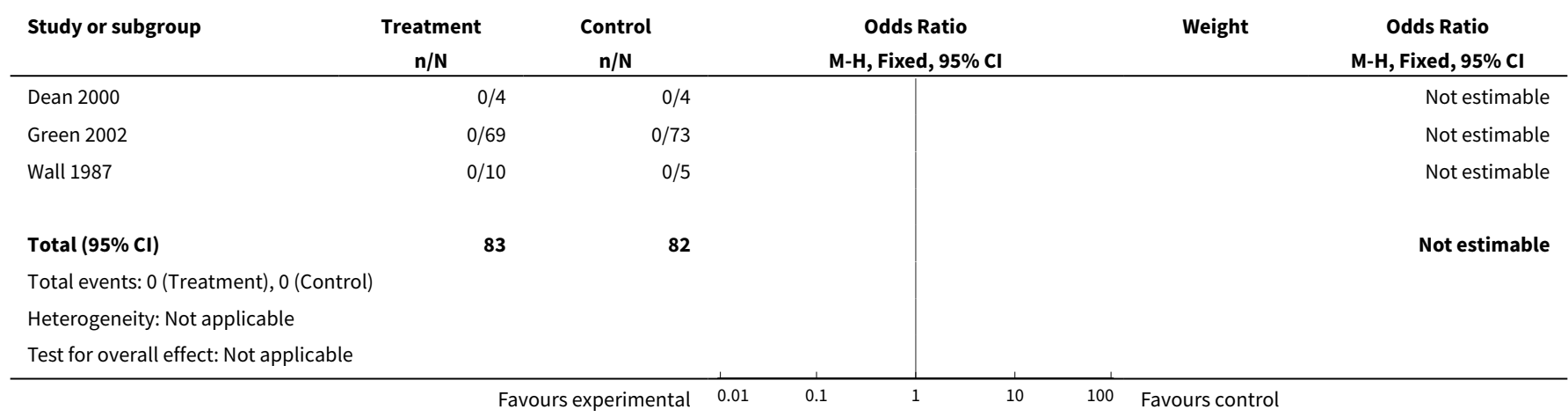

\section{Comparison 3. Subgroup analysis: extent of intervention}

\begin{tabular}{llllll}
\hline Outcome or subgroup title & $\begin{array}{l}\text { No. of } \\
\text { studies }\end{array}$ & $\begin{array}{l}\text { No. of } \\
\text { partici- } \\
\text { pants }\end{array}$ & Statistical method & Effect size \\
\hline 1 Gait speed $(\mathrm{m} / \mathrm{s})$ & 7 & 396 & Mean Difference (IV, Fixed, 95\% Cl) & $0.07[0.05,0.10]$ \\
\hline 1.1 Treatment $<29$ hours & 6 & 381 & Mean Difference (IV, Fixed, 95\% Cl) & $0.07[0.05,0.10]$ \\
\hline 1.2 Treatment $>29$ hours & 1 & 15 & Mean Difference (IV, Fixed, 95\% Cl) & $0.05[-0.08,0.19]$ \\
\hline 2 Six-minute-walk test $(\mathrm{m})$ & 4 & 181 & Mean Difference (IV, Fixed, 95\% CI) & $26.06[7.14,44.97]$ \\
\hline 2.1 Treatment $<29$ hours & 3 & 118 & Mean Difference (IV, Fixed, 95\% CI) & $26.05[5.31,46.78]$ \\
\hline 2.2 Treatment $>29$ hours & 1 & 63 & Mean Difference (IV, Fixed, 95\% CI) & $26.1[-20.07,72.27]$ \\
\hline
\end{tabular}

Analysis 3.1. Comparison 3 Subgroup analysis: extent of intervention, Outcome 1 Gait speed $(\mathrm{m} / \mathrm{s})$.

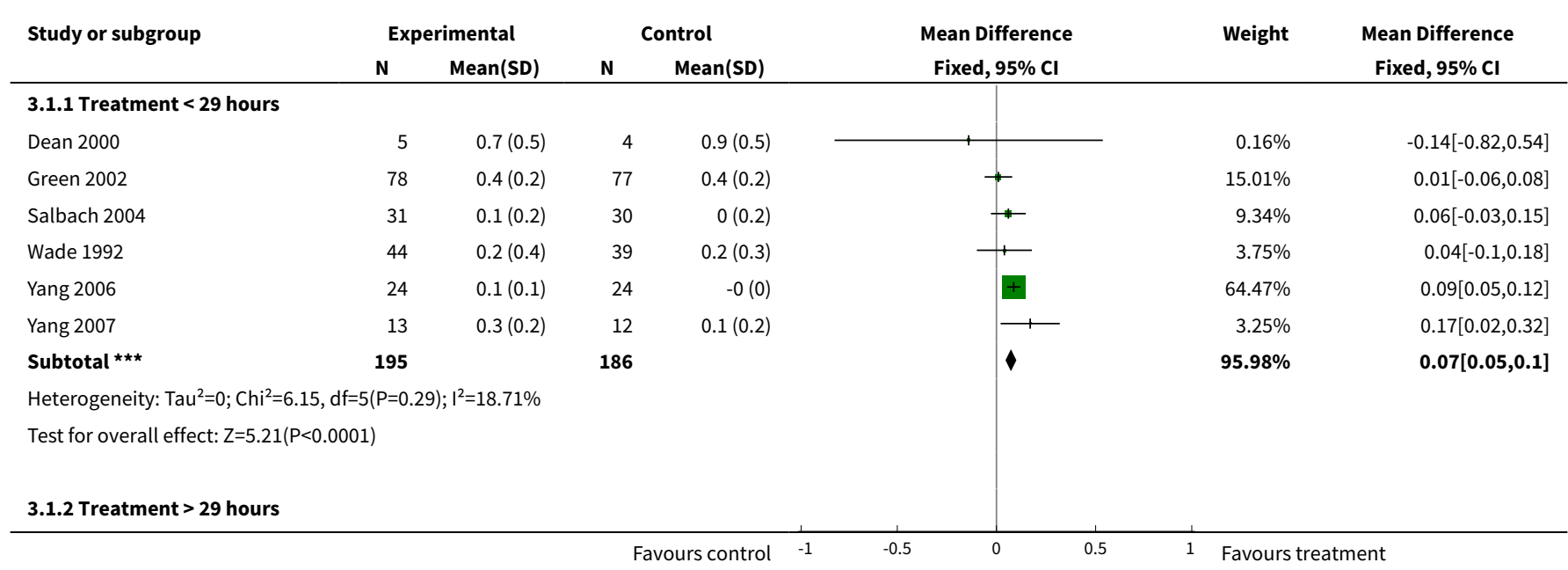




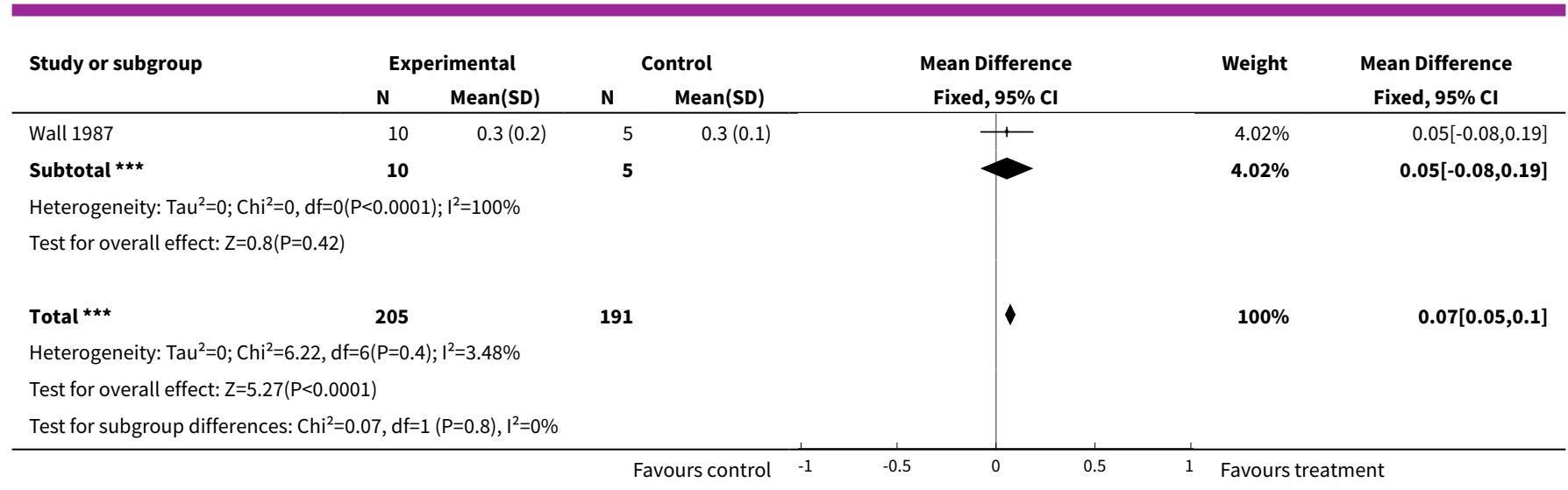

\section{Analysis 3.2. Comparison 3 Subgroup analysis: extent of intervention, Outcome 2 Six-minute-walk test (m).}

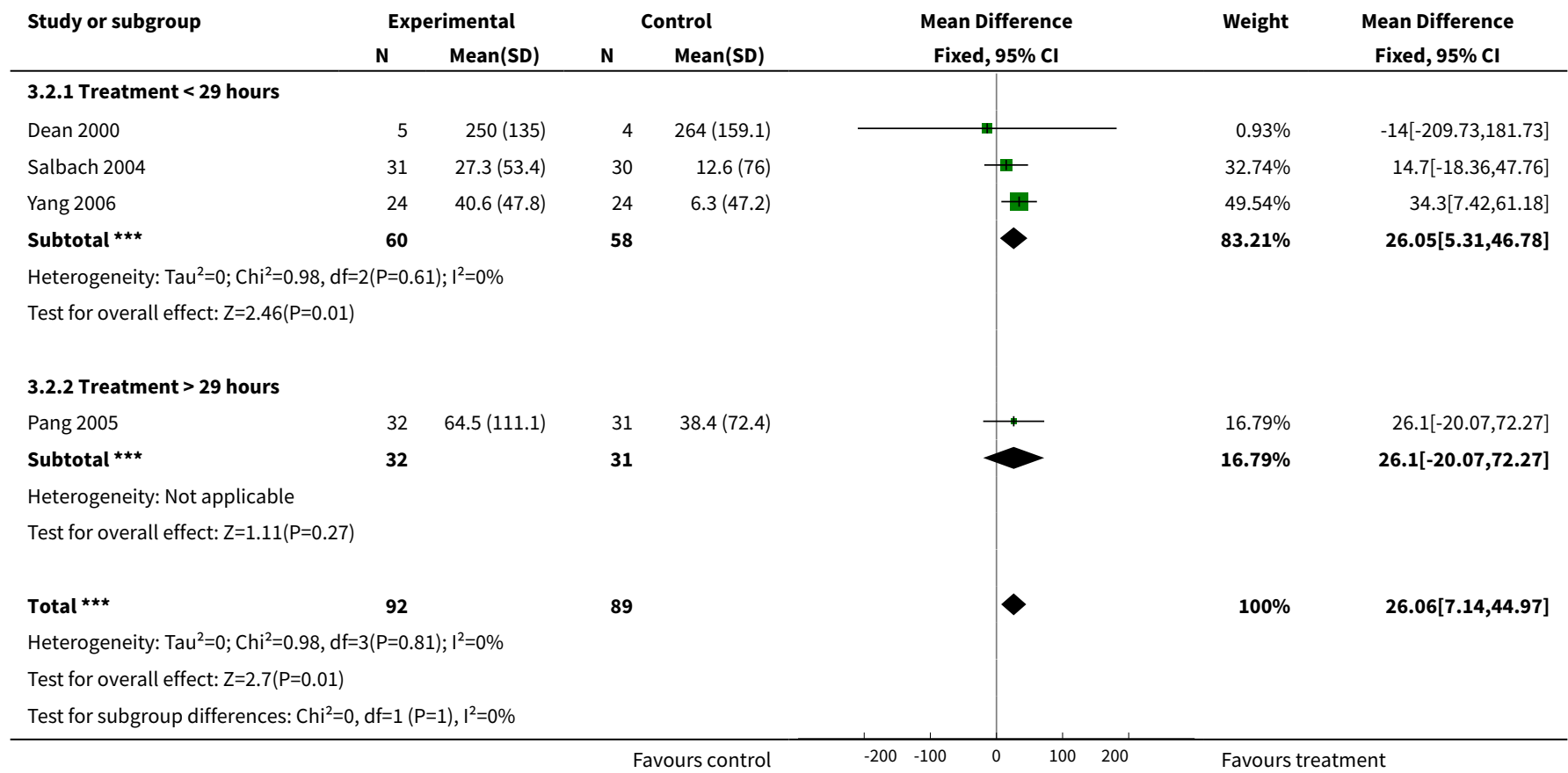

\section{ADDITIONAL TABLES}




\begin{tabular}{|c|c|c|c|c|c|c|c|}
\hline Study & Age & Sex & $\begin{array}{l}\text { Time since } \\
\text { stroke }\end{array}$ & $\begin{array}{l}\text { First } \\
\text { stroke? }\end{array}$ & Mobility criteria & $\begin{array}{l}\text { Cognitive cri- } \\
\text { teria }\end{array}$ & Comorbidities \\
\hline Dean 2000 & $\begin{array}{l}\text { No limit; } \\
\text { Exp = } 66 \text { y; Ctl = } 62 \text { y }\end{array}$ & $5 \mathrm{~F} ; 7 \mathrm{M}$ & $\geq 6 \mathrm{mo}$ & Yes & $\begin{array}{l}\text { Can walk } 10 \mathrm{~m} \text { independently with or } \\
\text { without assistive device }\end{array}$ & - & $\begin{array}{l}\text { Medical conditions } \\
\text { that preclude partici- } \\
\text { pation }\end{array}$ \\
\hline Green 2002 & $\begin{array}{l}>50 y \\
\operatorname{Exp}=72 y ; C t l=74 y\end{array}$ & $75 \mathrm{~F} ; 95 \mathrm{M}$ & $>1 \mathrm{y}$ & No & None & Dementia & $\begin{array}{l}\text { Severe comorbidity, } \\
\text { bedfast }\end{array}$ \\
\hline Lin 2004 & $\begin{array}{l}\text { No limit; } \\
\text { Exp = } 61 \text { y; Ctl }=63 \text { y }\end{array}$ & $6 \mathrm{~F} ; 14 \mathrm{M}$ & $>1 \mathrm{y}$ & No & BI score between 5 and 14 & $\begin{array}{l}\text { Inability to fol- } \\
\text { low directions }\end{array}$ & None \\
\hline Pang 2005 & $\begin{array}{l}>50 y ; \\
\operatorname{Exp}=66 y ; C t l=65 y\end{array}$ & $26 \mathrm{~F} ; 37 \mathrm{M}$ & $>1 \mathrm{y}$ & Yes & $\begin{array}{l}\text { Can walk } 10 \text { m independently with or } \\
\text { without assistive device } \\
\text { Hemiparesis }\end{array}$ & - & $\begin{array}{l}\text { Serious cardiac dis- } \\
\text { ease, uncontrolled } \\
\text { blood pressure, pain } \\
\text { while walking, other } \\
\text { neurological condi- } \\
\text { tions, or other serious } \\
\text { diseases that preclude } \\
\text { participation }\end{array}$ \\
\hline $\begin{array}{l}\text { Salbach } \\
2004\end{array}$ & $\begin{array}{l}\text { No limit; } \\
\text { Exp = } 69 \text { y; Ctl }=73 \text { y }\end{array}$ & $35 F ; 56 \mathrm{M}$ & $\begin{array}{l}<1 \text { y, } \\
\text { but only } \\
\text { analysed } \\
\text { data for }>6 \\
\text { mo }\end{array}$ & No & $\begin{array}{l}\text { Can walk } 10 \mathrm{~m} \text { independently with or } \\
\text { without assistive device } \\
\text { Results of } 6 \text { MWT below age and gen- } \\
\text { der norms }\end{array}$ & $\begin{array}{l}\text { Minimum score } \\
\text { on mental com- } \\
\text { petency test } \\
\text { (MMSE) }\end{array}$ & $\begin{array}{l}\text { Comorbidity that } \\
\text { would preclude par- } \\
\text { ticipation in either in- } \\
\text { tervention, neurolog- } \\
\text { ical deficit caused by } \\
\text { metastatic disease }\end{array}$ \\
\hline Wade 1992 & $\begin{array}{l}\text { No limit; } \\
\operatorname{Exp}=72 \mathrm{y} ; \mathrm{Ctl}=72 \mathrm{y}\end{array}$ & $47 \mathrm{~F} ; 47 \mathrm{M}$ & $>1 \mathrm{y} ;<7 y$ & No & - & None & None \\
\hline Wall 1987 & $\begin{array}{l}45 \text { to } 70 \text { y; Exp and } \\
\text { Ctl not reported }\end{array}$ & $\begin{array}{l}\text { Not report- } \\
\text { ed }\end{array}$ & $\begin{array}{l}>1.5 y ;<10 \\
y\end{array}$ & No & $\begin{array}{l}\text { Can walk with or without a cane, re- } \\
\text { duced support phase time on affected } \\
\text { limb; stroke related mobility deficit }\end{array}$ & $\begin{array}{l}\text { Cognitive dis- } \\
\text { turbances }\end{array}$ & $\begin{array}{l}\text { Serious unstable med- } \\
\text { ical condition, in- } \\
\text { tractable pain, inconti- } \\
\text { nence }\end{array}$ \\
\hline Yang 2006 & $\begin{array}{l}45 \text { to } 74 \mathrm{y} ; \operatorname{Exp}=57 \mathrm{y} \\
\mathrm{Ctl}=60 \mathrm{y}\end{array}$ & $16 \mathrm{~F} ; 32 \mathrm{M}$ & $\begin{array}{l}36 \mathrm{~m} \text { to } 120 \\
\mathrm{~m} \text { post- } \\
\text { stroke }\end{array}$ & Yes & $\begin{array}{l}\text { Hemiparetic, able to walk } 10 \mathrm{~m} \text { with- } \\
\text { out an assistive device }\end{array}$ & $\begin{array}{l}\text { Able to under- } \\
\text { stand instruc- } \\
\text { tions and follow } \\
\text { commands }\end{array}$ & $\begin{array}{l}\text { Medically stable, no } \\
\text { medical condition that } \\
\text { would preclude partic- } \\
\text { ipation, no health con- } \\
\text { dition for which exer- } \\
\text { cise in contraindicated }\end{array}$ \\
\hline
\end{tabular}




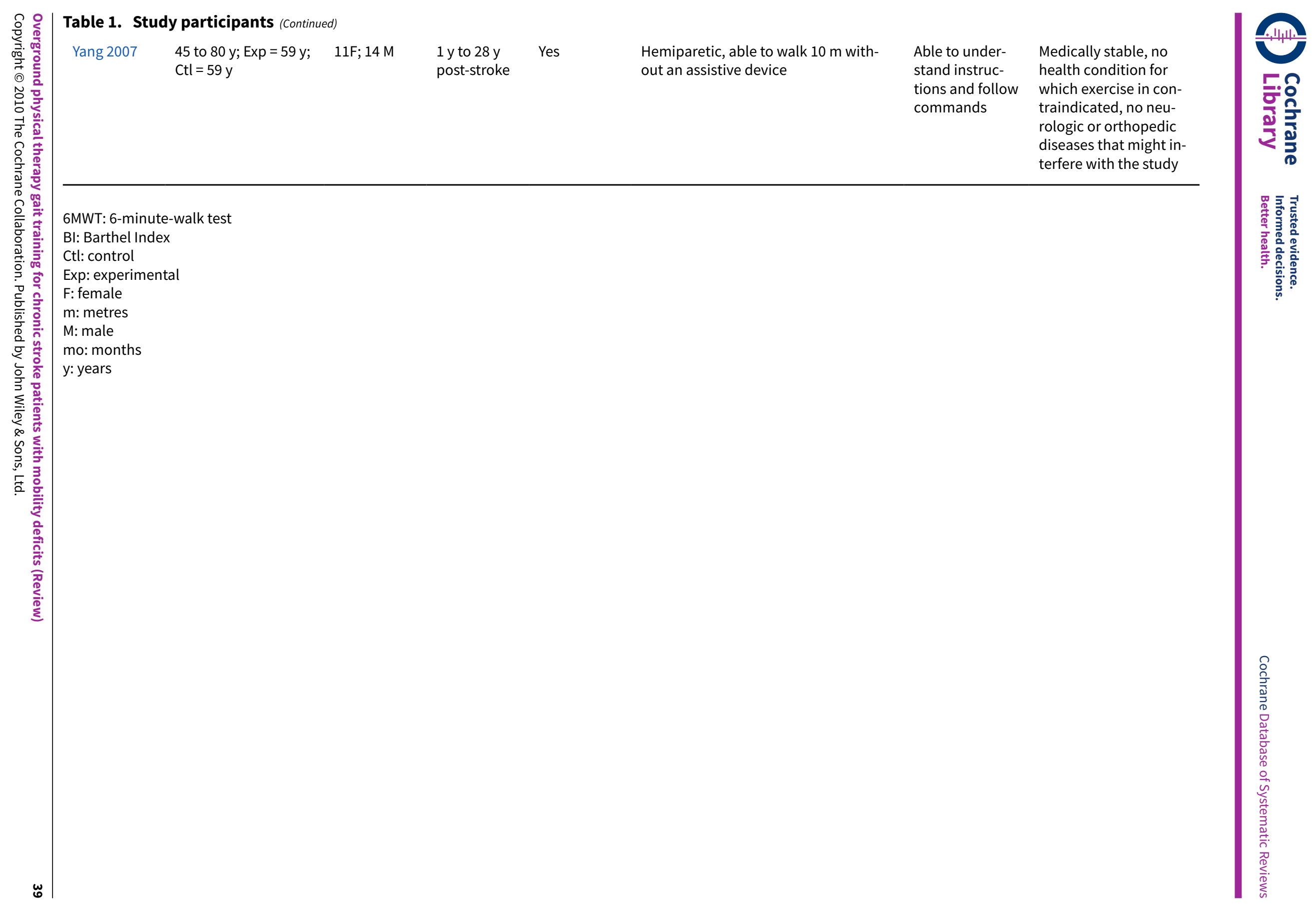


Table 2. Interventions and controls

\begin{tabular}{|c|c|c|c|c|c|c|}
\hline Study & $\begin{array}{l}\text { Interven- } \\
\text { tion }\end{array}$ & $\begin{array}{l}\text { Individ- } \\
\text { ual or } \\
\text { group }\end{array}$ & $\begin{array}{l}\text { Frequency, dura- } \\
\text { tion }\end{array}$ & Setting & Control & Intervention details \\
\hline Dean 2000 & $\begin{array}{l}\text { Circuit } \\
\text { training } \\
\text { with func- } \\
\text { tional } \\
\text { lower ex- } \\
\text { tremity } \\
\text { exercises }\end{array}$ & $\begin{array}{l}\text { Group (4 } \\
\text { to } 6 \text { pa- } \\
\text { tients su- } \\
\text { pervised } \\
\text { by } 2 \text { ther- } \\
\text { apists) }\end{array}$ & $\begin{array}{l}60 \text { minutes per } \\
\text { session, } 3 \text { times } \\
\text { per week for } 4 \\
\text { weeks; Net = } 12 \\
\text { hours }\end{array}$ & $\begin{array}{l}\text { Commu- } \\
\text { nity set- } \\
\text { ting }\end{array}$ & $\begin{array}{l}\text { Upper } \\
\text { extrem- } \\
\text { ity exer- } \\
\text { cise pro- } \\
\text { gramme } \\
\text { with par- } \\
\text { ticipant } \\
\text { seated }\end{array}$ & $\begin{array}{l}\text { Circuit training class with exercises aimed } \\
\text { at strengthening the lower extremities and } \\
\text { practising locomotor tasks } \\
10 \text { workstations were incorporated into } \\
\text { the circuit training including: (1) sitting and } \\
\text { reaching in different directions; (2) sit-to- } \\
\text { stand from various chair heights; (3) step- } \\
\text { ping forward, backward, and sideways; } \\
\text { (4) heel lift in standing; (5) standing with } \\
\text { constrained base of support and tandem } \\
\text { reaching for objects; (6) reciprocal leg flex- } \\
\text { ion and extension in standing; (7) stand- } \\
\text { ing up from a chair, walking short distance, } \\
\text { and returning to the chair; (8) walking on } \\
\text { a treadmill; (9) walking over various sur- } \\
\text { faces and obstacles; and (10) walking over } \\
\text { slopes and stairs }\end{array}$ \\
\hline $\begin{array}{l}\text { Green } \\
2002\end{array}$ & $\begin{array}{l}\text { Standard } \\
\text { PT with } \\
\text { emphasis } \\
\text { on mobili- } \\
\text { ty skills }\end{array}$ & 1 to 1 & $\begin{array}{l}\text { Variable length } \\
\text { session with av- } \\
\text { erage of } 44 \text { min- } \\
\text { utes; } 0 \text { to } 22 \text { ses- } \\
\text { sions with median } \\
\text { of } 3 \text { per patient; } \\
\text { frequency not re- } \\
\text { ported; typical net } \\
=2.25 \text { hours }\end{array}$ & $\begin{array}{l}\text { Home or } \\
\text { communi- } \\
\text { ty setting }\end{array}$ & $\begin{array}{l}\text { No treat- } \\
\text { ment }\end{array}$ & $\begin{array}{l}\text { Individualised problem-solving } \\
\text { Included gait re-education, exercise ther- } \\
\text { apy, functional exercises, and balance re- } \\
\text { education }\end{array}$ \\
\hline Lin 2004 & $\begin{array}{l}\text { Standard } \\
\text { PT with } \\
\text { emphasis } \\
\text { on mobili- } \\
\text { ty skills }\end{array}$ & 1 to 1 & $\begin{array}{l}60 \text { minutes per } \\
\text { session, } 1 \text { session } \\
\text { per week for } 10 \\
\text { weeks } \\
\text { Net }=10 \text { hours }\end{array}$ & Home & $\begin{array}{l}\text { No treat- } \\
\text { ment }\end{array}$ & $\begin{array}{l}\text { Motor facilitation, postural control train- } \\
\text { ing, functional ambulation and ADL train- } \\
\text { ing }\end{array}$ \\
\hline Pang 2005 & $\begin{array}{l}\text { Aerobic } \\
\text { and mo- } \\
\text { bility exer- } \\
\text { cise pro- } \\
\text { gramme }\end{array}$ & $\begin{array}{l}\text { Group (9 } \\
\text { to } 12 \text { pa- } \\
\text { tients su- } \\
\text { pervised } \\
\text { by } 3 \text { ther- } \\
\text { apists) }\end{array}$ & $\begin{array}{l}60 \text { minutes per } \\
\text { session, } 3 \text { times } \\
\text { per week for } 19 \\
\text { weeks } \\
\text { Net }=57 \text { hours }\end{array}$ & $\begin{array}{l}\text { Commu- } \\
\text { nity set- } \\
\text { ting }\end{array}$ & $\begin{array}{l}\text { Upper } \\
\text { extrem- } \\
\text { ity exer- } \\
\text { cise pro- } \\
\text { gramme } \\
\text { with par- } \\
\text { ticipant } \\
\text { seated }\end{array}$ & $\begin{array}{l}\text { Cardiorespiratory and mobility exercises } \\
\text { with time ranging from } 10 \text { minutes in week } \\
1 \text { to } 30 \text { minutes in week } 19 \\
\text { Included mobility and balance tasks, leg } \\
\text { muscle strengthening } \\
\text { The exercise programme included: brisk } \\
\text { walking; sit-to-stand; alternate stepping } \\
\text { onto lower rises; walking in different direc- } \\
\text { tions; tandem walking; walking through an } \\
\text { obstacle course; sudden stops and turns } \\
\text { during walking; walking on different sur- } \\
\text { faces; standing on foam, balance disc, or } \\
\text { wobble board; standing with one foot in } \\
\text { front of the other; kicking ball with either } \\
\text { foot; partial squats; and toe rises }\end{array}$ \\
\hline
\end{tabular}


Table 2. Interventions and controls (Continued)

\begin{tabular}{|c|c|c|c|c|c|}
\hline $\begin{array}{l}\text { Salbach } \\
2004\end{array}$ & $\begin{array}{l}10 \text { walk- } \\
\text { ing-relat- } \\
\text { ed tasks }\end{array}$ & 1 to 1 & $\begin{array}{l}\text { Variable length } \\
\text { session; } 3 \text { times } \\
\text { per week for } 6 \\
\text { weeks } \\
\text { Typical net = } 9 \\
\text { hours }\end{array}$ & $\begin{array}{l}\text { Commu- } \\
\text { nity set- } \\
\text { ting }\end{array}$ & $\begin{array}{l}\text { Upper } \\
\text { extrem- } \\
\text { ity exer- } \\
\text { cise pro- } \\
\text { gramme } \\
\text { with par- } \\
\text { ticipant } \\
\text { seated }\end{array}$ \\
\hline
\end{tabular}

10 walking related tasks designed to strengthen the lower extremities and enhance walking balance, speed and distance

Included up to 10 minutes on treadmill per session

Marching on the spot; stepping onto a step; walking forward, backward, and sideways between parallel lines or balance beam; kicking a ball against a wall; sit-to-stand; standing from a chair to walk and sit on a chair; walking over an obstacle course; 10 minutes walking at comfortable speed; 5 minutes of walking while carrying a grocery bag; walking 5 minutes at maximum speed; 5 minutes of walking backwards; and 5 minutes of climbing stairs

\begin{tabular}{|c|c|c|c|c|c|c|}
\hline $\begin{array}{l}\text { Wade } \\
1992\end{array}$ & $\begin{array}{l}\text { Standard } \\
\text { PT with } \\
\text { emphasis } \\
\text { on mobili- } \\
\text { ty skills }\end{array}$ & 1 to 1 & $\begin{array}{l}\text { Variable length } \\
\text { sessions with av- } \\
\text { erage of } 124 \text { min- } \\
\text { utes (includes } \\
\text { travel time); } 1 \text { to } \\
11 \text { sessions with } \\
\text { mean of } 4 \text { per pa- } \\
\text { tient; frequency } \\
\text { not reported } \\
\text { Typical net = } 8 \\
\text { hours }\end{array}$ & Home & $\begin{array}{l}\text { No treat- } \\
\text { ment }\end{array}$ & $\begin{array}{l}\text { Problem-solving approach and advice to } \\
\text { caregivers } \\
\text { Re-education of abnormal gait compo- } \\
\text { nents, supervised practice walking inside } \\
\text { and outside, standing balance, obstacle } \\
\text { courses, walking on uneven surfaces }\end{array}$ \\
\hline Wall 1987 & $\begin{array}{l}\text { Exercis- } \\
\text { es to im- } \\
\text { prove gait } \\
\text { Intensity } \\
\text { increased } \\
\text { systemati- } \\
\text { cally }\end{array}$ & 1 to 1 & $\begin{array}{l}60 \text { minutes per } \\
\text { session, } 2 \text { times } \\
\text { per week for } 6 \\
\text { months } \\
\text { Net }=48 \text { hours }\end{array}$ & $\begin{array}{l}\text { Commu- } \\
\text { nity set- } \\
\text { ting }\end{array}$ & $\begin{array}{l}\text { No treat- } \\
\text { ment }\end{array}$ & $\begin{array}{l}10 \text { exercises for } 5 \text { minutes each designed } \\
\text { to improve the gait pattern by increasing } \\
\text { the ability of patients to transfer weight } \\
\text { through the hemiplegic leg and increase } \\
\text { time on affected leg in single support } \\
\text { Exercises intensity progressed systemati- } \\
\text { cally }\end{array}$ \\
\hline Yang 2006 & $\begin{array}{l}\text { Task-ori- } \\
\text { ented pro- } \\
\text { gressive } \\
\text { resistance } \\
\text { strength } \\
\text { training } \\
\text { using pre- } \\
\text { gait activ- } \\
\text { ities, de- } \\
\text { signed as } \\
\text { a circuit } \\
\text { training } \\
\text { class }\end{array}$ & $\begin{array}{l}\text { Group } \\
\text { class }\end{array}$ & $\begin{array}{l}30 \text { minutes per } \\
\text { session, } 3 \text { sessions } \\
\text { per week for } 4 \\
\text { weeks } \\
\text { Net }=6 \text { hours }\end{array}$ & $\begin{array}{l}\text { Not re- } \\
\text { ported }\end{array}$ & $\begin{array}{l}\text { No treat- } \\
\text { ment }\end{array}$ & $\begin{array}{l}\text { Circuit training class } \\
6 \text { stations included standing and reach- } \\
\text { ing in different directions; sit to stand from } \\
\text { various chair heights; stepping forward, } \\
\text { backwards, and sideways onto and off of } \\
\text { blocks of various heights; heel rise and } \\
\text { lowering while maintaining standing }\end{array}$ \\
\hline Yang 2007 & $\begin{array}{l}\text { Dual-task } \\
\text { walking } \\
\text { exercis- } \\
\text { es using } \\
\text { a ball or }\end{array}$ & $\begin{array}{l}\text { Not re- } \\
\text { ported }\end{array}$ & $\begin{array}{l}30 \text { minutes per } \\
\text { session, } 3 \text { times } \\
\text { per week for } 4 \\
\text { weeks } \\
\text { Net }=6 \text { hours }\end{array}$ & $\begin{array}{l}\text { Not re- } \\
\text { ported }\end{array}$ & $\begin{array}{l}\text { No treat- } \\
\text { ment }\end{array}$ & $\begin{array}{l}\text { Ball exercises, including walking while ma- } \\
\text { nipulating } 1 \text { or } 2 \text { balls }\end{array}$ \\
\hline
\end{tabular}


Table 2. Interventions and controls (Continued)

other ob-

jects
Various sized balls were held, bounced, kicked while participants walked in a controlled setting

Variable practice for walking conditions included walking forward, walking backward, walking on a circular route, and walking on an S-shaped route

ADL: activities of daily living

PT: physical therapy 


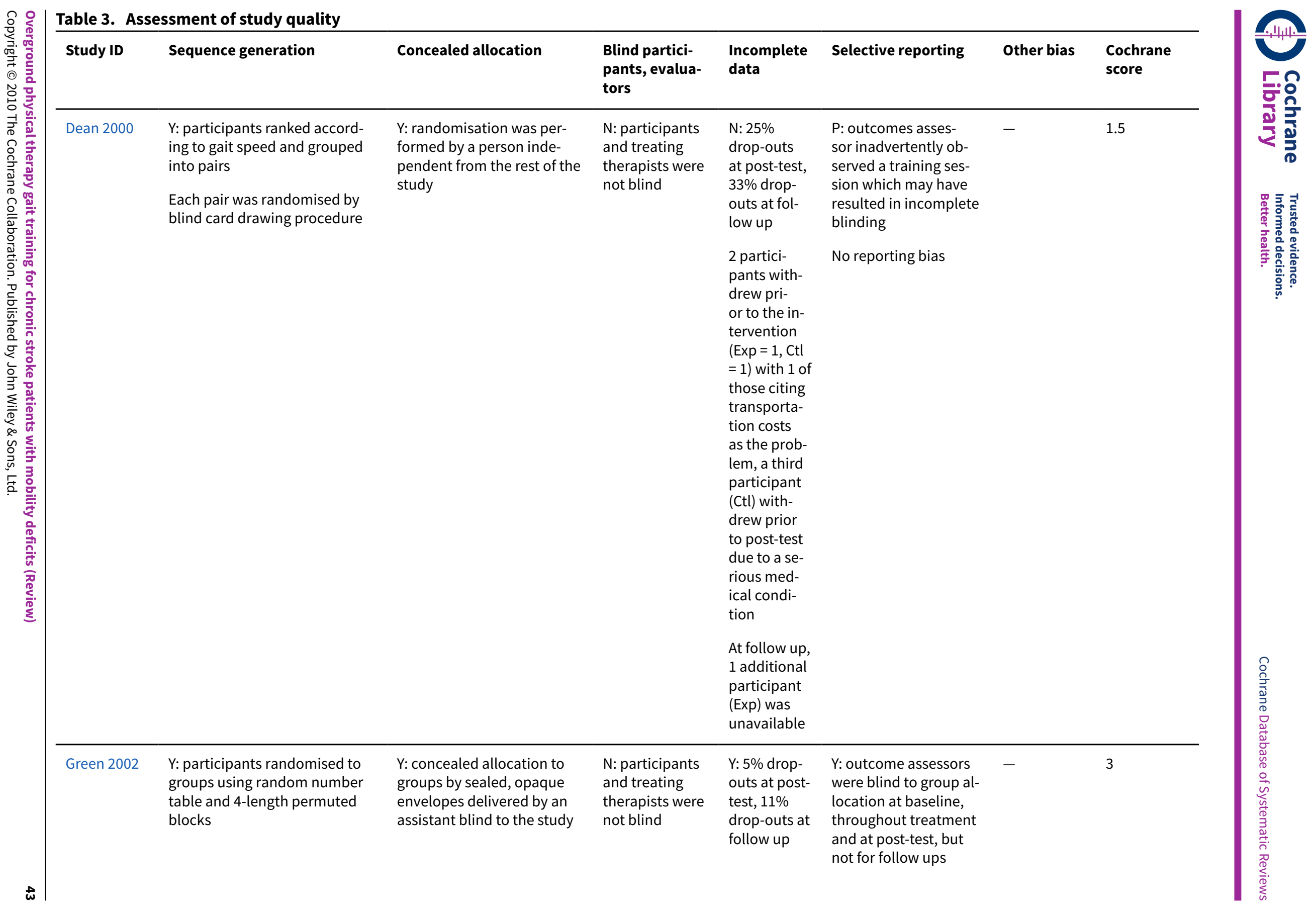




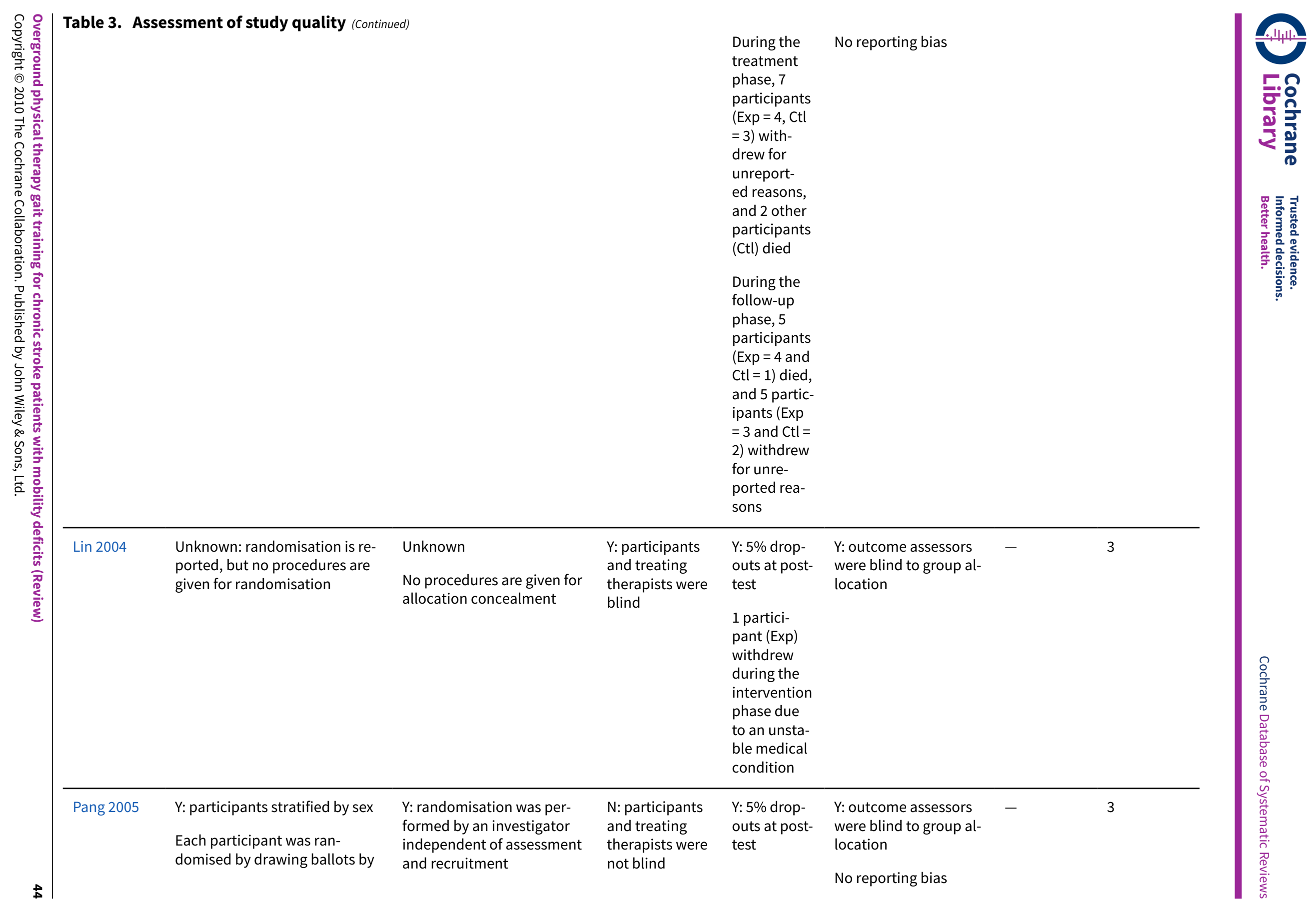




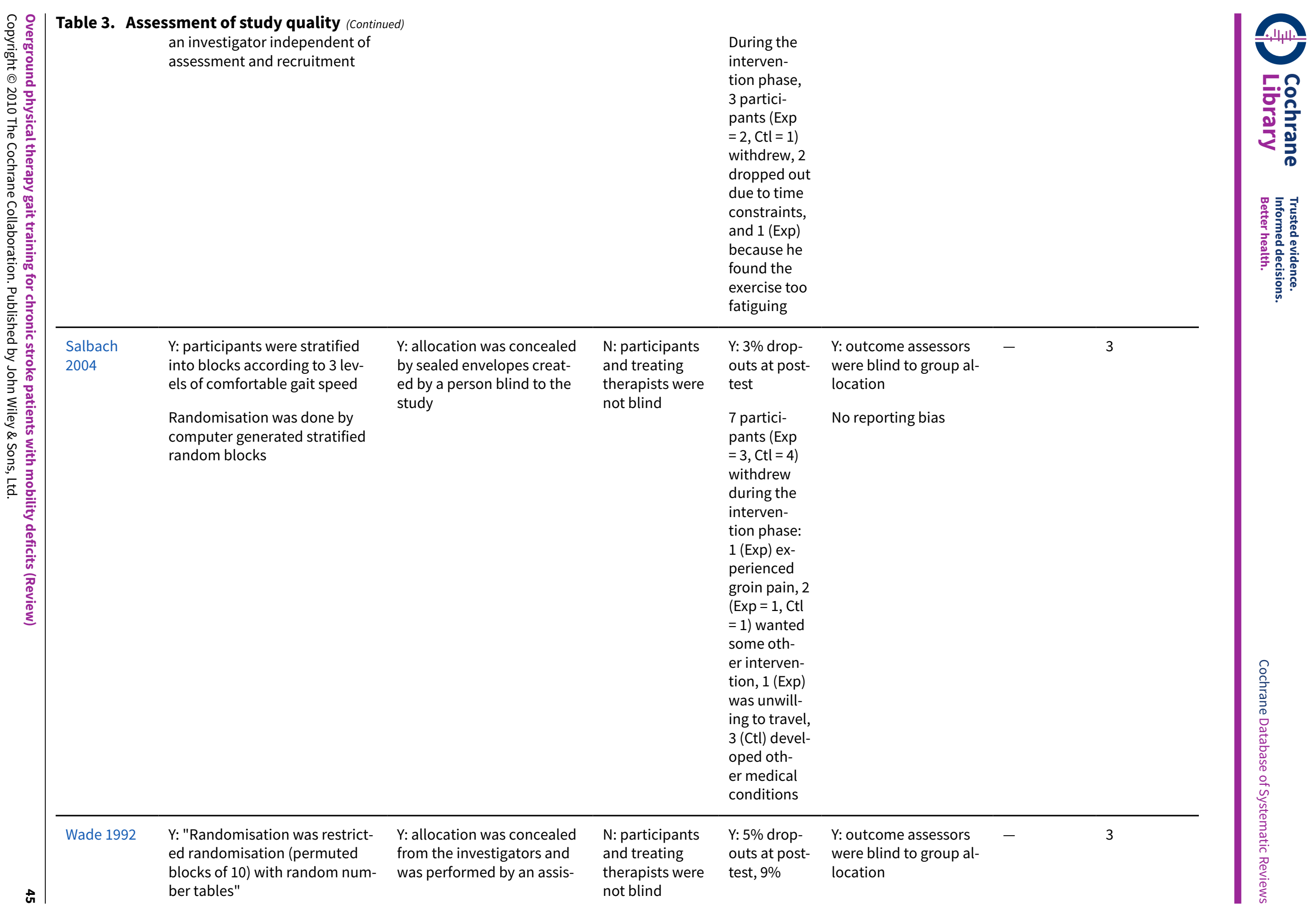




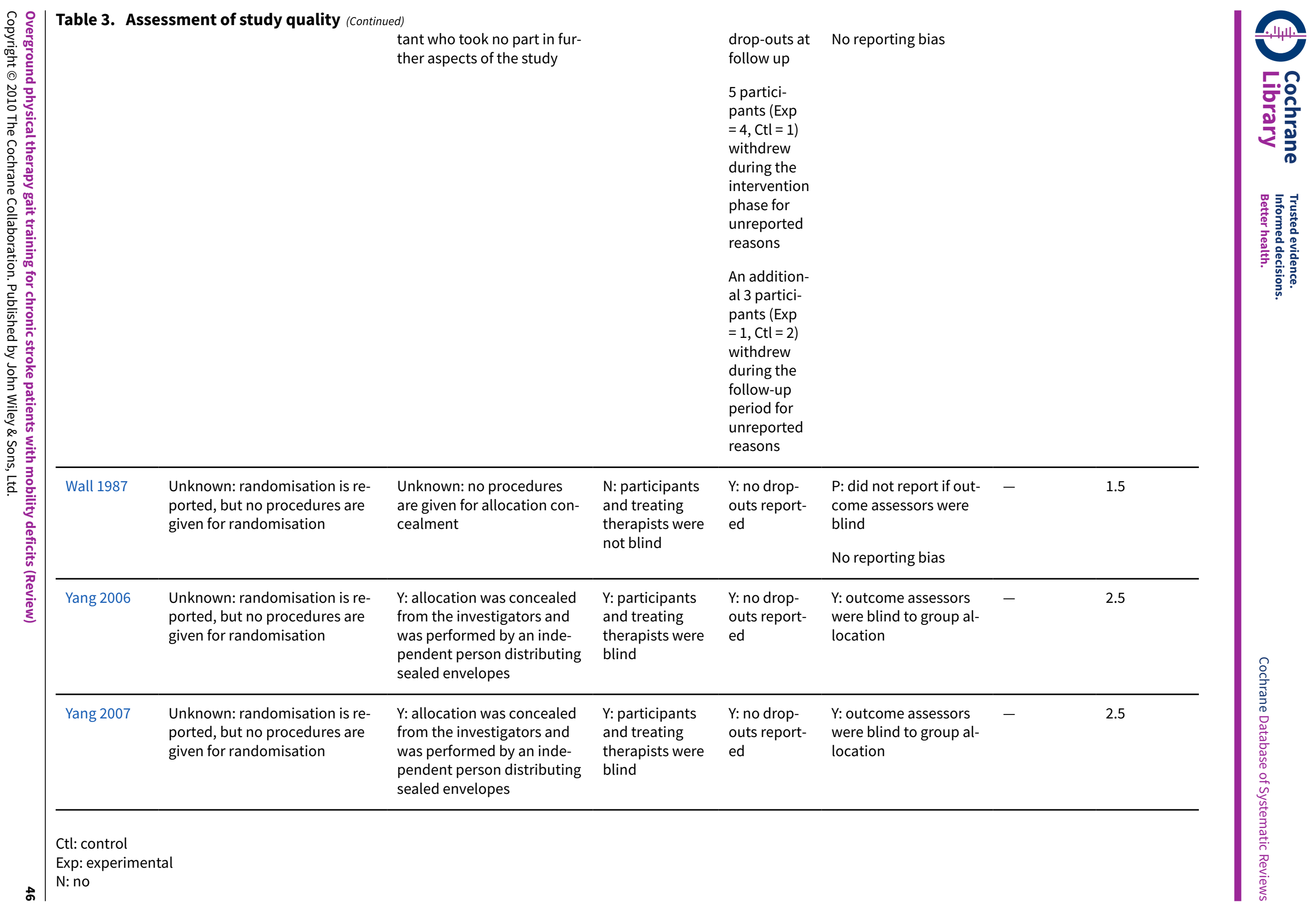



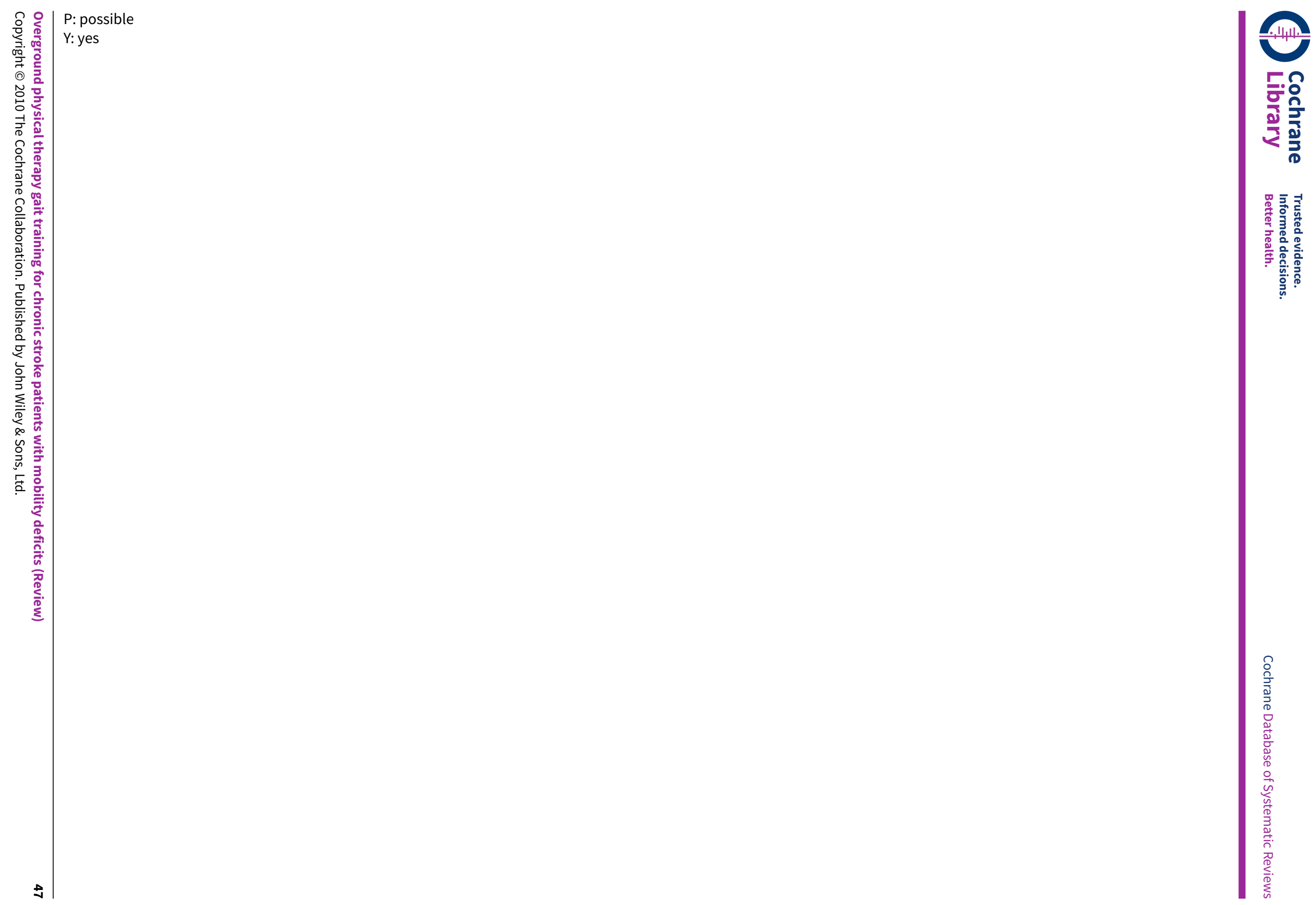
Table 4. PEDro scores

\begin{tabular}{|c|c|c|c|c|c|c|}
\hline Study ID & $\begin{array}{l}\text { PEDro } \\
\text { score }\end{array}$ & $\begin{array}{l}\text { Eligibility crite- } \\
\text { ria }\end{array}$ & $\begin{array}{l}\text { Baseline sim- } \\
\text { ilar }\end{array}$ & $\begin{array}{l}\text { Intention-to- } \\
\text { treat }\end{array}$ & Statistics & Means \& SDs \\
\hline Dean 2000 & 7 & Yes & Yes & Yes & Yes & Yes \\
\hline Green 2002 & 9 & Yes & Yes & Yes & Yes & Yes \\
\hline Lin 2004 & 9 & Yes & Yes & Yes & Yes & Yes \\
\hline Pang 2005 & 9 & Yes & Yes & Yes & Yes & Yes \\
\hline Salbach 2004 & 8 & Yes & Yes & Yes & Yes & Yes \\
\hline Wade 1992 & 9 & Yes & Yes & Yes & Yes & Yes \\
\hline Wall 1987 & 6 & Vague & Yes & Yes & Yes & Yes \\
\hline Yang 2006 & 9 & Yes & Yes & Yes & Yes & Yes \\
\hline Yang 2007 & 9 & Yes & Yes & Yes & Yes & Yes \\
\hline
\end{tabular}

SD: standard deviation

Table 5. Sensitivity analysis: true randomisation?

\begin{tabular}{|c|c|c|c|c|}
\hline Outcome or subgroup & Studies & $\begin{array}{l}\text { Partici- } \\
\text { pants }\end{array}$ & Statistical method & Effect estimate \\
\hline 1.1 Gait function (\%) & 2 & 250 & $\begin{array}{l}\text { Std. Mean Difference (IV, Fixed, } \\
95 \% \mathrm{CI})\end{array}$ & $0.17(-0.08$ to 0.42$)$ \\
\hline 1.2 Barthel Index (unitless) & 2 & 250 & $\begin{array}{l}\text { Std. Mean Difference (IV, Fixed, } \\
95 \% \mathrm{CI})\end{array}$ & $-0.11(-0.72$ to 0.50$)$ \\
\hline 1.3 Gait speed $(\mathrm{m} / \mathrm{s})$ & 4 & 208 & $\begin{array}{l}\text { Mean Difference (IV, Fixed, 95\% } \\
\mathrm{CI} \text { ) }\end{array}$ & $0.03(-0.02$ to 0.08$)$ \\
\hline 1.4 Timed up-and-go test (s) & 2 & 70 & $\begin{array}{l}\text { Mean Difference (IV, Fixed, 95\% } \\
\mathrm{CI} \text { ) }\end{array}$ & $-3.59(-10.40$ to 3.22$)$ \\
\hline 1.5 Six-minute-walk test (m) & 3 & 133 & $\begin{array}{l}\text { Mean Difference (IV, Fixed, 95\% } \\
\mathrm{CI} \text { ) }\end{array}$ & $17.96(-8.67$ to 44.59$)$ \\
\hline 2.1 Gait function (\%) & 1 & 150 & $\begin{array}{l}\text { Std. Mean Difference (IV, Fixed, } \\
95 \% \mathrm{CI} \text { ) }\end{array}$ & $0.34(0.01$ to 0.66$)$ \\
\hline 2.2 Barthel Index (unitless) & 1 & 150 & $\begin{array}{l}\text { Std. Mean Difference (IV, Fixed, } \\
95 \% \mathrm{CI} \text { ) }\end{array}$ & $0.00(-0.83$ to 0.83$)$ \\
\hline 2.3 Gait speed $(\mathrm{m} / \mathrm{s})$ & 2 & 150 & $\begin{array}{l}\text { Mean Difference (IV, Fixed, 95\% } \\
\mathrm{CI} \text { ) }\end{array}$ & $0.01(-0.06$ to 0.08$)$ \\
\hline 2.4 Timed up-and-go test (s) & 1 & 8 & $\begin{array}{l}\text { Mean Difference (IV, Fixed, 95\% } \\
\mathrm{CI} \text { ) }\end{array}$ & $-4.50(-41.10$ to 32.10$)$ \\
\hline
\end{tabular}


Table 5. Sensitivity analysis: true randomisation? (Continued)
2.5 Six-minute-walk test (m)
1
8
Mean Difference (IV, Fixed, 95\%
$\mathrm{Cl})$
$16.20(-184.09$ to 216.49$)$

$\mathrm{m}$ : metres

s: second

Table 6. Sensitivity analysis: concealed allocation?

\begin{tabular}{|c|c|c|c|c|}
\hline Outcome or subgroup & Studies & $\begin{array}{l}\text { Partici- } \\
\text { pants }\end{array}$ & Statistical method & Effect estimate \\
\hline 1.1 Gait function (\%) & 2 & 250 & $\begin{array}{l}\text { Std. Mean Difference (IV, Fixed, } \\
95 \% \mathrm{CI})\end{array}$ & $0.17(-0.08$ to 0.42$)$ \\
\hline 1.2 Barthel Index (unitless) & 2 & 250 & $\begin{array}{l}\text { Std. Mean Difference (IV, Fixed, } \\
95 \% \mathrm{CI})\end{array}$ & $-0.11(-0.72$ to 0.50$)$ \\
\hline 1.3 Gait speed $(\mathrm{m} / \mathrm{s})$ & 6 & 381 & $\begin{array}{l}\text { Mean Difference (IV, Fixed, 95\% } \\
\mathrm{CI} \text { ) }\end{array}$ & 0.07 (0.05 to 0.10$)$ \\
\hline 1.4 Timed up-and-go test $(\mathrm{s})$ & 3 & 118 & $\begin{array}{l}\text { Mean Difference (IV, Fixed, 95\% } \\
\mathrm{CI})\end{array}$ & $-1.81(-2.29$ to -1.33$)$ \\
\hline 1.5 Six-minute-walk test $(\mathrm{m})$ & 4 & 181 & $\begin{array}{l}\text { Mean Difference (IV, Fixed, 95\% } \\
\mathrm{CI})\end{array}$ & 26.06 (7.14 to 44.97$)$ \\
\hline 2.1 Gait function (\%) & 1 & 150 & $\begin{array}{l}\text { Std. Mean Difference (IV, Fixed, } \\
95 \% \mathrm{CI} \text { ) }\end{array}$ & 0.34 (0.01 to 0.66$)$ \\
\hline 2.2 Barthel Index (unitless) & 1 & 150 & $\begin{array}{l}\text { Std. Mean Difference (IV, Fixed, } \\
95 \% \mathrm{CI} \text { ) }\end{array}$ & $0.00(-0.83$ to 0.83$)$ \\
\hline 2.3 Gait speed $(\mathrm{m} / \mathrm{s})$ & 2 & 150 & $\begin{array}{l}\text { Mean Difference (IV, Fixed, 95\% } \\
\mathrm{CI} \text { ) }\end{array}$ & $0.01(-0.06$ to 0.08$)$ \\
\hline 2.4 Timed up-and-go test (s) & 1 & 8 & $\begin{array}{l}\text { Mean Difference (IV, Fixed, 95\% } \\
\mathrm{CI} \text { ) }\end{array}$ & $-4.50(-41.10$ to 32.10$)$ \\
\hline 2.5 Six-minute-walk test $(\mathrm{m})$ & 1 & 8 & $\begin{array}{l}\text { Mean Difference (IV, Fixed, 95\% } \\
\mathrm{CI} \text { ) }\end{array}$ & 16.20 (-184.09 to 216.49$)$ \\
\hline
\end{tabular}

$\mathrm{m}$ : metres

s: second

Table 7. Sensitivity analysis: acceptable number of withdrawals?

\begin{tabular}{lllll}
\hline Outcome or subgroup & Studies & $\begin{array}{l}\text { Partici- } \\
\text { pants }\end{array}$ & Statistical method & Effect estimate \\
\hline 1.1 Gait function (\%) & 3 & 269 & $\begin{array}{l}\text { Std. Mean Difference (IV, Fixed, } \\
95 \% \text { Cl) }\end{array}$ & $0.19(-0.05$ to 0.43$)$ \\
\hline 1.2 Barthel Index (unitless) & 3 & 269 & $\begin{array}{l}\text { Std. Mean Difference (IV, Fixed, } \\
95 \% \text { Cl) }\end{array}$ & $-0.07(-0.68$ to 0.53) \\
\hline
\end{tabular}


Table 7. Sensitivity analysis: acceptable number of withdrawals? (Continued)

\begin{tabular}{|c|c|c|c|c|}
\hline 1.3 Gait speed $(\mathrm{m} / \mathrm{s})$ & 6 & 390 & $\begin{array}{l}\text { Mean Difference (IV, Fixed, 95\% } \\
\mathrm{Cl} \text { ) }\end{array}$ & 0.07 (0.05 to 0.10$)$ \\
\hline 1.4 Timed up-and-go test (s) & 2 & 111 & $\begin{array}{l}\text { Mean Difference (IV, Fixed, 95\% } \\
\mathrm{Cl} \text { ) }\end{array}$ & $-1.81(-2.29$ to -1.33$)$ \\
\hline 1.5 Six-minute-walk test $(\mathrm{m})$ & 3 & 172 & $\begin{array}{l}\text { Mean Difference (IV, Fixed, 95\% } \\
\mathrm{Cl} \text { ) }\end{array}$ & 26.43 (7.43 to 45.44$)$ \\
\hline 2.1 Gait function (\%) & 1 & 150 & $\begin{array}{l}\text { Std. Mean Difference (IV, Fixed, } \\
95 \% \mathrm{CI})\end{array}$ & 0.34 (0.01 to 0.66$)$ \\
\hline 2.2 Barthel Index (unitless) & 1 & 150 & $\begin{array}{l}\text { Std. Mean Difference (IV, Fixed, } \\
95 \% \mathrm{CI} \text { ) }\end{array}$ & $0.00(-0.83$ to 0.83$)$ \\
\hline 2.3 Gait speed $(\mathrm{m} / \mathrm{s})$ & 2 & 176 & $\begin{array}{l}\text { Mean Difference (IV, Fixed, 95\% } \\
\mathrm{CI})\end{array}$ & $0.02(-0.05$ to 0.08$)$ \\
\hline 2.4 Timed up-and-go test (s) & 0 & - & - & - \\
\hline 2.5 Six-minute-walk test $(\mathrm{m})$ & 0 & - & - & - \\
\hline
\end{tabular}

m: metres

s: second

Table 8. Sensitivity analysis: blind evaluators?

\begin{tabular}{|c|c|c|c|c|}
\hline Outcome or subgroup & Studies & $\begin{array}{l}\text { Partici- } \\
\text { pants }\end{array}$ & Statistical method & Effect estimate \\
\hline 1.1 Gait function (\%) & 3 & 269 & $\begin{array}{l}\text { Std. Mean Difference (IV, Fixed, } \\
95 \% \mathrm{CI})\end{array}$ & $0.19(-0.05$ to 0.43$)$ \\
\hline 1.2 Barthel Index (unitless) & 3 & 269 & $\begin{array}{l}\text { Std. Mean Difference (IV, Fixed, } \\
95 \% \mathrm{Cl})\end{array}$ & $-0.07(-0.68$ to 0.53$)$ \\
\hline 1.3 Gait speed $(\mathrm{m} / \mathrm{s})$ & 5 & 372 & $\begin{array}{l}\text { Mean Difference (IV, Fixed, 95\% } \\
\mathrm{CI} \text { ) }\end{array}$ & $0.07(0.05$ to 0.10$)$ \\
\hline 1.4 Timed up-and-go test (s) & 3 & 109 & $\begin{array}{l}\text { Mean Difference (IV, Fixed, 95\% } \\
\mathrm{CI} \text { ) }\end{array}$ & $-1.81(-2.29$ to -1.33$)$ \\
\hline 1.5 Six-minute-walk test $(\mathrm{m})$ & 3 & 172 & $\begin{array}{l}\text { Mean Difference (IV, Fixed, 95\% } \\
\mathrm{CI})\end{array}$ & 26.43 (7.43 to 45.44$)$ \\
\hline 2.1 Gait function (\%) & 1 & 150 & $\begin{array}{l}\text { Std. Mean Difference (IV, Fixed, } \\
95 \% \mathrm{CI})\end{array}$ & 0.34 (0.01 to 0.66$)$ \\
\hline 2.2 Barthel Index (unitless) & 1 & 150 & $\begin{array}{l}\text { Std. Mean Difference (IV, Fixed, } \\
95 \% \mathrm{CI})\end{array}$ & $0.00(-0.83$ to 0.83$)$ \\
\hline 2.3 Gait speed $(\mathrm{m} / \mathrm{s})$ & 1 & 142 & $\begin{array}{l}\text { Mean Difference (IV, Fixed, 95\% } \\
\mathrm{CI} \text { ) }\end{array}$ & $0.01(-0.06$ to 0.08$)$ \\
\hline 2.4 Timed up-and-go test (s) & 0 & - & - & - \\
\hline
\end{tabular}


Table 8. Sensitivity analysis: blind evaluators? (Continued)

2.5 Six-minute-walk test $(\mathrm{m})$ 0

m: metres

s: second

\section{APPENDICES}

\section{Appendix 1. MEDLINE search strategy}

We used the following MEDLINE search strategy and adapted it to suit the other databases.

1. exp cerebrovascular disorders/

2. (stroke $\$$ or cva $\$$ or cerebrovascular or cerebral vascular).tw.

3. ((cerebral or cerebellar or brain\$ or vertebrobasilar) adj5 (infarct\$ or isch?emi\$ or thrombo or emboli\$ or apoplexy)).tw.

4. ((cerebral or brain\$ or subarachnoid) adj5 (haemorrhage or hemorrhage or haematoma or hematoma or bleed\$)).tw.

5. hemiplegia/ or brain injuries/

6. (hemipleg\$ or hemipar\$ or poststroke or post-stroke or brain injur\$).tw.

7. or/1-6

8. walking/ or gait/ or locomotion/ or exercise movement techniques/

9. exp gait disorders, neurologic/

10. (walk\$ or gait\$ or ambulat\$ or locomot\$).tw.

11. (overground or over ground or surface or floor).tw.

12. or/8-11

13. Randomised Controlled Trials/

14. random allocation/

15. Controlled Clinical Trials/

16. control groups/

17. clinical trials/

18. single-blind method/

19. Placebos/

20. placebo effect/

21. cross-over studies/

22. Multicenter Studies/

23. Research Design/

24. Program Evaluation/

25. evaluation studies/

26. randomised controlled trial.pt.

27. controlled clinical trial.pt.

28. clinical trial.pt.

29. multicenter study.pt.

30. evaluation studies.pt.

31. random\$.tw.

32. (controlled adj5 (trial\$ or stud\$)).tw.

33. (clinical\$ adj5 trial\$).tw.

34. ((control or treatment or experiment $\$$ or intervention) adj5 (group\$ or subject\$ or patient\$)).tw.

35. (quasi-random\$ or quasi random\$ or pseudo-random\$ or pseudo random\$).tw.

36. ((multicenter or multicentre or therapeutic) adj5 (trial\$ or stud\$)).tw.

37. ((control or experiment\$ or conservative) adj5 (treatment or therapy or procedure or manage\$)).tw.

38. (coin adj5 (flip or flipped or toss\$)).tw.

39. latin square.tw.

40. versus.tw.

41. (cross-over or cross over or crossover).tw.

42. placebo\$.tw.

43. sham.tw.

44. (assign\$ or alternate or allocat\$ or counterbalance\$ or multiple baseline).tw.

45. controls.tw.

46. (treatment\$ adj6 order).tw.

47. or/13-46 
48. 7 and 12 and 47

49. limit 48 to humans

50. Exp adult/

51.49 and 50

\section{H IST O R Y}

Protocol first published: Issue 3, 2006

Review first published: Issue 3, 2009

\begin{tabular}{lll}
\hline Date & Event & Description \\
\hline 27 May 2008 & Amended & Converted to new review format. \\
\hline
\end{tabular}

\section{CONTRIBUTIONS OF AUTHORS}

Conceiving the review: RAS

Designing the review: RAS, EP, YS

Co-ordinating the review: RAS

Data collection: RAS, EP, YS

Data management: RAS

Analysis of the data: RAS

Interpretation of the data: RAS, EP, YS

Writing the review: RAS, EP, YS

Providing general advice: RAS, EP, YS

Performing previous work that led to the review: RAS

\section{DECLARATIONS OF INTEREST}

None known.

\section{SOURCES OF SUPPORT}

\section{Internal sources}

- Long Island University, USA.

Four month sabbatical leave provided to lead author (RAS)

\section{External sources}

- No sources of support supplied

\section{INDEX TERMS}

\section{Medical Subject Headings (MeSH)}

*Gait; *Mobility Limitation; *Stroke Rehabilitation; *Walking; Exercise Therapy [ ${ }^{\star}$ methods]; Randomized Controlled Trials as Topic; Recovery of Function

\section{MeSH check words}

Aged; Humans; Middle Aged 